\title{
The dorsal column nuclei complex neuroanatomy reveals a complex sensorimotor integration and distribution hub
}

\author{
Alastair J Loutit ${ }^{1,2}$, Richard M Vickery ${ }^{1}$, and Jason R Potas ${ }^{1,2}{ }^{*}$ \\ ${ }^{1}$ School of Medical Sciences, UNSW Sydney, Sydney, New South Wales, 2052, Australia \\ ${ }^{2}$ The Eccles Institute of Neuroscience, John Curtin School of Medical Research, Australian National \\ University, Canberra, Australian Capital Territory, 2601, Australia \\ * Correspondence: \\ Dr Jason R Potas \\ j.potas@unsw.edu.au
}

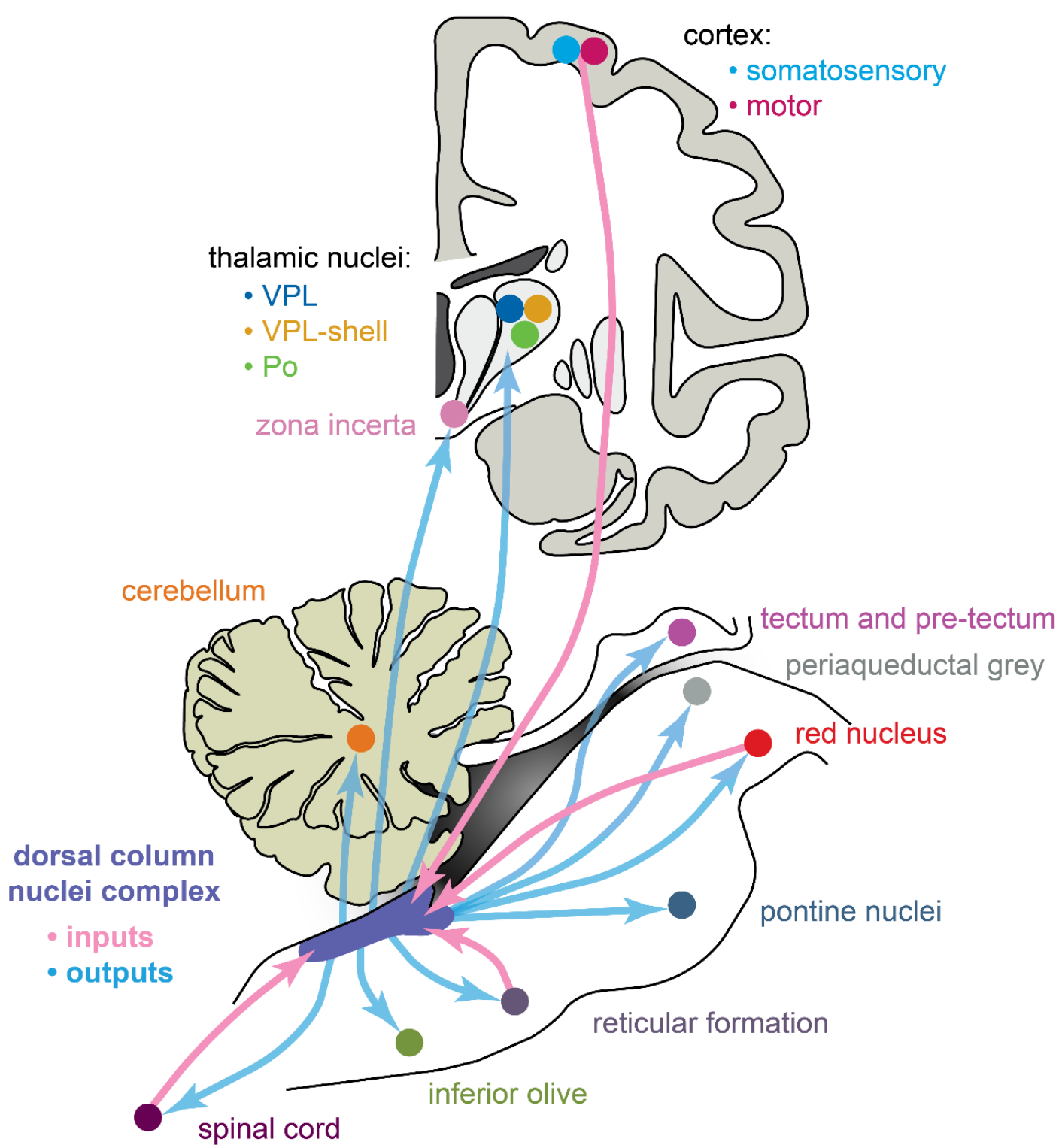




\section{Abstract}

The dorsal column nuclei complex (DCN-complex) includes the dorsal column nuclei (DCN, referring to the gracile and cuneate nuclei collectively), external cuneate, $X$, and $Z$ nuclei, and the median accessory nucleus. The DCN are organised by both somatotopy and modality, and have a diverse range of afferent inputs and projection targets. The functional organisation and connectivity of the DCN implicate them in a variety of sensorimotor functions, beyond their commonly accepted role in processing and transmitting somatosensory information to the thalamus, yet this is largely underappreciated in the literature. To consolidate insights into their sensorimotor functions, this review examines the morphology, organisation, and connectivity of the DCN and their associated nuclei. First, we briefly discuss the receptors, afferent fibres, and pathways involved in conveying tactile and proprioceptive information to the DCN. Next, we review the modality and somatotopic arrangements of the remaining constituents of the DCN-complex. Finally, we examine and discuss the functional implications of the myriad of DCN-complex projection targets throughout the diencephalon, midbrain, and hindbrain, in addition to their modulatory inputs from the cortex. The organisation and connectivity of the DCN-complex suggest that these nuclei should be considered a complex integration and distribution hub for sensorimotor information. 


\section{Contents}

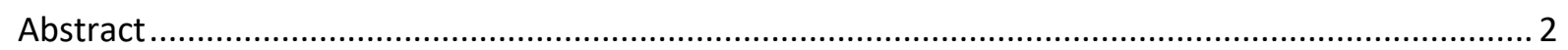

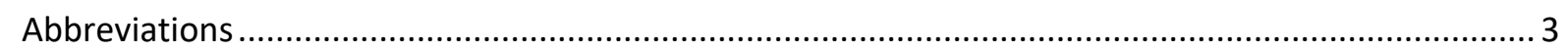

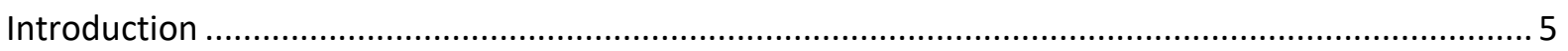

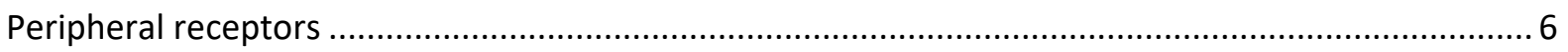

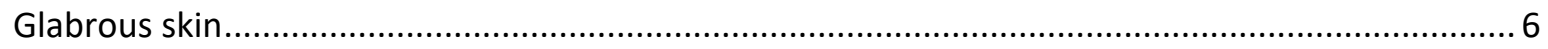

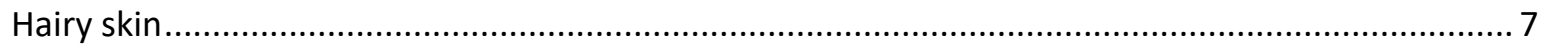

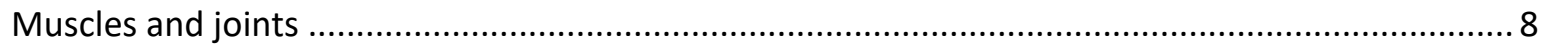

Spinal cord pathways to the dorsal column nuclei complex .............................................................

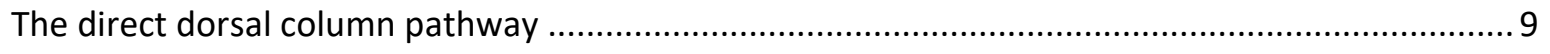

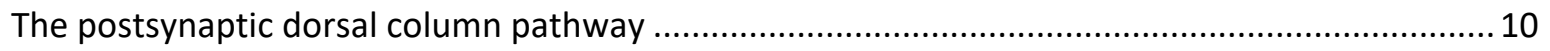

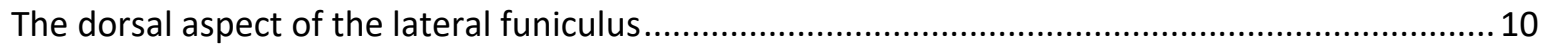

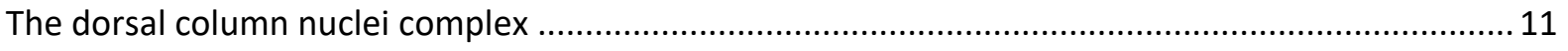

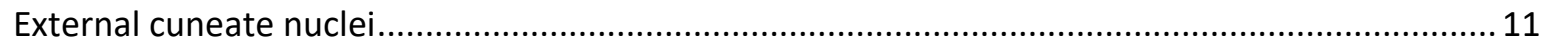

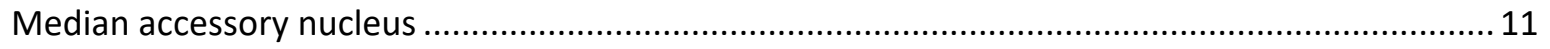

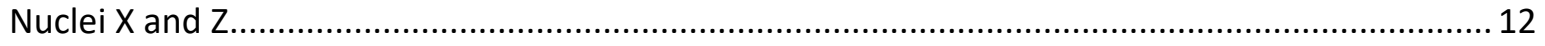

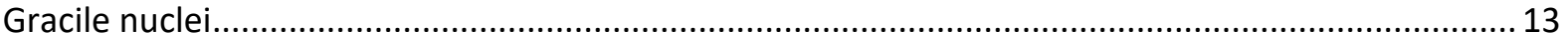

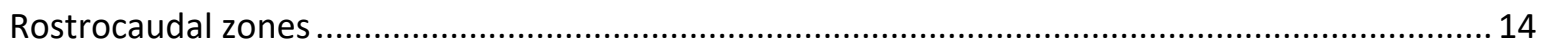

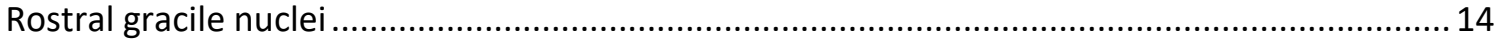

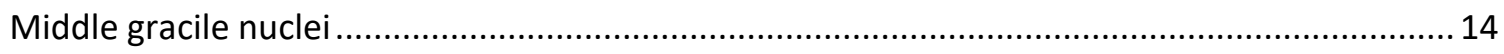

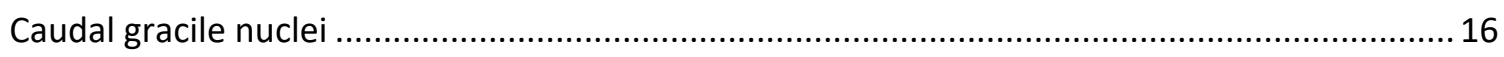

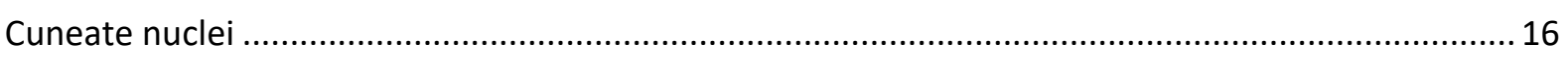

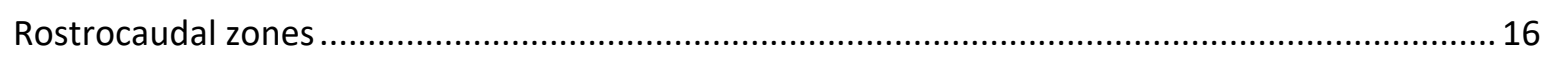

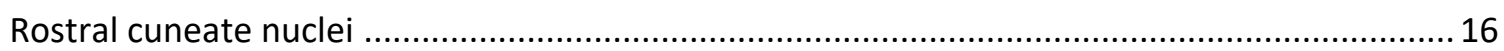

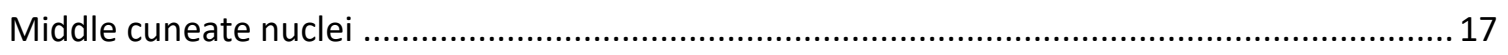

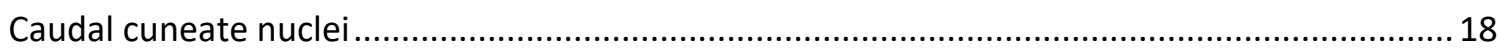

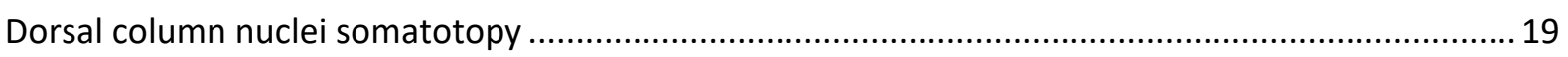

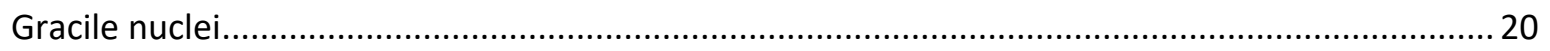

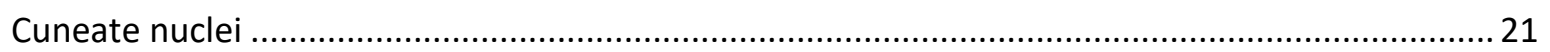

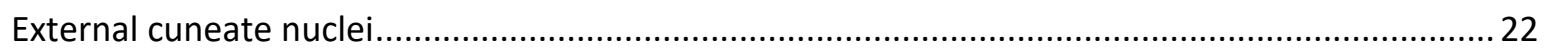

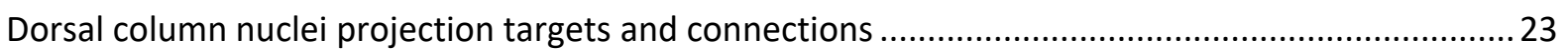

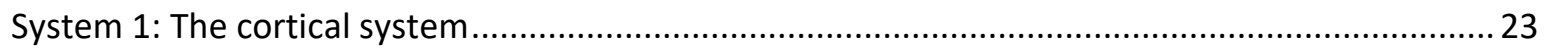

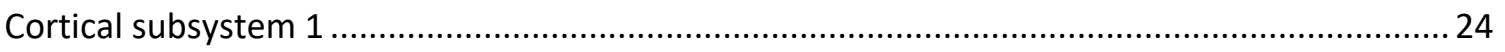

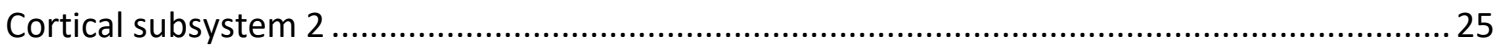

Cortical Subsystem 3 


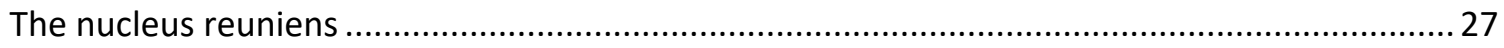

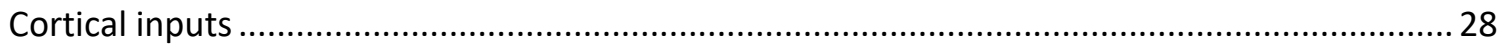

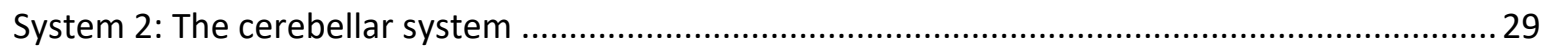

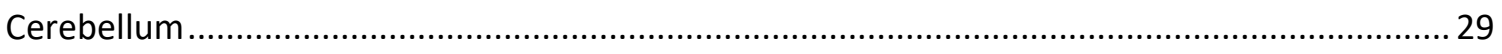

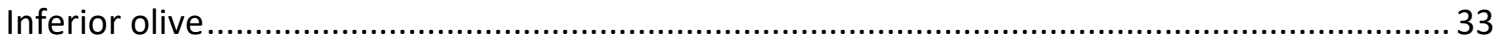

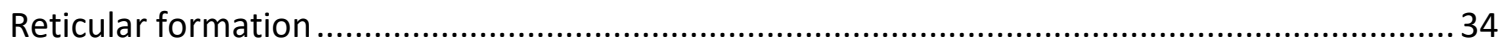

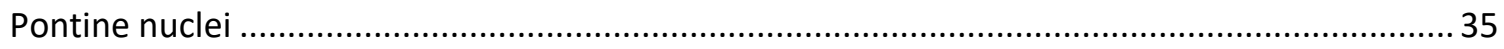

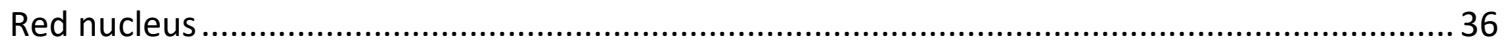

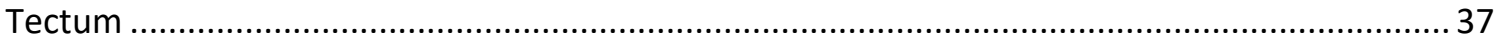

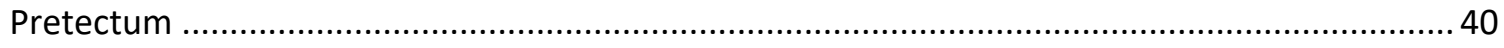

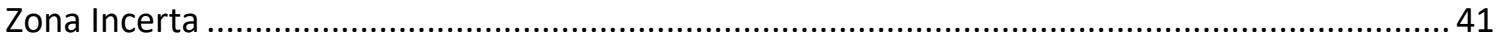

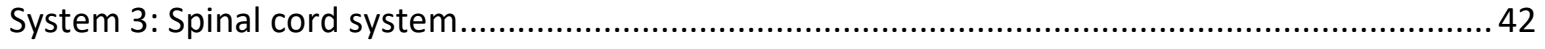

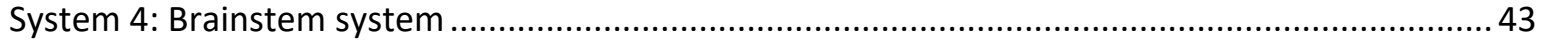

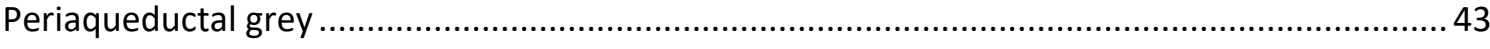

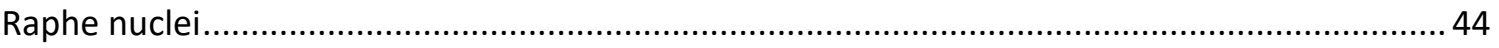

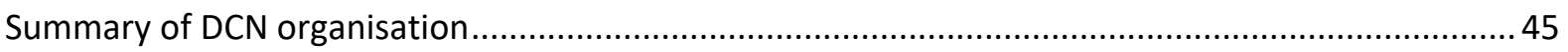

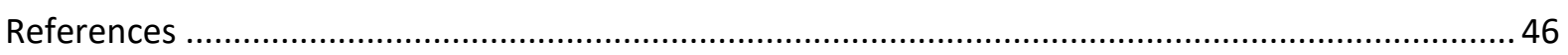

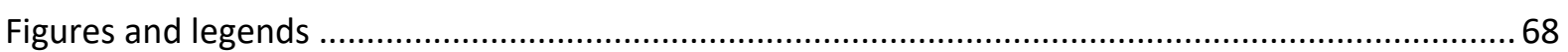




\section{Abbreviations}

cf: cuneate fasciculus

Cu: cuneate nuclei

CuC: cuneate nuclei caudal zone

CuM: cuneate nuclei middle zone

CuR: cuneate nuclei rostral zone

DCN: dorsal column nuclei - gracile (inclusive of Bischoff's nucleus) and cuneate nuclei

DCN-complex: dorsal column nuclei complex - gracile (inclusive of Bischoff's nucleus), cuneate, and external cuneate nuclei, nuclei $X$ and $Z$

DDC: direct dorsal column pathway

dLF: dorsal aspect of the lateral funiculus

gf: gracile fasciculus

Gr: gracile nuclei

GrC: gracile nuclei caudal zone

GrM: gracile nuclei middle zone

GrR: gracile nuclei rostral zone

IC: inferior colliculus

IO: inferior olive

IOD: inferior olive, dorsal nucleus

IODR: inferior olive, rostral region of the dorsal nucleus

IOM: inferior olive, medial nucleus

IOPr: inferior olive, principal nucleus

ICo: intercollicular region

LAC: lemniscal adjunct channel

MA: median accessory nucleus

MLLC: main line lemniscal channel

PAG: periaqueductal grey

Po: posterior nucleus of the thalamus

Pn: pontine nuclei

psdc, PSDC: postsynaptic dorsal column pathway

PV: parietal ventral area of the anterior parietal cortex 
Re: nucleus reuniens

RF: receptive field

RN: red nucleus

RNMg: red nucleus magnocellular region

Rt: reticular formation

SC: superior colliculus

VL: Ventrolateral nucleus of the thalamus

VP: ventroposterior nuclei of the thalamus

VPL: ventroposterior lateral nucleus of the thalamus

X: nuclei X

Z: nuclei Z 


\section{Introduction}

Somatosensation involves a complex group of senses that gather information about physical attributes of the external world and the body's internal physical state. It is essential for functions like texture discrimination, object manipulation, directing attention, regulating movement, avoidance behaviours, sensing pain and temperature, and affective touch. These diverse roles necessitate somatosensory information transmission to many brain structures, specialised for these different functions. The brainstem dorsal column nuclei (DCN) are recognised as a processing centre for touch and proprioceptive information ascending from the periphery to the somatosensory cortex. However, the DCN contain diverse cell groups that project to a myriad of targets throughout the brain and perform specialised roles in somatosensory processing and sensorimotor integration.

From the 1950 s to the 1980 s the DCN anatomy and connections were of high scientific interest, and the field was rapidly advanced by degeneration and electrophysiological techniques, and by the advent of horseradish peroxidase labelling (Kristensson, Olsson, \& Sjöstrand, 1971; Lavail \& Lavail, 1972). An excellent review of the discoveries from this period of the DCN organisation and projection targets was produced by Berkley, Budell, Blomqvist, and Bull (1986), in an effort to increase understanding of their functional significance. However, much of the research discussed used cats as the principle species. In the more than 30 years since their review, knowledge of the DCN functional organisation and connectivity has greatly increased, in particular for animals that exhibit grasping behaviours, including rats, raccoons, and primates. Understanding sensorimotor functions of the brain, of which reaching and grasping functions are of the highest importance, is a central question in neuroscience. The DCN has recently received attention for its potential for restoring somatosensory function (Loutit \& Potas, 2020). Here, we review the morphology, organisation, and afferent and efferent connections of the DCN and associated nuclei, with discussion of functional implications. Our comprehensive review of the DCN structural characteristics reveals that the DCN should be considered 
an essential integration and distribution hub for sensorimotor information across a multitude of brain centres.

Typically, the DCN are considered to comprise the cuneate nuclei $(\mathrm{Cu})$ and gracile nuclei ( $\mathrm{Gr}$ ), but there are several adjacent nuclei occasionally included. These are the external cuneate nuclei (ECu), the nucleus of median accessory nucleus (MA) (also known as the nucleus of Bischoff), nuclei X (X), and nuclei Z (Z) (Figure 1). Here, we use the term the dorsal column nuclei (DCN) to refer only to the $\mathrm{Gr}$ and the $\mathrm{Cu}$ combined (MA is assumed to be part of the $\mathrm{Gr}$ ). When including the $\mathrm{ECu}, \mathrm{X}$, and $\mathrm{Z}$ we refer to the dorsal column nuclei complex (DCN-complex) (Berkley et al., 1986; Mountcastle, 1984). We refer to each of the respective cell groups as the plural nuclei, rather than the singular nucleus (e.g. dorsal column nuclei, gracile nuclei, cuneate nuclei), as they are considered separate nuclei on either side of the midline (except for MA). Figure 1 summarises the arrangement of the DCN-complex. We begin by briefly discussing the mechanoreceptors for transducing somatosensory information and the pathways this information takes to the DCN-complex.

\section{Peripheral receptors}

Touch and proprioceptive stimuli are transduced by mechanoreceptors converting mechanical deformation of various tissues into electrical impulses. These mechanoreceptors reside in skin, muscles, tendons, and ligaments and each have specialised end organs with associated afferent types. Here, we briefly describe the structure and functional properties of somatosensory mechanoreceptors and associated afferents, but there are several excellent reviews on this topic providing greater detail (Abraira \& Ginty, 2013; Darian-Smith, 2011; R. S. Johansson \& Flanagan, 2009; K. O. Johnson, 2001; Zimmerman, Bai, \& Ginty, 2014).

\section{Glabrous skin}

Glabrous skin is specialised for discriminative touch and predominates on the palmar and plantar sides of mammalian hands and feet, respectively. There are four types of afferent fibres and associated end organs found in mammalian glabrous skin: slowly-adapting (SA) type 1 and 2 (SA1 and SA2), and fastadapting (FA; also called rapidly adapting) type 1 and 2 (FA1 and FA2). All four afferent types are 
classed as $A \beta$ fibres, which are myelinated large diameter fibres with fast conduction velocities (16100 m/s) (Abraira \& Ginty, 2013). Conduction velocities are species-dependent, humans (Knibestöl, 1973), monkeys (Perl, 1968), and cats (Brown \& Iggo, 1967; Burgess, Petit, \& Warren, 1968) have fibres that reach the upper limits of this range, while rat $A \beta$ fibres can conduct up to $~ 70 \mathrm{~m} / \mathrm{s}$ (Handwerker, Kilo, \& Reeh, 1991; Leem, Willis, \& Chung, 1993; Sanders \& Zimmermann, 1986). Slowly-adapting afferents respond best to maintained mechanical skin indentation with a characteristic sustained, slowly decreasing action potential firing rate. Fast-adapting afferents respond best to dynamic skin deformation changes, and their responses to sustained stimuli show a rapid decrease in firing rate ( $R$. S. Johansson \& Flanagan, 2009). Type 1 afferents are characterised by their small receptive fields (RFs), and superficial location in the dermis or epidermis, and are ideally suited for conveying spatial patterns of skin indentation. Type 2 afferents are characterised by large receptive fields and are typically located deeper in the dermis.

The four afferent types can also be defined by the specialised end-organs that they associate with. SA1 afferents terminals are known to associate closely with Merkel receptors (Halata, Grim, \& Bauman, 2003; Iggo \& Muir, 1969; Munger, Pubols, \& Pubols, 1971) and FA1 afferents associate with Meissner's corpuscles (Cauna \& Ross, 1960). These two afferent types work complementarily to facilitate fine tactile discrimination. SA2 afferents are thought to associate with Ruffini endings, although this remains controversial (see (Abraira \& Ginty, 2013) for discussion), and they respond best to skin stretch (Knibestöl, 1975). FA2 afferent terminals associate with Pacinian corpuscles, respond best to high frequency vibrations $(40-400 \mathrm{~Hz})$, and are extremely sensitive to small and fast mechanical skin deformations (Bell, Bolanowski, \& Holmes, 1994; R. S. Johansson, Landström, \& Lundström, 1982).

\section{Hairy skin}

The same four afferent types can be found in hairy skin. There are additional A $\beta$ FA afferents that form circumferential endings around many hairs. These are referred to as $A \beta$ field units and respond best to gentle stroking of large fields of hairy skin (Bai et al., 2015). Other A $\beta$ FA and SA fibres associate with hair follicles with longitudinal lanceolate endings and Merkel cell complexes, respectively 
(Abraira \& Ginty, 2013; Jenkins \& Lumpkin, 2017; L. Li et al., 2011). In addition to A $\beta$ fibres, slowerconducting fibres also associate with hair follicles. A $\delta$ fibres are thinly myelinated and have intermediate conduction velocities $(5-30 \mathrm{~m} / \mathrm{s})$, and C-fibres are unmyelinated and have the slowest conduction velocities $(0.2-2 \mathrm{~m} / \mathrm{s})$ (Abraira \& Ginty, 2013). These fibres show intermediate adaptation characteristics between SA and FA, form lanceolate endings around hair follicles, and are thought to play a role in affective touch (L. Li et al., 2011; Löken, Wessberg, McGlone, \& Olausson, 2009).

\section{Muscles and joints}

Afferents that respond to changes in muscle length, tendon tension, and joint movement are associated with proprioception. Muscle length is conveyed by specialised muscle fibres called muscle spindles, which are innervated by primary (Group la) and secondary (Group II) spindle afferent fibres. Tendon tension is conveyed by Golgi tendon organs (Group lb fibres) that respond best to isometric contractions that produce a load on a tendon and weakly respond to changes in muscle length (Edin \& Vallbo, 1990a, 1990b; Jami, 1992). Finally, joint receptors respond to joint movement, pressure over the joint capsule, or contraction of muscles inserted in the capsule (Macefield, 2005; Proske \& Gandevia, 2012). The end organs associated with these joint afferents are Ruffini-like endings, Pacinian-like corpuscles and Golgi organs in ligaments (Grigg, 1994). These afferents respond best at the end of the joint's movement range with SA characteristics (Grigg, 1994). Group I fibres have very fast conduction velocities $(30-120 \mathrm{~m} / \mathrm{s})$, whereas Group II fibres conduct more slowly $(15-80 \mathrm{~m} / \mathrm{s})$ (Cheney \& Preston, 1976; De-Doncker, Picquet, Petit, \& Falempin, 2003; Scott, 1990; Wei, Kripke, \& Burgess, 1986). As with $A \beta$ cutaneous fibres, rat proprioceptive fibres represent the lower end of this conduction velocity spectrum, whereas cats and primates have higher conduction velocities.

\section{Spinal cord pathways to the dorsal column nuclei complex}

Somatosensory information bound for the DCN-complex, ascends the spinal cord via multiple different paths. The pathway taken by afferent fibres is determined by the modality of the afferents, and whether they have receptive fields on the upper or lower body. 


\section{The direct dorsal column pathway}

The best known of the ascending pathways to the DCN-complex is the direct dorsal column pathway (DDC), in which primary afferents, transmitting tactile and proprioceptive information, ascend the spinal cord in the dorsal columns (DCs) and terminate on second order neurons in the ipsilateral DCN. The DCs comprise the gracile and cuneate fasciculi (gf and cf, Figure 1A), which are white matter tracts in the dorsal funiculus, housing lower and upper body afferents, respectively. Afferents entering the spinal cord at the most caudal dorsal roots ascend medially, and successive entry of afferents at more rostral spinal roots maintain their order of entry by ascending in progressively more lateral portions of the DCs (Smith \& Deacon, 1984; Whitsel, Petrucelli, Sapiro, \& Ha, 1970).

A modality-based organisation within the DCs coexists with the somatotopic organisation (Niu et al., 2013). Hindlimb Group I and II muscle and tendon afferents leave the gf to synapse onto second order neurons in the nucleus dorsalis (sometimes referred to as Clarke's column) (Bloedel \& Courville, 2011). Interestingly, SA-like responses are present in DCN recordings, yet most, if not all SA1 afferents are not found above mid-thoracic levels in the DCs, and SA1 responses are mostly absent from DC recordings in monkeys (Abraira \& Ginty, 2013; Whitsel, Petrucelli, \& Sapiro, 1969; Whitsel et al., 1970). Therefore, above mid-thoracic levels it appears that most FA afferents are found in the gf, and upperbody proprioceptive-related afferents are found laterally in the cf (Luo, Enomoto, Rice, Milbrandt, \& Ginty, 2009; Niu et al., 2013). Fibre-sorting in the DCN and the absence of SA1 afferents in the upper DC has been strangely overlooked in the literature but warrants future investigation to determine whether SA1 afferents ascend the spinal cord by another tract. Nevertheless, the current understanding of DC fibre sorting is similar to the modality-based organisation in the DCN (Dykes, Rasmusson, Sretavan, \& Rehman, 1982), thalamus (Dykes, Sur, Merzenich, Kaas, \& Nelson, 1981), and somatosensory cortex (Kaas, Nelson, Sur, Lin, \& Merzenich, 1979).

DCN neurons receive convergent inputs from multiple DC afferents (Bengtsson, Brasselet, Johansson, Arleo, \& Jörntell, 2013; Jörntell et al., 2014; Witham \& Baker, 2011). Therefore, it is important to note that descriptions of SA or FA responses in the $\mathrm{DCN}$ could potentially be receiving inputs from multiple 
SA and/or FA afferents, which could influence DCN neurons response properties and does not strictly mean they have responses properties like the stereotyped response properties described for peripheral afferents.

\section{The postsynaptic dorsal column pathway}

Complementary to the DDC fibres, some axons entering the spinal cord synapse onto second order neurons in spinal cord laminae 3-7 and 10, that have ascending axons in the DC and terminate in the ipsilateral DCN-complex (Abraira \& Ginty, 2013; Angaut-Petit, 1975a; Brown \& Fyffe, 1981; Enevoldson \& Gordon, 1989; Rustioni, 1973; Rustioni \& Kaufman, 1977; Uddenberg, 1968). Axons from postsynaptic dorsal column pathway (PSDC) neurons comprise more than $30 \%$ of gf and $38 \%$ of cf afferents (Giesler, Nahin, \& Madsen, 1984), which like the DDC are also somatotopically organised (Cliffer \& Giesler, 1989). PSDC neurons receive inputs from a mixture of tactile, proprioceptive, and visceral afferents, and a small population respond to noxious mechanical stimuli (Abraira \& Ginty, 2013; Angaut-Petit, 1975b; Jankowska, Rastad, \& Zarzecki, 1979). PSDC neurons, therefore, may play a role in integrating somatosensory information, as they can receive convergent inputs from more than one modality (Abraira \& Ginty, 2013; Angaut-Petit, 1975b; Jankowska et al., 1979).

\section{The dorsal aspect of the lateral funiculus}

Some afferents synapse onto second order neurons in the dorsal horn and then ascend the spinal cord in the dorsal aspect of the lateral funiculus (dLF, Figure 1A) (Dart \& Gordon, 1973; Gordon \& Grant, 1982; H. Johansson \& Silfvenius, 1977a, 1977b, 1977c; Landgren \& Silfvenius, 1971; Magherini, Pompeiano, \& Sequin, 1974; Nijensohn \& Kerr, 1975; Pompeiano \& Brodal, 1957). Many of these axons from T6 and below are dorsal spinocerebellar tract (DSCT) neurons with cell bodies in the nucleus dorsalis. Neurons comprising the DSCT convey lower body proprioceptive information (Group I and II muscle afferents) and terminate in the ipsilateral cerebellum, but they also send collaterals to the ipsilateral, and a small proportion to the contralateral, DCN-complex (H. Johansson \& Silfvenius, 1977a; Landgren \& Silfvenius, 1971; Low, John, \& Tracey, 1986; Mantle-St. John \& Tracey, 1987). There are also axons ascending to the DCN-complex within the dLF that are not part of the DSCT (Dart \& 
Gordon, 1973; Gordon \& Grant, 1982; H. Johansson \& Silfvenius, 1977b; Low et al., 1986), which likely make up the spinomedullothalamic tract. Little is known about this pathway, but it is described to comprise axons from neurons with cell bodies in dorsal horn lamina 4, which respond to stimulation of muscle, tendon, joint, and cutaneous SA afferents from the upper and lower body. Therefore, this tract may house second order SA neurons that are activated by the SA primary afferents reported to leave the DDC at mid-thoracic levels. The primary targets of the spinomedullothalamic tract are $\mathrm{X}$ and Z.

\section{The dorsal column nuclei complex}

The following review will examine the $\mathrm{Gr}$ and $\mathrm{Cu}$ in detail, but we will first introduce the ECu, MA, and $\mathrm{X}$ and $\mathrm{Z}$, for which, compared to the $\mathrm{DCN}$, there is relatively little information and reported inconsistencies.

\section{External cuneate nuclei}

The ECu lie dorsolateral to the $\mathrm{Cu}$ and originate around the level of obex (Figure 1A, insert). The ECu receives inputs from muscles, tendons, and joints of the upper body and forelimbs, via the DCs, and is largely composed of second-order cerebellar-projecting neurons. This cuneocerebellar pathway is the primary source of cerebellar inputs from upper-body muscles, tendons, and joints and is an upperbody equivalent of the DSCT (Paxinos, Huang, Sengul, \& Watson, 2012). The ECu mostly contains neurons with large cell bodies and its border with the rostral $\mathrm{CN}$ is often indistinguishable due to the population of large cells common to both nuclei. However, ECu neural populations typically appear more compact and homogenous than the reticulated appearance of rostral $\mathrm{Cu}$ (Bermejo, Jiménez, Torres, \& Avendaño, 2003). The ECu shows no evidence of topographic divisions defined by cell morphologies or neuronal response characteristics, but its somatotopic arrangement and projection targets are discussed in later sections.

\section{Median accessory nucleus}

Sometimes a slender group of cell bodies at the brainstem midline is identified between the Gr, named the median accessory nuclei (MA, also known as Bischoff's nucleus) (Bischoff, 1899), which receives 
afferents exclusively from the tail (Figure 1A, insert). The MA has been described in rats (Bermejo et al., 2003), raccoons (J. I. Johnson, Welker, \& Pubols, 1968), opossums (Robards, 1979), some primates (Chang \& Ruch, 1947), and possibly the cat (Kruger, Siminoff, \& Witkovsky, 1961), but is not typically considered separate from the Gr. When the MA is identified, it is described as originating at the spinomedullary junction and extending rostrally to the caudal border of area postrema, and is separated from the Gr by gf fibres ventrally and laterally (Bermejo et al., 2003; J. I. Johnson et al., 1968).

Large MA are found in some vertebrates that lack hind limbs, such as manatees (Sarko, Johnson, Switzer, Welker, \& Reep, 2007), or that have well-developed prehensile tails, such as pythons (Molenaar, 1976). Sea lions also appear to have a large, clearly separated MA (Sawyer, Turner, \& Kaas, 2016), but like in the spider monkey (Chang \& Ruch, 1947) it is not a thin midline structure, as described by Bischoff.

\section{Nuclei $X$ and Z}

Two small nuclei, named nuclei X (X) and nuclei Z (Z) by Pompeiano and Brodal (1957), are sometimes considered part of the DCN-complex (Mantle-St. John \& Tracey, 1987; Mountcastle, 1984). These nuclei do not have a clearly defined functional role but are likely involved in integrating and transmitting hindlimb ( $\mathrm{X}$ also receives forelimb inputs) proprioceptive and cutaneous information to the thalamus and cerebellum. However, these nuclei are not consistently identified, and their inputs and projection targets have not been well characterised.

Nucleus $\mathrm{X}$ comprises small to medium-sized loosely scattered cells found rostral to the ECu (Figure $1 \mathrm{~A}$, insert) (A. Brodal \& Pompeiano, 1957) in rats (Mantle-St. John \& Tracey, 1987), cats (H. Johansson \& Silfvenius, 1977b), raccoons (Ostapoff \& Johnson, 1988), and nonhuman primates (Albright \& Friedenbach, 1982; Pearson \& Garfunkel, 1983), but is rarely identified in humans (Kaas, 2004), likely because it is difficult to identify histologically. Nucleus $\mathrm{X}$ receives secondary afferents responsive to activation of ipsilateral hindlimb muscles, joints, and skin, which are primarily collaterals of DSCT 
neurons from the nucleus dorsalis (H. Johansson \& Silfvenius, 1977b; Landgren \& Silfvenius, 1971; Low et al., 1986; Mantle-St. John \& Tracey, 1987; Ostapoff, Johnson, \& Albright, 1988). In raccoons, X also receives some input from forelimb muscle, tendon, and joint afferents that ascend in the dLF (Ostapoff \& Johnson, 1988), but it is unclear if these are primary or secondary afferents, or whether the same inputs are found in other species.

Nucleus $Z$ lies rostrolateral to the Gr (Figure 1A, insert), and has been identified in rats (Low et al., 1986), cats (Asif \& Edgley, 1992; H. Johansson \& Silfvenius, 1977a, 1977c; Landgren \& Silfvenius, 1971), raccoons (Ostapoff \& Johnson, 1988; Ostapoff et al., 1988), nonhuman primates (Albright \& Friedenbach, 1982), and humans (Sadjadpour \& Brodal, 1968). Like X, Z receives ipsilateral hindlimb secondary afferents, which are predominantly DSCT collaterals from the dLF and respond to activation of muscles, joints, and skin (Asif \& Edgley, 1992; H. Johansson \& Silfvenius, 1977a, 1977c; Landgren \& Silfvenius, 1971; Low et al., 1986; Magherini, Pompeiano, \& Seguin, 1975; Magherini et al., 1974). Interestingly, some $Z$ afferents appear to have cell bodies in spinal cord lamina 10 (Low et al., 1986), but their function is unknown and they have not been described in other studies. Finally, some fibres that terminate in $\mathrm{Z}$ travel in the DCs, but whether these are primary or secondary afferents is unconfirmed (Hand, 1966; H. Johansson \& Silfvenius, 1977a, 1977b).

\section{Gracile nuclei}

The $\mathrm{Gr}$ are groups of cell bodies in the dorsal medulla that primarily receive inputs from the lower limbs and lower trunk. They have elongated, parallel cell arrangements lying either side of the midline and originate near the dorsal aspect of the spino-medullary junction. The cross-sectional area of the Gr is largest caudal to obex and tapers rostrally, ending just rostral to obex (Figure 1A, insert). The $\mathrm{Gr}$ are mostly bordered ventrally by the nuclei solitarius, and the Cu laterally (Bermejo et al., 2003; Paxinos et al., 2012). Medially, the two sides of the Gr are separated from each other by a thin layer of gf fibres and MA, if present (see median accessory nucleus section above; Figure 1A, insert) (Bermejo et al., 2003). At its rostral extremity the Gr borders Z, which is sometimes confused with the 
rostral portion of the Gr due to the similar appearance and projection targets (Quy, Fujita, Sakamoto, $\mathrm{Na}$, \& Sugihara, 2011).

The Gr were originally thought to be a simple relay for tactile information being transmitted to the thalamus and subsequently the cortex, for conscious perception (Therman, 1941). However, investigations from the past several decades depict the $\mathrm{Gr}$ as a heterogeneous cell population that acts as a hub for processing tactile and proprioceptive information and distributing it throughout several different sensorimotor systems (Berkley et al 1986). Gr cells are arranged in distinct populations, with different cell types, population densities, receptive field sizes, response modalities, and projection targets (Berkley et al., 1986; Boivie, 1978; Dykes et al., 1982; Gordon \& Jukes, 1964a, 1964b; Gordon \& Paine, 1960; Gordon \& Seed, 1961; Noriega \& Wall, 1991; Qi \& Kaas, 2006). These population differences has led to the separation of the Gr into three regions along its rostrocaudal extent, named the rostral, middle, and caudal zones (Figure 1A, insert, Table 1).

\section{Rostrocaudal zones}

Rostral gracile nuclei

The rostral gracile nuclei (GrR) (Figure 1A, insert) have a reticulated appearance, with a mix of large and small cell bodies of various shapes (Table 1). In the cat, Dykes et al. (1982) found that GrR cells predominantly respond to stimulation of muscles and joints, with smaller populations of cells driven by mixed cutaneous and Pacinian-like inputs (Table 1). GrR cells typically have large RFs (Gordon \& Jukes, 1964b; Gordon \& Paine, 1960; McComas, 1963), consistent with the predominance of muscle and joint inputs, or potentially due to primary afferent convergence onto GrR cells. Rostral Gr RFs are mostly on the proximal lower limb and axial lower body regions and the majority are FA (Table 1) (Dykes et al., 1982; Luo et al., 2009; Niu et al., 2013).

\section{Middle gracile nuclei}

The gracile nuclei middle zone (GrM) (Figure 1A, insert) is characterised by dense cell clusters, surrounded by a medial, dorsal, and lateral 'shell' region of reticulated appearance (Figure 1A) (Berkley et al., 1986; Bermejo et al., 2003). Cells in the clusters region of the GrM mostly have small 
or medium-sized, round cell bodies and small RFs compared to rostral and caudal Gr cells (Table 1) (Gordon \& Paine, 1960; Gordon \& Seed, 1961; McComas, 1963). The RFs of GrM cluster neurons are predominantly found on distal body parts, particularly the toes, while the surrounding reticulated regions include cells with larger RFs on the proximal body. GrM cells predominantly receive FA cutaneous inputs (Dykes et al., 1982; Luo et al., 2009; Niu et al., 2013).

The GrM clusters are best visualised using histochemical staining of the mitochondrial enzyme cytochrome oxidase (CO), which shows areas of high metabolic synaptic activity (Mjaatvedt \& WongRiley, 1988; Wong-Riley, 1989). The clusters are salient in several species of primates (Noriega \& Wall, 1991; Qi \& Kaas, 2006; Strata, Coq, \& Kaas, 2003), raccoons (J. I. Johnson et al., 1968), and are present, but less clear, in cats (Hand, 1966; Kuypers, Hoffman, \& Beasley, 1961; Kuypers \& Tuerk, 1964). In rats, Crockett, Maslany, and Egger (1996) showed that a Gr middle region was cytoarchitecturally distinct from the rostral and caudal regions, but clear $\mathrm{CO}$ clusters were absent. Rather, there is weak evidence of irregular cell clusters, described as 'vertical slabs' in the rostrodorsal region of the Gr, but this pattern was inconsistent across rats (Bermejo et al., 2003). Ventral to the clusters is another reticulated zone that preferentially receives muscle, tendon, and joint afferents, but this region is more apparent in the $\mathrm{Cu}$.

The Gr shell and ventral regions are less well characterised compared to their $\mathrm{Cu}$ counterparts, but they do appear to have distinct characteristics that identify them as separate zones within the Gr. The Gr shell region has a reticulated appearance and is characterised by small spindle and round neurons that respond with mostly SA-like characteristics, receive input from proximal body regions, and respond to mixed somatosensory inputs (Table 1) (Berkley et al., 1986; Bermejo et al., 2003). Neurons in the Gr ventral region respond with mostly SA-like characteristics, receive some proprioceptiverelated inputs mostly from proximal body regions, and have different projection targets than the other Gr zones (Table 1) (Berkley et al., 1986; Berkley \& Hand, 1978a; Dykes et al., 1982; Millar \& Basbaum, 1975). 


\section{Caudal gracile nuclei}

The caudal Gr zone ( $\mathrm{GrC}$ ) (Figure 1A, insert) has predominantly medium and large, round cells that do not show obvious clustering, and some multipolar or fusiform neurons scattered throughout (Table 1). The GrC cells have very large RFs from the entire body with less defined somatotopy, compared to GrM, and the largest proportion of Pacinian-like cell responses of the three rostrocaudal zones (Dykes et al., 1982).

\section{Cuneate nuclei}

The Cu lie lateral to the Gr on either side of the brainstem and contain heterogeneous cell groups that receive afferent input from the upper limbs and trunk. The $\mathrm{Cu}$ originate at the spinomedullary junction where they are separated from the Gr dorsomedially by cf fibres (Figure 1A, insert). Rostrally, the $\mathrm{Cu}$ and the $\mathrm{Gr}$ meet as the gracile and cuneate fascicular fibres become sparser just caudal to obex. At the level of area postrema the $\mathrm{Cu}$ are bordered by the nucleus solitarius complex ventromedially, the ECu dorsolaterally, and the spinal trigeminal nuclei ventrolaterally (Bermejo et al., 2003). The most rostral portion of the $\mathrm{Cu}$ is displaced slightly more laterally compared to the middle region and ends at a juncture with $\mathrm{X}$ and $\mathrm{Z}$, and the ECu (Figure 1A, insert).

Early investigations in the cat and rat, determined that these nuclei have only two divisions with different cytoarchitecture in the rostral and caudal zones (Basbaum \& Hand, 1973; Keller \& Hand, 1970; Kuypers \& Tuerk, 1964), afferent inputs (Keller \& Hand, 1970), and top-down cortical inputs (Kuypers \& Tuerk, 1964). However, these rostrocaudal divisions were revised to a tripartite arrangement including rostral, middle, and caudal zones, analogous to their Gr counterparts, in macaques (Biedenbach, 1972), cats (Berkley et al., 1986; Cheema, Whitsel, \& Rustioni, 1983), raccoons (Rasmusson, 1988), and rats (Maslany, Crockett, \& Egger, 1991; Maslany, Crockett, \& Egger, 1992).

\section{Rostrocaudal zones}

\section{Rostral cuneate nuclei}

The rostral cuneate nuclei (CuR) (Figure 1A, insert) division is characterised by a reticulated arrangement of large cell bodies and many small cell bodies, grouped throughout bundles of the cf, 
which mostly have large RFs on the proximal and axial upper body (Bermejo et al., 2003; Cheema et al., 1983). The rostral border of CUR meets $X$ and $Z$ and intermingles with ECu dorsolaterally (Figure 1A, insert). It can be difficult to observe a clear separation between the $\mathrm{CUR}$ and $\mathrm{ECu}$, as both contain similar populations of large cell bodies (Bermejo et al., 2003) and primarily respond to stimulation of muscles, tendons, and joints (Table 1) (Cheema et al., 1983; Dykes et al., 1982). However, the CuR receive more cutaneous afferents than the ECU and almost exclusively display SA characteristics.

\section{Middle cuneate nuclei}

The middle cuneate nuclei (CuM) are the largest and densest Cu zones (Bermejo et al., 2003; Heino \& Westman, 1991). The CuM are predominantly made up of medium and small cells, with a higher proportion of medium-sized neurons compared to caudal and rostral Cu zones (Table 1) (Cheema et al., 1983). The CuM can be subdivided into three zones - the shell, the clusters, and the ventral zone - which are summarized for rats, cats, raccoons, and macaques in the Figure 1B.

Like the GrM, the CuM cluster zone has dense, roughly ovoid, groups of cell bodies, separated by cellpoor fibre septa, best visualised by their CO activity (Crockett, Maslany, Harris, \& Egger, 1993; Florence, Wall, \& Kaas, 1989). Dense somatotopically organised cutaneous afferent terminals primarily from the distal forelimbs target these clusters. Cluster neurons are characterised by having the smallest RFs relative to rostral and caudal $\mathrm{Cu}$, and are specialised for processing and transmitting precise discriminative touch information (Table 1) (Cheema et al., 1983; C. X. Li, Yang, \& Waters, 2012). All four species have a CuM cluster region (Figure 1B) (Cheema et al., 1983; Crockett et al., 1996; Crockett et al., 1993; Florence et al., 1989; J. I. Johnson et al., 1968; C. X. Li et al., 2012; Maslany et al., 1991; Maslany et al., 1992), but it is often called the pars rotunda in primates (Ferraro \& Barrera, 1935).

The CuM shell region has dense fields of non-clustered cell bodies displaying high CO activity, which is common to all four species (Figure 1B) (C. X. Li et al., 2012). Typically, afferents from proximal upper body regions terminate in the CuM shell, and cells in this region have larger RFs and respond to a mixture of tactile and proprioceptive stimuli. 
Interestingly, the cat ventral CuM shows dense unclustered CO labelling and receives inputs from primary afferents that innervate muscles, tendons, joints, and cutaneous structures of the proximal and axial upper body, but is dominated by responses to proprioceptive stimuli (Table 1) (Figure 1B) (Cheema et al., 1983; Dykes et al., 1982; Jasmin, Courville, \& Bakker, 1985; Millar \& Basbaum, 1975; Nyberg \& Blomqvist, 1982, 1984; Rosén, 1969). In primates, a ventral and lateral region of CuM named the pars triangularis (Ferraro \& Barrera, 1935) exhibits the same characteristics as the cat ventral CuM (Figure 1B) (Hummelsheim \& Wiesendanger, 1985; Hummelsheim, Wiesendanger, Wiesendanger, \& Bianchetti, 1985). In raccoons a so-called "tongue" or "bridge" region at the ventrolateral portion of CuM forms a bridge of cells with the ECu (Figure 1B). The bridge region receives muscle afferent terminals and contains cells responsive to muscle stretch from the proximal and axial upper body (J. I. Johnson et al., 1968). The similarities of the pars triangularis, the bridge region, and the ventral zone suggest that they are homologous structures and, here, we consider them the same functional region referred to as ventral $\mathrm{Cu}$. Finally, a recent report in rats reported that they did not find any proprioceptive responses in the ventral Cu (C. X. Li et al., 2012), and it is unclear if they have an analogous ventral zone.

\section{Caudal cuneate nuclei}

The $\mathrm{CuC}$ has a reticulated appearance, predominated by neurons with small cell bodies (Table 1), but there is also a mixed population of medium and large neurons, which are mostly found in the dorsal portion (Cheema et al., 1983). Primary afferent fibre terminals are less discretely arranged in CuC compared to CuM (Florence et al., 1989; Maslany et al., 1992). CuC neurons have large RFs and respond with a mix of FA and SA characteristics from skin, muscles, and joints of the digits, arm, and upper trunk (Cheema et al., 1983; Dykes et al., 1982). Compared to middle and rostral Cu zones, a relatively large proportion of cells in the caudal zone show Pacinian-like responses. Like CuM, CuC appears to have a ventral region with a larger proportion of cells responding to movement of the elbow and shoulder joints, and respond almost exclusively with SA characteristics (Table 1) (Figure 1A) (Cheema et al., 1983; Dykes et al., 1982). 
In summary, the DCN have clear morphological and modality-based segregation in three rostrocaudal zones, as well as cross-sectional segregation, particularly in the middle region. The clusters receive almost exclusively cutaneous afferents from the distal limbs and are specialised for precise discriminative touch. The shell, rostral, and caudal DCN have mixed cell populations, RFs on more proximal and axial body regions, and appear to receive afferent types of all modalities. The ventral regions extend the rostrocaudal length of the DCN and predominantly receive muscle, tendon, and joint inputs. Finally, the caudal zones excluding the ventral portion appear to have the largest proportion of Pacinian-like responses of the three zones. The $\mathrm{Gr}$ and $\mathrm{Cu}$ rostrocaudal zones have similar attributes but, notable differences are the preponderance of FA afferents terminating in the Gr, and the more defined clusters, shell, and ventral regions of the $\mathrm{Cu}$ (Table 1) (Figure 1).

\section{Dorsal column nuclei somatotopy}

The DCN were first shown to be somatotopically organised by Kruger et al. (1961) by electrophysiologically mapping the peripheral RFs of DCN neurons in cats. Using a variety of electrophysiological and labelling methods a stereotyped map was confirmed by others, with a mediolateral progression of tail, foot, lower leg, and upper leg representation in the Gr, followed by the ulnar forelimb, digits and hand/forepaw, radial forelimb, shoulder, and neck in the $\mathrm{Cu}$ (Figure 2). DCN somatotopy is present throughout the rostrocaudal zones, but is best defined in the middle regions, and poorly defined in the rostral and caudal zones. The stereotyped map has been demonstrated in several mammalian species including cats (Dykes et al., 1982; Jasmin et al., 1985; Millar \& Basbaum, 1975; Nyberg, 1988; Nyberg \& Blomqvist, 1982), rats (C. X. Li et al., 2012; Maslany et al., 1991; Nord, 1967), sheep (Woudenberg, 1970), raccoons (J. I. Johnson et al., 1968; Rasmusson, 1988, 1989), squirrels (Ostapoff, Johnson, \& Albright, 1983), opossums (Hamilton \& Johnson, 1973), and non-human primates (Culberson \& Brushart, 1989; Florence, Wall, \& Kaas, 1988; Florence et al., 1989; Florence, Wall, \& Kaas, 1991; Qi \& Kaas, 2006; Strata et al., 2003; Xu \& Wall, 1996, 1999). Most of the lower and upper trunk representation lies in a transition zone between the $\mathrm{Gr}$ and the $\mathrm{Cu}$ (Figure 2). The neck, ear, and posterior head are represented most laterally in the $\mathrm{Cu}$ (J. I. Johnson et al., 1968; 
C. X. Li et al., 2012; Millar \& Basbaum, 1975), in a transition zone between the Cu and the face representation in the spinal trigeminal nuclei. While the stereotyped map holds true in most cases, there are some crucial differences among species, particularly related to the orientation of the hind and forelimb digits, which are discussed next.

\section{Gracile nuclei}

Although the somatotopic arrangement of the $\mathrm{Gr}$ is relatively consistent across species, the organisation of the hind paw/foot is variable. In the rat, cat, and raccoon toes 1-5 (T1-T5) are arranged in a lateral to medial line near the dorsal surface of the Gr (Figure 2) (Kruger et al., 1961; Nord, 1967). The footpads are represented dorsally, with the toes and the dorsal surface of the foot represented in progressively more ventral zones (Figure 2) (J. I. Johnson et al., 1968; Maslany et al., 1991; Millar \& Basbaum, 1975). However, the toes of non-human primates including galagos, owl monkeys, squirrel monkeys, and macaques are represented in the medial region of the Gr, in a crescent shape with T5 dorsal and slightly lateral relative to the other toes, and T1 most ventral (Figure 2) (Qi \& Kaas, 2006; Strata et al., 2003). Even among these primate species there is moderate variability in foot representation (see Qi and Kaas (2006)).

In the CuM clusters, different body regions are represented in specific CO-dense clusters (Crockett et al., 1993; Florence et al., 1989, 1991; Noriega \& Wall, 1991; Nyberg, 1988; Rasmusson, 1988; Xu \& Wall, 1996, 1999). However, in the Gr, sometimes more than one toe or other body region is represented in the same cluster, and afferents from specific body regions may terminate in several CO-dense clusters along the rostrocaudal extent of the Gr (Qi \& Kaas, 2006; Strata et al., 2003).

Interestingly, in one rat study the lateral to medial arrangement of T1 and T4 was shown to completely reverse several times throughout the rostral caudal axis in the same rat, such that at some levels, T1 was most medial and T4 (and presumably T5) was most lateral (Maslany et al., 1991). Although this phenomenon has not been shown in other studies, asymmetry in rat electrophysiological Gr surface 
recordings (Loutit et al., 2017; Loutit et al., 2019), and variability in cat hindlimb projection maps have also been reported (Millar and Basbaum, 1975).

\section{Cuneate nuclei}

The glabrous skin of the forepaw/hand digits were initially reported to be represented at the dorsal surface of the $\mathrm{Cu}$ in cats (Kruger et al., 1961), and rats (Nord, 1967). Later electrophysiology and labelling studies mostly confirmed this in cats, showing the digit pads represented almost linearly with digits 1-4 (D1-D4) lateral to medial and the palmar pad dorsal to the digit representation (Figure 2) (Millar \& Basbaum, 1975; Nyberg, 1988; Nyberg \& Blomqvist, 1982). The original rat somatotopic map proposed by Nord (1967) resembles that shown in the cat, but has been updated by more accurate electrophysiological mapping combined with horseradish peroxidase and CO labelling. The newer maps show D1-D5 representation rotated about 90 degrees ventral and lateral from Nord's map, in a crescent shape with the convex side facing dorsolaterally (Figure 2) (C. X. Li et al., 2012; Maslany et al., 1991). The palmar pads are represented medial to the digits, while the dorsal forepaw is represented at the dorsal border of the $\mathrm{Cu}$, which is similar to that shown in raccoons (Figure 2) (J. I. Johnson et al., 1968; Rasmusson, 1988), and opossums (Hamilton \& Johnson, 1973). In non-human primates including galagos, marmosets, and squirrel monkeys, digit representation is dorsal and lateral to the palmar pads (Florence et al., 1991; Strata et al., 2003; Xu \& Wall, 1996), resembling that of the rat and raccoon. However, representation of the hand in macaques appears to be turned upside-down relative to the abovementioned species with the digits represented ventromedially to the palmar and dorsal hand (Figure 2) (Culberson \& Brushart, 1989; Florence et al., 1989). The functional significance of the different hand representation in macaques is unclear, but it appears that a similar arrangement is also likely in humans (Florence et al., 1989). Potentially, this flipped macaque arrangement positions the digit representation closer to ventral CuM which receives a preponderance of descending cortical inputs and ascending muscle and joint afferent inputs, which may enhance tactile discrimination and/or grasping abilities. Further investigation is needed to explore these possibilities. 
Interestingly, the crescent-shaped digit representation appears to correlate with animals that exhibit grasping behaviours e.g. monkeys, rats, and raccoons (Figure 2). The raccoon is a particularly interesting example, as it is phylogenetically closer to cats and sheep, but its crescent CuM digit representation is more like grasping animals than its genetic neighbours.

\section{External cuneate nuclei}

The ECu have a somatotopic map of muscles from the forelimbs and upper body, but comparatively little is known about this map. Early macaque and cat degeneration studies found ECu afferents terminating in a topographic arrangement, with afferents entering the spinal cord in upper cervical segments terminating in caudal and ventral ECu, and afferents from successively lower spinal segments terminating progressively more rostral and dorsal (Ferraro \& Barrera, 1935; C. N. Liu, 1956). Later, more precise electrophysiological mapping and afferent tracing studies of the ECu demonstrated a so-called 'musculotopic' map, with individual muscles, or functionally related muscle groups, represented topographically in rats, cats, and raccoons (Abrahams \& Swett, 1986; Bakker, Richmond, Abrahams, \& Courville, 1985; Campbell, Parker, \& Welker, 1974; Dykes et al., 1982; Jasmin et al., 1985; J. I. Johnson et al., 1968; Nyberg \& Blomqvist, 1984; Rosén, 1969). The muscles of the distal forelimb are represented medially in the $\mathrm{ECu}$, and proximal forelimb and axial muscles represented progressively laterally, with some variation between species. In the lateral portion, the neck is represented ventral to the shoulder and upper trunk. This arrangement was also found to be displaced along the rostro caudal axis of the $\mathrm{ECu}$, with neck muscle afferents represented in the rostro lateral $\mathrm{ECu}$, the proximal arm and shoulder muscles caudal, and the forearm and forepaw muscles more caudally still (Campbell et al., 1974; Jasmin et al., 1985; J. I. Johnson et al., 1968; Nyberg \& Blomqvist, 1984). Interestingly, to our knowledge a detailed musculotopic map has not been described in primates.

Generally, ECu cells with distinct functional roles are intermingled, such that afferent terminal distributions of flexor and extensor muscles of the arm appear to overlap (Jasmin et al., 1985), but individual ECu cells only respond to a single muscle or a group of agonistic muscles (Campbell et al., 
1974). However, the proximity of cells responding to antagonistic muscles seems well suited to facilitate communication between these groups. Therefore, ECu cells could potentially communicate closely with their antagonistic muscle counterparts, situated nearby within the ECu.

\section{Dorsal column nuclei projection targets and connections}

The DCN have a complex and diverse population of projection targets throughout the brain and spinal cord. This suggests that these nuclei act not as simple relays, but as processing and distribution hubs for ascending somatosensory information. Berkley et al. (1986) produced an excellent review of the DCN projection targets and separated them into three broad systems: a cortical system, a cerebellar system, and a spinal cord system. In this review, we will adopt these categorisations as a framework to discuss the interconnectedness of the DCN. We further add a system (a brainstem system) for brain regions that do not fit the existing framework.

\section{System 1: The cortical system}

Ascending somatosensory information from the DCN-complex reaches somatosensory primary and unimodal cortical regions via the thalamus. These cortical destinations include Brodmann's areas 3b (also known as the primary somatosensory cortex (S1)), 3a, 1, and 2 in the anterior parietal cortex, and somatosensory association areas including the secondary somatosensory cortex (S2) and the parietal ventral area (PV) (also referred to as the fourth somatosensory cortex (S4) in some species). Areas $3 \mathrm{a}$ and $3 \mathrm{~b}$ primarily, but not exclusively, receive proprioceptive and cutaneous information, respectively, and each contain a separate somatotopic map of the entire body. Areas 1 and 2 have larger RFs and complex response properties. For an excellent recent review on these systems in primates see Delhaye, Long, and Bensmaia (2018).

The cortical system proposed by Berkley et al. (1986) includes three subsystems with different DCNcomplex neural populations, separated by their thalamic intermediate targets and subsequent cortical targets (Figure 3). The first cortical subsystem is the pathway for discriminative touch information through the ventroposterior lateral nucleus (VPL) of the thalamus. The second subsystem conveys proprioceptive information through a region along the border of the VPL and ventrolateral nucleus 
(VL) of the thalamus. The third subsystem conveys multimodal information from the DCN-complex to the posterior group $(\mathrm{Po})$ of the thalamus.

Reports vary, but thalamic-projecting neurons appear to make up the largest proportion of DCN neurons in rats, cats, and monkeys (Bermejo et al., 2003; Blomqvist, 1980; Ellis \& Rustioni, 1981; Gordon \& Seed, 1961; Kemplay \& Webster, 1989; Rustioni, Hayes, \& O’Neill, 1979; Rustioni, Schmechel, Cheema, \& Fitzpatrick, 1984). DCN neurons included in the cortical system are, therefore, considered the dominant DCN population.

\section{Cortical subsystem 1}

The first cortical subsystem involves the well-known dorsal column-medial lemniscus system. This subsystem comprises mostly medium-sized round DCN cells of the clusters region, and a small proportion from rostral and caudal $\mathrm{DCN}$, that project through the medial lemniscus (ML) to the contralateral VPL of the thalamus (Figure 3). The DCN-VPL projections terminate somatotopically with the opposite medial-lateral (due to the fibres crossing the midline) and dorsal-ventral (upside-down) orientation of the $\mathrm{DCN}$ somatotopic map. Therefore, Gr projections terminate rostral and lateral to $\mathrm{Cu}$ projections, and distal body parts are represented ventrally, with more proximal body parts dorsally (Feldman \& Kruger, 1980; Massopust, Hauge, Ferneding, Doubek, \& Taylor, 1985; Schroeder \& Jane, 1971; Villanueva, Desbois, le Bars, \& Bernard, 1998). The VPL is sometimes referred to as part of the "core" region of the thalamic ventroposterior nucleus (the ventroposterior medial nucleus is also included) and has discrete clusters separated by cell-poor septa (Qi, Gharbawie, Wong, \& Kaas, 2011), analogous to the DCN clusters regions.

The DCN-VPL projection is thought to be exclusively contralateral but, interestingly, Wree, Itzev, Schmitt, and Usunoff (2005) found a moderate (5\%) population of DCN-thalamic ventroposterior nucleus cells that project to the ipsilateral VPL in rats. Ipsilateral-projecting neurons are found throughout the Gr, and in CuR and CuM, but are almost completely absent from CuC (Figure 3). The authors did not speculate on the functional significance of this ipsilateral population and we do not know whether it is present in other species other than rats. 
Congruent with the role of the DCN clusters and thalamic VPL regions in processing and transmitting discriminative touch information, neurons in VPL project heavily onto cortical areas $3 \mathrm{~b}$ and 1 , but also onto areas $3 a$ and 2 (Figure 3 ).

\section{Cortical subsystem 2}

The second cortical subsystem comprises neurons conveying proprioceptive information, with cell bodies in $\mathrm{X}$ and $\mathrm{Z}$, ventral $\mathrm{Cu}$, and the $\mathrm{ECu}$ (Figure 3 ). These neurons project via the $\mathrm{ML}$ to a proprioceptive region of the contralateral thalamus, which has been referred to by many names (see Berkley (1983) and Padberg et al. (2009) for discussion). The borders of the region are difficult to ascertain and vary between species, but in the cat, Berkley et al. (1986) referred to it as the border of VPL and the anterior thalamic motor nuclei. This region forms a shell around the anterior border of VPL, so we will refer to it as the VPL shell region, like Jones and Friedman (1982). The lack of evidence for Gr projections to the VPL shell may be because the Gr appears to receive fewer proprioceptive inputs (Table 1; Figure 1,3) (Dykes et al., 1982; Niu et al., 2013; Whitsel et al., 1969; Whitsel et al., 1970). Instead, DSCT axon collaterals and the spinomedullothalamic tract project to $X$ and $Z$, which appears to be the main route by which lower body proprioceptive-related information reaches the VPL shell.

Projections from the ECu to the VPL shell are present in rats (Mantle-St. John \& Tracey, 1987), raccoons (Ostapoff et al., 1988), and monkeys (Boivie \& Boman, 1981; Pearson \& Garfunkel, 1983), but not cats (Berkley et al., 1986; Rosén, 1969). Like the somatotopic arrangement of the CuM clusters (see Dorsal column nuclei somatotopy, cuneate nuclei section), the ECu-thalamic projections are present in rats, raccoons, and monkeys, but not in cats. This further supports the notion that the DCN-complex is functionally organised for dexterous limb and digit control in these animals, as noted by Ostapoff et al. (1988). Raccoons are more phylogenetically similar to cats than to rats or monkeys, yet cats lack ECU-thalamic connections, and have different somatotopic DCN organisation, which may be related to their lack of forepaw dexterity. 
Like DCN-VPL connections, afferents conveying upper body information from the ECu and ventral $\mathrm{Cu}$ neurons project to the medial portion of the VPL shell, while afferents conveying lower body information from $\mathrm{Z}$ and $\mathrm{X}$ neurons project to the lateral portion, showing some somatotopic organisation (Berkley et al., 1986; Grant, Boivie, \& Silfvenius, 1973; H. Johansson \& Silfvenius, 1977b; Mantle-St. John \& Tracey, 1987; Ostapoff \& Johnson, 1988; Ostapoff et al., 1988; Pearson \& Garfunkel, 1983). Each of these DCN-complex regions are known to carry information related to proprioception, which is congruent with VPL shell neurons responding to proprioception-related stimuli. The primary target of VPL shell neurons is area 3a, but some projections also terminate in areas 2 and $3 \mathrm{~b}$ (Clemo \& Stein, 1983; McHaffie, Kruger, Clemo, \& Stein, 1988; Padberg et al., 2009). The role of this cortical subsystem is to convey proprioceptive information from the entire body to the somatosensory cortex.

\section{Cortical Subsystem 3}

The third proposed group within the cortical system is a population of DCN-complex neurons that project to the contralateral posterior nuclei (Po) of the thalamus via the ML (Figure 3). The Po contains a complete somatotopic representation of the contralateral body surface, albeit with large RFs, and appears to play a role in processing both nociceptive and innocuous touch information (Brinkhus, Carstens, \& Zimmermann, 1979; Diamond, Armstrong-James, \& Ebner, 1992). Direct DCN-complex to Po projections derive from a small population of neurons scattered throughout the DCN-complex (Berkley, 1980; Berkley et al., 1986; Feldman \& Kruger, 1980; Hand \& Van Winkle, 1977; Itoh, Kaneko, Kudo, \& Mizuno, 1984; Lund \& Webster, 1967). Inputs from the DCN-complex are mostly found in dorsal Po with Gr neurons terminating lateral and rostral compared to Cu terminals (Berkley, 1980; Villanueva et al., 1998).

A possible indirect DCN-complex to Po pathway via the intercollicular region of the tectum (ICo) has also been suggested (Berkley et al., 1986; Itoh et al., 1984). There is a dense, roughly somatotopic connection between DCN-complex neurons (excluding the clusters zones) and the contralateral ICo (Björkeland \& Boivie, 1984; Robards, Watkins, \& Masterton, 1976; Schroeder \& Jane, 1976; Wiberg \& Blomqvist, 1984a; Wiberg, Westman, \& Blomqvist, 1987). Neurons in a region of the ICo that roughly 
overlaps with terminals from DCN-complex neurons send projections to the lateral division of Po (Itoh et al., 1984). These projections to Po are bilateral, but numbers of ipsilateral connections far outweigh contralateral ones. Direct DCN-Po terminations are denser in medial Po, while the possible indirect terminations are focused in lateral Po (Berkley, 1980; Hand \& Van Winkle, 1977).

The function of either the direct or indirect DCN-complex to Po pathways is not clear. The Po projects to cortical areas 1, 2, 3b, S2, and PV (Figure 3) (Burton \& Jones, 1976; Naito \& Kawamura, 1982; Padberg et al., 2009; Roda \& Reinoso-Suárez, 1983; Stein, Spencer, \& Edwards, 1983), which suggests a role beyond precise discriminative touch. Both the Po and the ICo also receive dense reciprocal inputs from the PV (McHaffie et al., 1988). Top-down inputs from PV to the superior colliculus (SC) are essential for development and function of multisensory integration in the SC (McHaffie et al., 1988; Stein, Stanford, \& Rowland, 2014), so perhaps the top-down PV-ICo and/or PV-Po connections serve a similar function.

\section{The nucleus reuniens}

Villanueva et al (1998) found a group of neurons in the $\mathrm{Cu}$ that project bilaterally to the nucleus reuniens (Re) of the rat thalamus. We have not included this Cu-thalamic connection as a major pathway, as this appears to be the only example of these projections. However, such a connection has interesting functional implications. The Re is found at the ventral midline of the thalamus, above the third ventricle, and is the largest of the midline thalamic nuclei (Griffin, 2015). The Cu-Re projections terminate mostly in the dorsal Re, which is an area that predominantly projects to CA1 of the hippocampus (Dolleman-van Der Weel \& Witter, 1996). It is not clear whether the Cu projections terminate directly onto cells that project to the Re, but their colocalization may indicate a pathway for information from the DCN to access the limbic system. The Re interactions with the hippocampus form a reciprocal network with the medial prefrontal cortex and contribute to spatial working memory (Griffin, 2015) and contextual memories for discriminating dangerous and safe contexts (Ramanathan, Ressler, Jin, \& Maren, 2018). The Cu-Re connection might convey somatosensory information to this network, which is used for spatial working memory. 


\section{Cortical inputs}

In addition to the diverse ascending projections of the DCN-complex, they also receive descending input from the sensorimotor cortex. Cortical to DCN-complex axons are collaterals from both corticospinal and corticobulbar neurons that travel in the pyramidal tract and originate in cortical layer 5 (Figure 4) (Martinez, Lamas, \& Canedo, 1995; Rustioni \& Hayes, 1981). The corticofugal projections are functionally matched, such that motor (primary motor cortex (M1); area 4) and proprioceptive (area 3a) cortical regions send most projections to the proprioceptive-related regions in rostral and ventral DCN (Cheema, Rustioni, \& Whitsel, 1985; Cheema et al., 1983; Gordon \& Jukes, 1964a; Kuypers, 1958; Kuypers et al., 1961; Kuypers \& Tuerk, 1964). Similarly, discriminative touch-related cortical and DCN regions are reciprocally connected, as area $3 \mathrm{~b}$ sends projections primarily to the DCN cluster regions (Cheema et al., 1985; Cheema et al., 1983; Gordon \& Jukes, 1964a; Kuypers, 1958; Kuypers et al., 1961; Kuypers \& Tuerk, 1964). Cortical areas 1 and 2 also project primarily onto rostral DCN, but also to the Cu shell, and sparsely to the cluster regions (Bentivoglio \& Rustioni, 1986; Cheema et al., 1985). Like ascending afferents, cortical-Cu inputs are somatotopically organised, such that neurons representing a body region in the cortex project to neurons representing the same body region in the $\mathrm{Cu}$ (Cheema et al., 1985; Cheema et al., 1983).

The $\mathrm{ECu}, \mathrm{X}$, and $\mathrm{Z}$ also receive cortical inputs, which have a mix of excitatory and inhibitory effects (Cheema et al., 1983; Cooke, Larson, Oscaesson, \& Sjölund, 1971). However, the inputs were broadly described to originate in the sensorimotor cortex, so it is not clear which cortical areas project to each of these nuclei.

Cortical inputs to the DCN-complex are primarily excitatory, mediated by glutamate, but can also have inhibitory effects via DCN-complex inhibitory interneurons (Aguilar, Rivadulla, Soto, \& Canedo, 2003). When DCN cell groups are activated by peripheral tactile stimuli, the group of cells with overlapping RFs are also excited by corticofugal inputs to amplify the signal in cats (Aguilar et al., 2003; Canedo, 1997; Canedo \& Aguilar, 2000; Palmeri, Bellomo, Giuffrida, \& Sapienza, 1999) and rats (Malmierca \& Nuñez, 1998, 2004). Surrounding cells with non-overlapping RFs are simultaneously inhibited, 
potentially reducing the RF size of the sensory input. Similarly, DCN neurons transmitting proprioceptive information to the thalamus are modulated by input from cortical motor area 4 and proprioceptive area $3 a$ in addition to modulation from intrinsic neurons in the ventral DCN (Leiras, Velo, Martín-Cora, \& Canedo, 2010). DCN neural activity is only enhanced by other DCN or motor cortical inputs if they process information from the same joint, whereas DCN neurons receiving inputs from other joints are inhibited by DCN interneurons (Leiras et al., 2010). However, there is still little known about the anatomy and function of this system, which has mostly been investigated in cats and rats. This system has interesting implications for sensorimotor functions like reaching and grasping movements, and tactile exploration, and would benefit from future investigations in primates.

During sleep, cortical inputs to the DCN appear to induce low-frequency rhythmic firing in DCN neurons that match thalamo-cortical-thalamic network oscillations, in cats (Mariño, Aguilar, \& Canedo, 1999; Mariño, Canedo, \& Aguilar, 1999; Steriade \& Llinás, 1988), but it is unclear if this is also the case in rats or monkeys. Taken together, it appears that cortical inputs to the DCN play a role in amplifying relevant somatosensory stimuli and inhibiting non-relevant stimuli during movement or tactile exploration in an awake state, in addition to gating information from the external environment to facilitate sleep.

\section{System 2: The cerebellar system}

Berkley et al. (1986) named a second DCN system the cerebellar system. This system includes a diverse array of projection targets and interconnected regions including the tectum, pretectum, inferior olive (IO), pontine nuclei $(\mathrm{Pn})$, red nucleus $(\mathrm{RN})$ and zona incerta $(\mathrm{ZI})$, in addition to direct connections to the cerebellum. Generally, the DCN-complex neurons involved in the cerebellar system are varied in morphology and primarily found in the $\mathrm{ECu}, \mathrm{DCN}$ areas outside the clusters regions, and $\mathrm{X}$, and only sparsely, if at all in the cluster regions.

\section{Cerebellum}

The cerebellar cortex receives climbing fibre inputs from the IO (Desclin, 1974) and mossy fibre inputs 
from the spinal cord (Ji \& Hawkes, 1994; M. Matsushita, 1999; Matsuo Matsushita \& Yaginuma, 1989), DCN-complex (Gerrits, Voogd, \& Nas, 1985; Quy et al., 2011), Pn (Serapide, Pantó, Parenti, Zappalá, \& Cicirata, 2001), and the lateral reticular nuclei (Chan-Palay, Palay, Brown, \& Van Itallie, 1977; Wu, Sugihara, \& Shinoda, 1999). In the posterior folia, mossy fibre inputs terminate in the granular layer in what has been described as 'patches' that make up a 'fractured' somatotopic map (Shambes, Gibson, \& Welker, 1978). These patches vary in size and shape and representations of different body parts are repeated within and across multiple folia. For a review of cerebellar cortical organisation, see Apps and Hawkes (2009).

The most direct route by which the cerebellum receives information from peripheral afferents is via mossy fibres from the ECu (for the upper limb) (Figure 5) and lamina 6 and 7 of the spinal cord (lower limb) via the DSCT and ventral spinocerebellar tract (VSCT) (Kitamura \& Yamada, 1989). Both these ascending spinocerebellar tracts carry proprioceptive fibres that travel via the inferior (DSCT) or superior (VSCT) cerebellar peduncle to terminate in the ipsilateral cerebellum (Matsuo Matsushita \& Yaginuma, 1989; Yamada, Shirao, Kitamura, \& Sato, 1991). Although the DSCT send some collaterals from hindlimb afferents to $X$ and $Z$, both the DSCT and VSCT predominantly bypass the DCN-complex altogether, so will not be covered in the remainder of this section. The cerebellum also receives a smaller population of mossy fibre inputs from other DCN-complex regions receiving information from the upper ( $\mathrm{C}$ and $\mathrm{X}$ ) and lower body ( $\mathrm{Gr}, \mathrm{X}$ and $\mathrm{Z})$.

\section{External cuneate nuclei}

The ECu-cerebellar pathway is the dominant group of projections from the DCN-complex to the cerebellum. Cerebellar projecting cells in the ECu are relatively large and homogenous and convey forelimb proprioceptive information to the somatosensory cerebellum via mossy fibres input (Figure 5) (Quy et al., 2011).

Caudal ECu neurons that respond to hand and arm movement project to the caudal aspect of lobule 5 and the rostral paramedian lobule, whereas rostral ECu neurons, which have a higher proportion of 
neurons responding to neck and should movement, project to rostral lobule 5 and the caudal paramedian lobule (Quy et al., 2011; Rinvik \& Walberg, 1975). ECu projections have also been reported to other lobules 4, 6, and 9 (Somana \& Walberg, 1980). Besides the abundance of ipsilateral projections, a smaller number of ventral and lateral ECu cells - regions that typically respond to movement of axial body regions (Campbell et al., 1974) - project to the contralateral anterior lobe vermis, likely through the restiform body, and crossing the midline in the cerebellar white matter (Gerrits et al., 1985; Haring \& Rowinski, 1982). These contralateral projections to the axial body representation in the vermis correspond to the projections from ECu neurons that respond to axial muscles just to either side of the midline.

\section{Cuneate nuclei}

The cerebellum is also the target of ipsilateral Cu projections (Figure 5) (Cerminara, Makarabhirom, \& Rawson, 2003; Cooke, Larson, Oscaesson, et al., 1971; Cooke, Larson, Oscarsson, \& Sjölund, 1971; Quy et al., 2011). Cu-cerebellar neurons are found almost exclusively in CuR, with some in the CuM shell (Haring \& Rowinski, 1982), and are typically much smaller than thalamic projecting Cu neurons (Cheek, Rustioni, \& Trevino, 1975; Mantle-St. John \& Tracey, 1987; Rinvik \& Walberg, 1975; Somana \& Walberg, 1980). These neurons have large RFs and receive inputs from muscle, joint, and cutaneous afferents (Cerminara et al., 2003; Cooke, Larson, Oscaesson, et al., 1971; Cooke, Larson, Oscarsson, et al., 1971; Leiras et al., 2010).

In the cat, the DCN-complex inputs are segregated in the cerebellum by their modalities, such that cutaneous and proprioceptive fibres project to superficial and deeper portions of the folia, respectively (Cerminara et al., 2003; Cooke, Larson, Oscarsson, et al., 1971; Ekerot \& Larson, 1972; Rinvik \& Walberg, 1975). However, proprioceptive and cutaneous inputs from Cu and ECu were found to be overlapping in the cerebellum of raccoons, suggesting that these animals do not have the same discrete modality segregation within folia (Haring \& Rowinski, 1982). It is unclear whether modality segregation in the cerebellar folia is a feature of other mammals. 
The CuR-cerebellar neurons send axons that pass by the ECu and through the restiform body, and mostly terminate in the ipsilateral lobule 4, 5, 6, 8A, and the paramedian lobule, which corresponds to the cerebellar regions that are also the target of ECu terminals (Cheek et al., 1975; Cooke, Larson, Oscarsson, et al., 1971; Gordon \& Horrobin, 1967; Rinvik \& Walberg, 1975; Somana \& Walberg, 1980). Based on electrophysiological responses, Cooke, Larson, Oscarsson, et al. (1971) noted that CuRcerebellar neurons appear to bifurcate and project to both forelimb cerebellar body schemas in lobule 5 and the paramedian cerebellar lobes, which is corroborated by some weak anatomical evidence (Cheek et al., 1975; Haring \& Rowinski, 1982). However, a double-labelling study is needed to confirm these results, and it is unclear what their function might be. Like the $\mathrm{ECu}$, the $\mathrm{Cu}$ send some contralateral projections to the anterior lobe of the cerebellum, which travel via the ipsilateral restiform body and cross the midline through the cerebellar white matter (Cheek et al., 1975; Haring \& Rowinski, 1982).

\section{Gracile nuclei}

Compared to the ECu and Cu, the Gr have few projections to the cerebellum (Quy et al., 2011; Somana \& Walberg, 1980). The paucity of Gr-cerebellar connections is likely because most cells from the lower body, conveying information to the cerebellum, travel via second order DSCT or VSCT neurons originating in the nucleus dorsalis and dorsal horn lamina 7, respectively (Ito, 1984; Quy et al., 2011). The Gr-cerebellar projections are ipsilateral and, like the $\mathrm{Cu}$, originate predominantly from $\mathrm{GrR}$, with some cells projecting from the shell and ventral aspects of GrM (Figure 5) (Cheek et al., 1975; Quy et al., 2011; Rinvik \& Walberg, 1975; Somana \& Walberg, 1980). These cells project to the vermal and paravermal parts of anterior lobules 1, 2, 4 and 5 (Cheek et al., 1975; Gordon \& Horrobin, 1967; Rinvik \& Walberg, 1975).

\section{DCN-complex dual cerebellar-thalamic projections}

Authors of some early electrophysiology and degeneration studies tentatively suggested that there might be DCN-complex neurons that send dual projections to both the thalamus and cerebellum (Gordon \& Seed, 1961; J. I. Johnson et al., 1968). However, this was refuted by several 
electrophysiological studies that were unable to activate DCN-complex neurons from both thalamic and cerebellar stimulation (Cooke, Larson, Oscaesson, et al., 1971; Cooke, Larson, Oscarsson, et al., 1971; Gordon \& Horrobin, 1967; Haring, Rowinski, \& Pubols, 1984). A comprehensive double-labelling study in rats subsequently confirmed that DCN-complex neurons project either exclusively to thalamus or cerebellum, but not both (Mantle-St. John \& Tracey, 1987). This suggests that the somatosensory information requirements for processing in thalamic and cerebellar systems are different.

\section{Inferior olive}

The IO provides an error signal that the cerebellum can use to reduce mismatches between sensory input matching the body's current status, and a target movement. They can be separated into the medial (IOM), principal (IOPr), and the dorsal (IOD) inferior olivary nuclei. The rostral portion of the IOD (IODR) receives inputs from the DCN and sends projections to the intermediate anterior lobe and paramedian lobule of the cerebellum (Armstrong, Harvey, \& Schild, 1974; Bloedel \& Courville, 2011; A. Brodal, Walberg, \& Hoddevik, 1975; Groenewegen, Boesten, \& Voogd, 1975; Molinari, 1984).

The IODR receives projections from two distinct populations within the $\mathrm{Cu}$ : one from CuR and another from CuC (Figure 5) (McCurdy, Gibson, \& Houk, 1992; McCurdy, Houk, \& Gibson, 1998). These cells tend to form clusters, but are not part of the DCN clusters zone (Molinari, Schultze, \& Strominger, 1996). The CuC population forms a contiguous nucleus with cells in lamina 6 of the dorsal horn of C1 and $\mathrm{C} 2$ to form a spinal-CuC column. Cells in the spinal-CuC column send the densest input to IO, projecting contralaterally to the IODR via internal arcuate fibres (Ebbesson, 1968; McCurdy et al., 1998; Molinari et al., 1996). The DCN-IO input regions are somatotopically organised such that the medial border of the IODR has cutaneous RFs from the distal forelimb and receives most of its input via the caudal part of the spinal-CuC input column (Berkley \& Hand, 1978b; Molinari et al., 1996). The densest input to the trunk and shoulder region of IODR comes from the rostral portion of the spinalCuC column (McCurdy et al., 1998). The transitional forelimb region of IODR, inclusive of the paw/hand, wrist and upper forelimb, receives roughly equal input from the whole spinal-CuC column. 
Interestingly, IODR projecting cells in CuR appear to be quite different to those of the spinal-CuC column. The CuR group projects bilaterally to the IODR forelimb and trunk regions (Alonso, Blanco, Paino, \& Rubia, 1986; Gerrits et al., 1985; McCurdy et al., 1998). However, IODR neurons are only activated by contralateral stimuli, so given that the CuR population project bilaterally to IODR it seems unlikely that they provide the main excitatory drive to IODR, but serve some other role (McCurdy et al., 1998).

The DCN also send projections to the caudal half of the contralateral IOM and caudal IOD. Both regions project to the cerebellar vermis (Azizi \& Woodward, 1987; P. Brodal \& Brodal, 1981). These neurons are found in the DCN shell regions and rostral and caudal DCN, and their projection patterns appear to be more variable than those to the IODR (Berkley \& Hand, 1978b; Boesten \& Voogd, 1975; Gerrits et al., 1985; McCurdy et al., 1998; Molinari, 1984).

\section{Reticular formation}

The brainstem reticular formation (Rt) extends from the spino-medullary junction to the caudal border of the thalamus, ventral to the SC. In the medulla, the Rt lies ventral to the DCN-complex. The Rt comprises an array of nuclei (of which we exclude the reticulotegmental and lateral reticular nuclei, see Watson (2012)) with vast connections throughout the central nervous system and is involved in various functions including a significant role in motor function (Matyas et al., 2010; Takakusaki, Chiba, Nozu, \& Okumura, 2016). Several nuclei within the Rt, including the nuclei reticularis dorsalis, ventralis, parvicellularis, and gigantocellularis, project mostly contralaterally to the DCN (Figure 6), particularly the rostral portion, in cats (Sotgiu \& Margnelli, 1976; Sotgiu \& Marini, 1977) and rats (Odutola, 1977; Weinberg \& Rustioni, 1989), but has not been confirmed in other mammals. Rt activation can presynaptically inhibit somatosensory signal transmission through the DCN (Cesa-Bianchi \& Sotgiu, 1969), but the specific nuclei that facilitate this effect are unknown. Interestingly, DCN neural populations oscillate with slow rhythms during sleep that match thalamocortical-thalamic network oscillations (Mariño, Canedo, et al., 1999; Steriade \& Llinás, 1988). The Rt has been suggested as a possible pathway by which some DCN oscillations are generated (Mariño, 
Canedo, et al., 1999), as the Rt is also thought to be involved in sleep-wake transitions and receives inputs from the cortex (Lamas, Martinez, \& Canedo, 1994). However, hindbrain sleep and arousal functions likely involve the locus coeruleus and serotonergic raphe nuclei, which are not considered part of the Rt (Watson, 2012).

Electrophysiological evidence suggests that some ventral DCN neurons responding to proprioceptive stimuli also project to the ipsilateral nucleus reticularis gigantocellularis via ML collaterals (Leiras et al., 2010), which is supported by anatomical studies that showed sparse projections from the rostral DCN to the nucleus reticularis gigantocellularis in opossums, rats, mice, and guinea pigs (Hazlett, Dom, \& Martin, 1972; Valverde, 1966). Leiras et al. (2010) suggest that this reciprocal DCN-Rt connection may be involved in modulating limb motor patterns.

\section{Pontine nuclei}

The $\mathrm{Pn}$ are precerebellar nuclei situated in the ventral pons. They receive inputs from the motor and somatosensory cortex, in addition to ascending somatosensory information, which facilitates modification of motor commands. DCN neurons project to the Pn, predominantly contralaterally, but with some ipsilateral connections (Figure 5) (Aas, 1989; Jane \& Schroeder, 1971; Kosinski, Azizi, Border, \& Mihailoff, 1986; Kosinski, Lee, \& Mihailoff, 1988; Schroeder \& Jane, 1971; Swenson, Kosinski, \& Castro, 1984). DCN-Pn projections mostly originate from the large round cells of the cluster regions in middle and caudal DCN (Kosinski, Azizi, \& Mihailoff, 1988). These are the same neurons that project onto VPL in thalamus via the ML, and DCN-Pn projections are almost entirely collaterals of these ML projections (Kosinski, Lee, et al., 1988).

DCN-Pn projections terminate somatotopically, such that neurons in the Gr project to ventral regions and Cu projections terminate rostral and dorsal relative to the Gr terminations (Swenson et al., 1984). Interestingly, the somatosensory and motor cortices send projections to the pontine grey in a somatotopic pattern, which partially overlaps with the DCN input terminals (Kosinski, Azizi, et al., 1988; Kosinski, Neafsey, \& Castro, 1986). Many pontine neurons show convergent inputs from both the DCN and cortex: neurons activated by peripheral tactile stimuli appear to mostly receive input 
from the corresponding somatosensory cortex region, while neurons activated by proprioceptive stimuli preferentially receive input from corresponding motor cortex regions (Kosinski, Azizi, et al., 1988; Rüegg, Séguin, \& Wiesendanger, 1977; Rüegg \& Wiesendanger, 1975). The convergent inputs onto $\mathrm{Pn}$ neurons are spatially differentiated, as DCN-Pn afferents synapse on proximal and intermediate dendrites, while corticopontine axons terminate more distally (Kosinski, Azizi, et al., 1986; Kosinski, Azizi, et al., 1988; Mihailoff, Watt, \& Burne, 1981).

Regions of the Pn receiving Gr input overlap with groups of pontocerebellar projections to vermal lobule 8, and Cu regions overlap with pontocerebellar projections to the paramedian lobule (Mihailoff, Burne, Azizi, Norell, \& Woodward, 1981; Swenson et al., 1984). DCN neurons appear to project onto pontocerebellar neurons that predominantly project contralaterally (although there are some ipsilateral projecting cells), resulting in an ipsilateral DCN-Pn-cerebellar pathway. The function of this pathway is yet to be understood, but it is significant that the $\mathrm{Pn}$ is a non-thalamic target that receives a reasonable amount of input from the DCN clusters region, which appears to be transmitted to the cerebellum.

\section{Red nucleus}

The red nucleus (RN) receives motor system inputs from the cortex and cerebellum and is involved in motor control and potentially motor learning. The DCN project roughly somatotopically onto the contralateral magnocellular region of the red nucleus (RNMg) (Figure 5) (Robinson, Houk, \& Gibson, 1987). Gr cells project to the ventral lateral RNMg, while Cu cells project to the dorsal medial RNMg (Berkley \& Hand, 1978a). The densest DCN-RNMg projections arise from the ventral caudal DCN (Robinson et al., 1987).

The DCN-complex also receives a small amount of reciprocal input from the contralateral RN (Figure 6), which appear to come from large cells in the RNMg, which give rise to the rubrospinal tract (Berkley et al., 1986; Edwards, 1972; McCurdy et al., 1992; McCurdy et al., 1998; Robinson et al., 1987). Evidence from the cat suggest that fibres from the RN pass around the lateral edge of the ECu and then move medially to predominantly terminate in CuR and CuC, with sparse terminals in amongst the 
clusters of CuM (Edwards, 1972; McCurdy et al., 1992). The RN-CuR connections terminate in a semicircular shell around the ventral, medial and dorsal borders of CuR (McCurdy et al., 1992). Most connections from the RN are focused in ventral CuR and $\mathrm{CuC}$, which coincide with terminals from the sensorimotor cortex and with cell bodies that project to the contralateral IODR (McCurdy et al., 1992). Regions of RNMg that receive inputs from, and project to, the DCN are the same.

The ECu, X, and $\mathrm{Z}$ also receive a small number of inputs from the contralateral RN (Edwards, 1972) (Figure 6). Edwards (1972) showed RN-ECu inputs that terminated exclusively in the dorsomedial tip of ECu. Although they suggest this region was part of the ECu, it was described to be often separated from the rest of the ECu by fibre septa, receive afferents from both the hind and forelimb, and degenerate after hemi-decerebellation, suggesting that it could be part of $X$.

The functional significance of the RN-DCN system has not been confirmed, but it has been shown that activation of RNMg neurons leads to a suppression of IODR climbing fibres (Weiss, Houk, \& Gibson, 1990). However, the main output of RNMg is excitatory. Recently, Geborek, Jörntell, and Bengtsson (2013) have shown that electrical stimulation in the Cu results in significant suppression of climbing fibre field potentials, which could be mediated by GABAergic cells in CuR that are known to project to IODR (Isomura \& Hámori, 1988). Therefore, it seems likely that contralateral IODR receives excitatory input from spinal-CuC and bilateral IODR receive inhibitory input from CuR cells, which likely facilitates movement-related climbing fibre suppression (Geborek et al., 2013).

\section{Tectum}

The tectum refers to the roof of the mid brain, which includes, but is not exclusive to, the superior colliculus (SC), inferior colliculus (IC) and the ICo. All three regions receive projections from neurons in the mixed cell populations of the rostral, shell, and ventral DCN regions (Figure 7) (Berkley, Blomqvist, Pelt, \& Flink, 1980; Blomqvist, Flink, Bowsher, Griph, \& Westman, 1978; Bull \& Berkley, 1984). 


\section{Superior colliculus}

The SC is a midbrain structure involved in a multitude of functions including attention, decision making, planning, and orienting an organism toward stimuli of interest (Basso \& May, 2017; Crapse, Lau, \& Basso, 2018; Gandhi \& Katnani, 2011; Krauzlis, Lovejoy, \& Zénon, 2013). Most of these functions require or are dominated by visual inputs in most vertebrates. The SC has a laminar structure with the visual portion in superficial layers whereas deeper layers, namely the stratum griseum intermediate and stratum griseum profundum, are considered the motor layers of the SC, but they also receive somatosensory and auditory inputs (May, 2006). SC neurons are arranged in a topographic map of the visual field, with the superficial layer showing a map of stimulus position and the deeper layers representing a motor map for movement orientation.

DCN-SC terminals are somatotopically arranged, such that the caudal lateral deep layers receive $\mathrm{Cu}$ inputs, and the caudal medial deep portion receives Gr projection terminals (Edwards, Ginsburgh, Henkel, \& Stein, 1979; Wiberg \& Blomqvist, 1984a; Wiberg et al., 1987). However, it has been suggested that this somatotopy conforms to the dominant visuomotor topography, which may change according to motor errors indicated by the position of the eyes relative to a target (Chalupa \& Rhoades, 1977; Drager \& Hubel, 1975; Groh \& Sparks, 1996; Krauzlis, Basso, \& Wurtz, 2000).

These projections travel via the lemniscal adjunct channel (LAC) which is an auxillary ML pathway that exits the ML to reach non-thalamic brainstem and midbrain targets. The DCN-SC fibres of the LAC are almost entirely contralateral (Figure 7), but there are some ipsilateral DCN-SC projections (Massopust et al., 1985; May, 2006). SC inputs originate from the rostral, caudal, shell, and ventral DCN regions (Berkley et al., 1980; Berkley et al., 1986; Blomqvist et al., 1978; Bull \& Berkley, 1984; Cooper \& Dostrovsky, 1985; Wiberg \& Blomqvist, 1984a). Very few SC-projecting neurons are found in the DCN clusters. Rostral, caudal, and shell DCN regions are the target of primary and secondary afferents (Nijensohn \& Kerr, 1975; Rustioni, 1973; Rustioni et al., 1979; Rustioni \& Kaufman, 1977), conveying information from muscles, joints, Pacinian afferents, and proximal cutaneous regions with large RFs, and may also receive information from noxious stimuli (Angaut-Petit, 1975b; Gordon \& Jukes, 1964b; 
Hummelsheim \& Wiesendanger, 1985; Hummelsheim et al., 1985; Nyberg \& Blomqvist, 1984; Rosén, 1969). This is consistent with the idea that the DCN sends multimodal somatosensory information to the SC for directing attention and triggering motor responses to salient stimuli (Blomqvist et al., 1978; Nagata \& Kruger, 1979).

\section{Inferior colliculus}

The IC is best known for its auditory response properties, particularly in processing interaural time and intensity asymmetries (Aitkin, Dickhaus, Schult, \& Zimmermann, 1978; Aitkin, Webster, Veale, \& Crosby, 1975; Tawil, Saadé, Bitar, \& Jabbur, 1983). Like the SC, the IC receives projections conveying multimodal somatosensory input from the rostral, caudal, and shell regions of the DCN in rats and cats (Figure 7) (Aitkin et al., 1978; Aitkin, Kenyon, \& Philpott, 1981; Tawil et al., 1983; Wiberg et al., 1987). These inputs project bilaterally, with an ipsilateral dominance, and simultaneously project to the cochlear nuclei via collaterals (Itoh et al., 1987; H. Li \& Mizuno, 1997; Weinberg \& Rustioni, 1987). The IC is organised tonotopically and has three distinct regions known as the central IC, surrounded by the pericentral IC or dorsal cortex of the IC, and the external IC. The DCN project via the ML LAC onto the contralateral dorsal and external IC, but minimally to the central IC (Cooper \& Dostrovsky, 1985; Wiberg et al., 1987). It is unclear whether the projections are somatotopic, but given that projections to the SC and ICo (see below) are somatotopic, it seems likely that DCN-IC projections would be similar. The central IC receives ascending brainstem auditory inputs (Cant \& Benson, 2006), whereas the dorsal and external IC receive both ascending and descending inputs (Winer \& Schreiner, 2005), in addition to somatosensory information (Aitkin et al., 1978; Aitkin et al., 1981; Tawil et al., 1983; Wiberg et al., 1987). The function of the overlapping auditory and somatosensory inputs is still unclear, but inputs from the spinal trigeminal nucleus can modulate dorsal and external IC neurons to suppress or enhance sound-evoked IC responses, which has been suggested to play a role in cancelling selfgenerated sounds, and enhancing external vocalisations (Jain \& Shore, 2006; Tammer, Ehrenreich, \& Jürgens, 2004; Zhou \& Shore, 2006). Thus, DCN-IC inputs may play a similar role. 


\section{Intercollicular region}

The ICo is a distinct region between the IC and SC, that receives somatosensory inputs from the spinal cord and the DCN (Blomqvist, Danielsson, \& Norrsell, 1990; Danielsson \& Norrsell, 1985; Danielsson \& Norssell, 1986; Flink, Wiberg, \& Blomqvist, 1983; E. Puelles, Martínez-de-la-Torre, Watson, \& Puelles, 2012; Robards et al., 1976; Wiberg \& Blomqvist, 1984a, 1984b; Wiberg et al., 1987). Like the SC and IC, the ICo receives inputs from rostral, caudal, and, shell DCN regions, but the ICo receives densest DCN input of the three tectal regions (Figure 7) (Berkley \& Hand, 1978a; Björkeland \& Boivie, 1984; Boivie, 1978; Cooper \& Dostrovsky, 1985; Schroeder \& Jane, 1976; Wiberg \& Blomqvist, 1984a; Wiberg et al., 1987). The DCN projections terminate somatotopically such that Gr projections terminate in the caudal ICo region and the Cu more rostrally (Danielsson \& Norrsell, 1985; Danielsson \& Norssell, 1986; Flink et al., 1983; Wiberg \& Blomqvist, 1984a, 1984b; Wiberg, Westman, \& Blomqvist, 1986; Wiberg et al., 1987).

The functional role of DCN-ICo connections is unclear, but the ICo receives information from afferents with small cutaneous RFs on distal body regions in monkeys (Wiberg et al., 1987). The main projection field of ICo neurons appears to be in the Po of the thalamus (see Cortical Subsystem 3: Posterior group of the thalamus), which primarily projects to $\mathrm{S} 2$ and is reciprocally connected to the cortical PV.

\section{Pretectum}

The pretectum is a caudal region of the diencephalon perhaps best known for its role in relaying visual inputs from the retina and optic tectum to other brain centres mediating functions like the pupillary light reflex (May, Sun, Wright, \& Erichsen, 2020; L. Puelles, Martinez-de-la-Torre, Ferran, \& Watson, 2012; Sun \& May, 2014; Yáñez, Suárez, Quelle, Folgueira, \& Anadón, 2018). The pretectal area consists of several nuclei, of which two receive input from the DCN: the posterior pretectal nucleus, and the pars compacta of the anterior pretectal nucleus (Berkley \& Hand, 1978a; Berkley \& Mash, 1978; Björkeland \& Boivie, 1984; Wiberg \& Blomqvist, 1984b; Wiberg et al., 1987). Similar to DCN-tectal neurons, DCN-pretectal neurons are located in rostral, shell, and ventral DCN regions (Figure 7), although the pretectal- and tectal-projections appear to derive from different neurons within these 
regions (Berkley et al., 1980; Blomqvist et al., 1978; Bull \& Berkley, 1984). Terminations in the pretectal area appear to be somatotopic: Gr-pretectal projections terminate preferentially in the anterior nucleus and Cu projections terminate in the posterior nucleus (Wiberg \& Blomqvist, 1984a).

Pretectum efferents project to a variety of targets, of which many are discussed in this review as targets of direct $\mathrm{DCN}$ projections, including the $\mathrm{Pn}, \mathrm{RN}, \mathrm{IO}$, zona incerta, and non-VPL thalamic regions (Abols \& Basbaum, 1979; Benevento, Rezak, \& Santos-Anderson, 1977; Berman, 1977; Walberg, Nordby, Hoffmann, \& Holländer, 1981; Weber \& Harting, 1980). Interestingly the anterior pretectal nucleus, which receives inputs from the Gr does not receive inputs from visual centres, but is involved in pain modulation and has strong connections with thalamic Po and zona incerta among other painrelated regions (Murray, Masri, \& Keller, 2010; Rees \& Roberts, 1993; Villarreal, Del Bel, \& Prado, 2003; Villarreal \& Prado, 2007). The DCN-pretectal connection has been suggested to be involved in multisensory integration, but a functional role is yet to be elucidated (Berkley et al., 1986).

\section{Zona Incerta}

The zona incerta (ZI) is an elongated prethalamic structure in the diencephalon consisting of heterogenous groups of cells, separated into sectors with distinct cytoarchitecture, chemoarchitecture, and connections (Mitrofanis, 2005; L. Puelles et al., 2012). Various types of neurons in rostral DCN project via the ML and terminate in ventral ZI (Figure 7) in rats, cats, and monkeys (Aumann, Rawson, Pichitpornchai, \& Horne, 1996; Berkley et al., 1986; Berkley \& Hand, 1978a; Boivie, 1971; Hand \& Van Winkle, 1977; Lund \& Webster, 1967; Roger \& Cadusseau, 1985; Shammah-Lagnado, Negrão, \& Ricardo, 1985). Projections from the $\mathrm{Cu}$ are more numerous and terminate more medially, whereas Gr projections terminate more laterally (Boivie, 1971; Villanueva et al., 1998).

Ventral ZI neurons, coinciding with DCN input locations, have large RFs and many respond to noxious stimulation of cutaneous, muscle, and joint receptors, but whether DCN inputs are the source of these response characteristics remains unknown (Kaelber \& Smith, 1979; Nicolelis, Chapin, \& Lin, 1992). Neurons in ZI have a variety of efferent projection targets throughout the neuraxis, of which the SC 
seems dominant (May \& Basso, 2018; Mitrofanis, 2005; Nicolelis et al., 1992; Ricardo, 1981; Romanowski, Mitchell, \& Crossman, 1985). The ZI has been associated with diverse functions including appetite and visceral regulation, sleep, attention, locomotion and postural control, and pain regulation (Huang \& Mogenson, 1974; K. Liu et al., 2017; M. Liu et al., 2011; Moon \& Park, 2017; Périer, Tremblay, Féger, \& Hirsch, 2002; Roger \& Cadusseau, 1985; Supko, Uretsky, \& Wallace, 1991; Tait, Phillips, Blackwell, \& Brown, 2017; Zhang \& van den Pol, 2017; Z. D. Zhao et al., 2019). One could imagine a role for the $\mathrm{DCN}$ to provide somatosensory information for postural control as the rostral DCN has its main receptive fields proximal and axial body parts.

\section{System 3: Spinal cord system}

The third DCN projection subsystem proposed by Berkley et al. (1986) is the spinal cord system (Figure 7). Spinal cord inputs from the DCN originate from medium-sized neurons, with large stellate dendritic arbours, preferentially located in the ventral $\mathrm{Gr}$ and $\mathrm{Cu}$, and between the two nuclei, and a small population scattered throughout the clusters (Berkley et al., 1986; Bermejo et al., 2003; Burton \& Loewy, 1977; Enevoldson \& Gordon, 1984; Kuypers \& Maisky, 1975). The dendrites of cells outside the clusters region appear to be restricted from entering the cluster regions, whereas a small amount of spinal projecting cells are found inside the cluster region and have no restriction on their arborisation (Enevoldson \& Gordon, 1984).

Spinal-projecting axons from the DCN course through both the ipsilateral DC and the dLF to terminate in the ipsilateral dorsal horn laminae 1, 3, 4 and 5 (Berkley et al., 1986; Bromberg, Burnham, \& Towe, 1981; Burton \& Loewy, 1977; Enevoldson \& Gordon, 1984; Kwiat \& Basbaum, 1992; Leong, Shieh, \& Wong, 1984; Villanueva, Bernard, \& Le Bars, 1995). A small proportion of DCN-spinal projections are collaterals of axons projecting to the thalamus (Bermejo et al., 2003).

The function of the DCN-spinal projections is still unknown. However, DCN regions containing the most spinal-projecting neurons coincide with the predominant cortico-DCN input, which has led to suggestions that these neurons may be involved in a cortico-DCN-spinal modulation system for 
movement-related touch or proprioceptive information. Finally, the DCN-spinal target laminae, 4 and 5 , contain origin cells of the PSDC pathway, suggesting there may be a DCN-spinal-DCN system. Many neurons in the PSDC have response properties similar to DCN cells, but with more discrete RFs, but this pathway has also been postulated to play a role in pain modulation (de Pommery, Roudier, \& Menétrey, 1984; Giesler et al., 1984; Villanueva et al., 1995). However, the existence of a potential DCN-spinal-DCN connection and whether it plays a role in tactile or pain processing is yet to be elucidated.

\section{System 4: Brainstem system}

Periaqueductal grey

Surrounding the cerebral aqueduct in the tegmentum, the periaqueductal grey (PAG) receives afferents from the spinothalamic tract that transmit pain and temperature information. Interestingly, the DCN have also been shown to send contralateral projections via the ML LAC to the PAG (Figure 7) (Barbaresi \& Mensà, 2016; Björkeland \& Boivie, 1984; García Del Caño, Uria, Gerrikagoitia, \& MartínezMillán, 2004; Hazlett et al., 1972; Schroeder \& Jane, 1971; Villanueva et al., 1998; Wiberg et al., 1987), which terminate somatotopically such that the Gr project to the caudal lateral PAG and the Cu to rostral lateral PAG (Barbaresi \& Mensà, 2016).

The functional properties of these DCN-PAG neurons have not been characterised, nor has a role in pain processing been established for the DCN. However, some DCN neurons respond to, or are modulated by, noxious skin, muscle, joint, and visceral stimulation (Al-Chaer, Feng, \& Willis, 1998; AlChaer, Westlund, \& Willis, 1997; Cliffer, Hasegawa, \& Willis, 1992; Costa-García \& Nuñez, 2004; Ferrington, Downie, \& Willis, 1988; Kitagawa et al., 2005; Miki, Fukuoka, Tokunaga, \& Noguchi, 1997; Schwark \& Ilyinsky, 2001; Wang \& Westlund, 2001; F. Zhao et al., 2012). The PAG coordinates varied autonomic, behavioural, and analgesic responses to different situations such as experiencing deep visceral or somatic pain, or acute cutaneous injury, but physiological studies are needed to determine how the DCN interacts with this system. 


\section{Raphe nuclei}

The raphe nuclei are serotonergic cell groups along the midline and paramedian brainstem, which include the dorsal, median, paramedian, and pontine raphe nuclei in a rostral group, and the raphe obscuris, pallidus, and magnus, in a caudal group. The raphe interpositus lies in between the rostral and caudal groups and is not serotonergic. The raphe nuclei are involved in pain modulation, motor functions, mood regulation, and sleep functions (Hornung, 2003). The raphe nuclei send bilateral serotonergic projections to the DCN (Figure 6), but there are conflicting reports as to which regions receive the predominant input. In rats, Willcockson, Carlton, and Willis (1987) reported that most raphe-DCN projections terminated in the middle DCN (presumably outside the clusters), whereas in cats and owl monkeys most afferents were reported to terminate in all rostrocaudal regions but excluding the clusters regions (Blomqvist \& Broman, 1993). Whether this represents species differences in raphe-DCN connections or differences in methodology remains unknown.

Activation of the raphe nuclei can modulate spiking activity of DCN projection neurons mostly through inhibitory input, which occurs directly from inhibitory raphe projections, or indirectly by exciting DCN interneurons (Dostrovsky, 1980; Gerhart, Wilcox, Chung, \& Willis, 1981; Grasso, Li Volsi, \& Barresi, 2016; Jundi, Saadé, Banna, \& Jabbur, 1982). Raphe-DCN projections were suggested to presynaptically inhibit DCN afferents via axoaxonic contacts (Jundi et al., 1982), but Willcockson et al. (1987) showed that raphe projections terminate directly onto the dendrites and somas of DCN neurons, suggesting that raphe nuclei modulation of DCN activity acts postsynaptically.

The function of the raphe-DCN connection remains unknown. Blomqvist and Broman (1993) suggest that it may involve modulation of sensorimotor activity, as they found most of the raphe projections terminated in DCN regions involved in sensorimotor function, while others have suggested a role in pain modulation (Willcockson et al., 1987). 


\section{Summary of DCN organisation}

The organisation of the DCN-complex can by summarised by the neural populations' modality, somatotopy, and connectivity into three functional systems: discriminative touch, multi-modal, and proprioceptive (Figure 8). The clusters and shell of the middle DCN, and caudal DCN zones, excluding the ventral regions are dominated by tactile-related information processing and transmission, whereas the ventral $\mathrm{DCN}, \mathrm{ECu}$, and $\mathrm{X}$ and $\mathrm{Z}$ can be considered proprioceptive-dominated. The rostral DCN appears to process a relatively equal mixture of tactile and proprioception-related information. Within the tactile-dominated regions, the clusters region specifically processes and transmits spatially precise discriminative touch information from the distal limbs. The largest representation in the cluster regions is of glabrous skin, which is specialised for exploring the physical environment and provides high-quality sensory feedback necessary for dextrous motor tasks. The rostral, caudal, and shell regions process less spatially precise, multimodal information, contributing less to fine motor control, and receive a larger proportion of inputs from the proximal limbs and axial body regions.

The clusters region receives inputs from primary cutaneous afferents of the DCs, and cortical area $3 b$, and primarily projects onto the thalamic VPL, with some outputs to other targets, including the thalamic Po and the Pn. The multimodal rostral, shell, and caudal regions receive primary and secondary afferents from the DCs, and inputs from the RN and cortical areas $3 \mathrm{~b}, 1$, and 2 , and project to a variety of targets including the thalamic Po, tectum, pretectum, PAG, RN, Pn, ZI, and IO. Finally, the proprioceptive-dominated regions including ventral $\mathrm{DCN}, \mathrm{ECu}, \mathrm{X}, \mathrm{Z}$, and potentially rostral $\mathrm{DCN}$ receive inputs from the primary and secondary afferents of the DCs, the dLF, and also receive inputs from RN and sensorimotor cortex, particularly cortical areas 3a and 4. These neural populations primarily project to the cerebellum, the thalamic VPL shell, and the spinal cord dorsal horn.

These organising and connectivity of the DCN-complex demonstrates that it is more than a simple relay for tactile information, but rather should be considered an integration and distribution hub for tactile and proprioceptive information ascending the neuraxis to the cortex, in addition to a extensive variety of other targets throughout the midbrain and hindbrain. 


\section{References}

Aas, J. E. (1989). Subcortical projections to the pontine nuclei in the cat. Journal of Comparative Neurology, 282(3), 331-354. doi:https://doi.org/10.1002/cne.902820303

Abols, I. A., \& Basbaum, A. I. (1979). The posterior pretectal nucleus: Evidence for a direct projection to the inferior olive of the cat. Neuroscience Letters, 13(2), 111-116. doi:https://doi.org/10.1016/0304-3940(79)90026-0

Abrahams, V. C., \& Swett, J. E. (1986). The pattern of spinal and medullary projections from a cutaneous nerve and a muscle nerve of the forelimb of the cat: a study using the transganglionic transport of HRP. Journal of Comparative Neurology, 246(1), 70-84. doi:https://doi.org/10.1002/cne.902460105

Abraira, V. E., \& Ginty, D. D. (2013). The sensory neurons of touch. Neuron, 79(4), 618-639. doi:https://doi.org/10.1016/j.neuron.2013.07.051

Aguilar, J., Rivadulla, C., Soto, C., \& Canedo, A. (2003). New corticocuneate cellular mechanisms underlying the modulation of cutaneous ascending transmission in anesthetized cats. Journal of Neurophysiology, 89(6), 3328-3339. doi:https://doi.org/10.1152/jn.01085.2002

Aitkin, L. M., Dickhaus, H., Schult, W., \& Zimmermann, M. (1978). External nucleus of inferior colliculus: auditory and spinal somatosensory afferents and their interactions. Journal of Neurophysiology, 41(4), 837-847. doi:https://doi.org/10.1152/jn.1978.41.4.837

Aitkin, L. M., Kenyon, C. E., \& Philpott, P. (1981). The representation of the auditory and somatosensory systems in the external nucleus of the cat inferior colliculus. Journal of Comparative Neurology, 196(1), 25-40. doi:https://doi.org/10.1002/cne.901960104

Aitkin, L. M., Webster, W. R., Veale, J. L., \& Crosby, D. C. (1975). Inferior colliculus. I. Comparison of response properties of neurons in central, pericentral, and external nuclei of adult cat. Journal of Neurophysiology, 38(5), 1196-1207. doi:https://doi.org/10.1152/jn.1975.38.5.1196

Al-Chaer, E. D., Feng, Y., \& Willis, W. D. (1998). A role for the dorsal column in nociceptive visceral input into the thalamus of primates. Journal of Neurophysiology, 79(6), 3143-3150. doi:https://doi.org/10.1152/in.1998.79.6.3143

Al-Chaer, E. D., Westlund, K. N., \& Willis, W. D. (1997). Nucleus gracilis: An integrator for visceral and somatic information. Journal of Neurophysiology, 78(1), 521-527. doi:https://doi.org/10.1152/in.1997.78.1.521

Albright, B. C., \& Friedenbach, D. J. (1982). The distribution of lateral funicular and cortical fibers to the dorsal column, $Z$ and $X$ nuclei in the prosimian Galago. Neuroscience, 7(5), 1175-1185. doi:https://doi.org/10.1016/0306-4522(82)91124-1

Alonso, A., Blanco, M. J., Paino, C. L., \& Rubia, F. J. (1986). Distribution of neurons in the main cuneate nucleus projecting to the inferior olive in the cat. Evidence that they differ from those directly projecting to the cerebellum. Neuroscience, 18(3), 671-683. doi:https://doi.org/10.1016/0306-4522(86)90062-X

Angaut-Petit, D. (1975a). The dorsal column system: I. Existence of long ascending postsynaptic fibres in the cat's fasciculus gracilis. Experimental Brain Research, 22(5), 457-470. doi:https://doi.org/10.1007/BF00237348

Angaut-Petit, D. (1975b). The dorsal column system: II. Functional properties and bulbar relay of the postsynaptic fibres of the cat's fasciculus gracilis. Experimental Brain Research, 22(5), 471-493. doi:https://doi.org/10.1007/BF00237349

Apps, R., \& Hawkes, R. (2009). Cerebellar cortical organization: a one-map hypothesis. Nature Reviews Neuroscience, 10(9), 670-681. doi:https://doi.org/10.1038/nrn2698

Armstrong, D. M., Harvey, R. J., \& Schild, R. F. (1974). Topographical localization in the olivo-cerebellar projection: An electrophysiological study in the cat. Journal of Comparative Neurology, 154(3), 287-302. doi: https://doi.org/10.1002/cne.901540305 
Asif, M., \& Edgley, S. A. (1992). Projections of group Il-activated midlumbar spinocerebellar tract neurones to the region of nucleus $Z$ in the cat. The Journal of Physiology, 448(1), 565-578. doi: https://doi.org/10.1113/jphysiol.1992.sp019058

Aumann, T. D., Rawson, J. A., Pichitpornchai, C., \& Horne, M. K. (1996). Projections from the cerebellar interposed and dorsal column nuclei to the thalamus in the rat: A double anterograde labelling study. Journal of Comparative Neurology, 368(4), 608-619. doi: https://doi.org/10.1002/(sici)1096-9861(19960513)368:4<608::Aid-cne11>3.0.Co;2-d

Azizi, S. A., \& Woodward, D. J. (1987). Inferior olivary nuclear complex of the rat: morphology and comments on the principles of organization within the olivocerebellar system. Journal of Comparative Neurology, 263(4), 467-484. doi:https://doi.org/10.1002/cne.902630402

Bai, L., Lehnert, B. P., Liu, J., Neubarth, N. L., Dickendesher, T. L., Nwe, P. H., . . Ginty, D. D. (2015). Genetic identification of an expansive mechanoreceptor sensitive to skin stroking. Cell, 163(7), 1783-1795. doi:https://doi.org/10.1016/i.cell.2015.11.060

Bakker, D., Richmond, F., Abrahams, V., \& Courville, J. (1985). Patterns of primary afferent termination in the external cuneate nucleus from cervical axial muscles in the cat. Journal of Comparative Neurology, 241(4), 467-479. doi:https://doi.org/10.1002/cne.902410406

Barbaresi, P., \& Mensà, E. (2016). Connections from the rat dorsal column nuclei (DCN) to the periaqueductal gray matter (PAG). Neuroscience Research, 109, 35-47. doi:https://doi.org/10.1016/j.neures.2016.02.003

Basbaum, A. I., \& Hand, P. J. (1973). Projections of cervicothoracic dorsal roots to the cuneate nucleus of the rat, with observations on cellular "bricks". Journal of Comparative Neurology, 148(3), 347-359. doi:https://doi.org/10.1002/cne.901480304

Basso, M. A., \& May, P. J. (2017). Circuits for Action and Cognition: A View from the Superior Colliculus. Annual Review of Vision Science, 3(1), 197-226. doi:https://doi.org/10.1146/annurev-vision102016-061234

Bell, J., Bolanowski, S., \& Holmes, M. H. (1994). The structure and function of pacinian corpuscles: A review. Progress in Neurobiology, 42(1), 79-128. doi:https://doi.org/10.1016/0301$\underline{0082(94) 90022-1}$

Benevento, L. A., Rezak, M., \& Santos-Anderson, R. (1977). An autoradiographic study of the projections of the pretectum in the rhesus monkey (Macaca mulatta): evidence for sensorimotor links to the thalamus and oculomotor nuclei. Brain Research, 127(2), 197-218. doi:https://doi.org/10.1016/0006-8993(77)90536-4

Bengtsson, F., Brasselet, R., Johansson, R. S., Arleo, A., \& Jörntell, H. (2013). Integration of sensory quanta in cuneate nucleus neurons in vivo. Plos One, 8(2), e56630.

Bentivoglio, M., \& Rustioni, A. (1986). Corticospinal neurons with branching axons to the dorsal column nuclei in the monkey. Journal of Comparative Neurology, 253(2), 260-276. doi:https://doi.org/10.1002/cne.902530212

Berkley, K. J. (1980). Spatial relationships between the terminations of somatic sensory and motor pathways in the rostral brainstem of cats and monkeys. I. Ascending somatic sensory inputs to lateral diencephalon. Journal of Comparative Neurology, 193(1), 283-317. doi:https://doi.org/10.1002/cne.901930119

Berkley, K. J. (1983). Spatial relationships between the terminations of somatic sensory motor pathways in the rostral brainstem of cats and monkeys. II. Cerebellar projections compared with those of the ascending somatic sensory pathways in lateral diencephalon. Journal of Comparative Neurology, 220(2), 229-251. doi:https://doi.org/10.1002/cne.902200210

Berkley, K. J., Blomqvist, A., Pelt, A., \& Flink, R. (1980). Differences in the collateralization of neuronal projections from the dorsal column nuclei and lateral cervical nucleus to the thalamus and tectum in the cat: An anatomical study using two different double-labeling techniques. Brain Research, 202(2), 273-290. doi:https://doi.org/10.1016/0006-8993(80)90141-9 
Berkley, K. J., Budell, R. J., Blomqvist, A., \& Bull, M. (1986). Output systems of the dorsal column nuclei in the cat. Brain Research Reviews, 11(3), 199-225. doi:https://doi.org/10.1016/01650173(86)90012-3

Berkley, K. J., \& Hand, P. J. (1978a). Efferent projections of the gracile nucleus in the cat. Brain Research, 153(2), 263-283. doi:https://doi.org/10.1016/0006-8993(78)90406-7

Berkley, K. J., \& Hand, P. J. (1978b). Projections to the inferior olive of the cat II. Comparisons of input from the gracile, cuneate and the spinal trigeminal nuclel. Journal of Comparative Neurology, 180(2), 253-264. doi:https://doi.org/10.1002/cne.901800205

Berkley, K. J., \& Mash, D. C. (1978). Somatic sensory projections to the pretectum in the cat. Brain Research, 158(2), 445-449. doi:https://doi.org/10.1016/0006-8993(78)90687-X

Berman, N. (1977). Connections of the pretectum in the cat. Journal of Comparative Neurology, 174(2), 227-254. doi:https://doi.org/10.1002/cne.901740204

Bermejo, P. E., Jiménez, C. E., Torres, C. V., \& Avendaño, C. (2003). Quantitative stereological evaluation of the gracile and cuneate nuclei and their projection neurons in the rat. Journal of Comparative Neurology, 463(4), 419-433. doi:https://doi.org/10.1002/cne.10747

Biedenbach, M. A. (1972). Cell density and regional distribution of cell types in the cuneate nucleus of the rhesus monkey. Brain Research, 45(1), 1-14. doi:https://doi.org/10.1016/00068993(72)90212-0

Bischoff, E. (1899). Zur Anatomie der Hinterstrangkerne bei Säugethieren. Psychiatria et Neurologia, 18, 371-384.

Björkeland, M., \& Boivie, J. (1984). An anatomical study of the projections from the dorsal column nuclei to the midbrain in cat. Anatomy and Embryology, 170(1), 29-43. doi:https://doi.org/10.1007/bf00319455

Bloedel, J. R., \& Courville, J. (2011). Cerebellar Afferent Systems. Comprehensive Physiology, 735-829. doi: https://doi.org/10.1002/cphy.cp010216

Blomqvist, A. (1980). Gracilo-diencephalic relay cells: A quantitative study in the cat using retrograde transport of horseradish peroxidase. Journal of Comparative Neurology, 193(4), 1097-1125. doi:https://doi.org/10.1002/cne.901930419

Blomqvist, A., \& Broman, J. (1993). Serotoninergic innervation of the dorsal column nuclei and its relation to cytoarchitectonic subdivisions: An immunohistochemical study in cats and monkeys (Aotus trivirgatus). Journal of Comparative Neurology, 327(4), 584-596. doi:https://doi.org/10.1002/cne.903270409

Blomqvist, A., Danielsson, I., \& Norrsell, U. (1990). The somatosensory intercollicular nucleus of the cat's mesencephalon. The Journal of Physiology, 429(1), 191-203. doi:https://doi.org/10.1113/jphysiol.1990.sp018251

Blomqvist, A., Flink, R., Bowsher, D., Griph, S., \& Westman, J. (1978). Tectal and thalamic projections of dorsal column and lateral cervical nuclei: a quantitative study in the cat. Brain Research, 141(2), 335-341. doi:https://doi.org/10.1016/0006-8993(78)90202-0

Boesten, A. J. P., \& Voogd, J. (1975). Projections of the dorsal column nuclei and the spinal cord on the inferior olive in the cat. Journal of Comparative Neurology, 161(2), 215-237. doi:https://doi.org/10.1002/cne.901610206

Boivie, J. (1971). The termination in the thalamus and the zona incerta of fibres from the dorsal column nuclei (DCN) in the cat. An experimental study with silver impregnation methods. Brain Research, 28(3), 459-490. doi:https://doi.org/10.1016/0006-8993(71)90056-4

Boivie, J. (1978). Anatomical observations on the dorsal column nuclei, their thalamic projection and the cytoarchitecture of some somatosensory thalamic nuclei in the monkey. Journal of Comparative Neurology, 178(1), 17-47. doi:https://doi.org/10.1002/cne.901780103

Boivie, J., \& Boman, K. (1981). Termination of a separate (proprioceptive?) cuneothalamic tract from external cuneate nucleus in monkey. Brain Research, 224(2), 235-246. doi:https://doi.org/10.1016/0006-8993(81)90856-8 
Brinkhus, H. B., Carstens, E., \& Zimmermann, M. (1979). Encoding of graded noxious skin heating by neurons in posterior thalamus and adjacent areas in the cat. Neuroscience Letters, 15(1), 3742. doi:https://doi.org/10.1016/0304-3940(79)91526-X

Brodal, A., \& Pompeiano, O. (1957). The vestibular nuclei in the cat. Journal of Anatomy, 91(Pt 4), 438. Brodal, A., Walberg, F., \& Hoddevik, G. H. (1975). The olivocerebellar projection in the cat studied with the method of retrograde axonal transport of horseradish peroxidase. Journal of Comparative Neurology, 164(4), 449-469. doi:https://doi.org/10.1002/cne.901640405

Brodal, P., \& Brodal, A. (1981). The olivocerebellar projection in the monkey. Experimental studies with the method of retrograde tracing of horseradish peroxidase. Journal of Comparative Neurology, 201(3), 375-393. doi:https://doi.org/10.1002/cne.902010306

Bromberg, M. B., Burnham, J. A., \& Towe, A. L. (1981). Doubly projecting neurons of the dorsal column nuclei. Neuroscience Letters, 25(3), 215-220. doi:https://doi.org/10.1016/03043940(81)90394-3

Brown, A. G., \& Fyffe, R. E. (1981). Form and function of dorsal horn neurones with axons ascending the dorsal columns in cat. The Journal of Physiology, 321(1), 31-47. doi:https://doi.org/10.1113/jphysiol.1981.sp013970

Brown, A. G., \& Iggo, A. (1967). A quantitative study of cutaneous receptors and afferent fibres in the cat and rabbit. The Journal of Physiology, 193(3), 707. doi:https://doi.org/10.1113/jphysiol.1967.sp008390

Bull, M. S., \& Berkley, K. J. (1984). Differences in the neurons that project from the dorsal column nuclei to the diencephalon, pretectum, and tectum in the cat. Somatosensory Research, 1(3), 281-300. doi:https://doi.org/10.3109/07367228409144551

Burgess, P. R., Petit, D., \& Warren, R. M. (1968). Receptor types in cat hairy skin supplied by myelinated $\begin{array}{llll}\text { fibers. Journal of } & \text { 833-848. }\end{array}$ doi:https://doi.org/10.1152/jn.1968.31.6.833

Burton, H., \& Jones, E. G. (1976). The posterior thalamic region and its cortical projection in New World and Old World monkeys. Journal of Comparative Neurology, 168(2), 249-301. doi:https://doi.org/10.1002/cne.901680204

Burton, H., \& Loewy, A. D. (1977). Projections to the spinal cord from medullary somatosensory relay nuclei. Journal of Comparative Neurology, 173(4), 773-792. doi:https://doi.org/10.1002/cne.901730408

Campbell, S. K., Parker, T. D., \& Welker, W. (1974). Somatotopic organization of the external cuneate nucleus in albino rats. Brain Research, 77(1), 1-23. doi:https://doi.org/10.1016/00068993(74)90801-4

Canedo, A. (1997). Primary motor cortex influences on the descending and ascending systems. Progress in Neurobiology, 51(3), 287-335. doi:https://doi.org/10.1016/S0301-0082(96)00058$\underline{5}$

Canedo, A., \& Aguilar, J. (2000). Spatial and cortical influences exerted on cuneothalamic and thalamocortical neurons of the cat. European Journal of Neuroscience, 12(7), 2515-2533. doi:https://doi.org/10.1046/j.1460-9568.2000.00107.x

Cant, N. B., \& Benson, C. G. (2006). Organization of the inferior colliculus of the gerbil (Meriones unguiculatus): Differences in distribution of projections from the cochlear nuclei and the superior olivary complex. Journal of Comparative Neurology, 495(5), 511-528. doi:https://doi.org/10.1002/cne.20888

Cauna, N., \& Ross, L. L. (1960). The fine structure of Meissner's touch corpuscles of human fingers. The Journal of Cell Biology, 8(2), 467-482. doi:https://doi.org/10.1083/jcb.8.2.467

Cerminara, N. L., Makarabhirom, K., \& Rawson, J. A. (2003). Somatosensory properties of cuneocerebellar neurones in the main cuneate nucleus of the rat. The Cerebellum, 2(2), 131145. doi:https://doi.org/10.1080/14734220309406 
Cesa-Bianchi, M. G., \& Sotgiu, M. L. (1969). Control by brain stem reticular formation of sensory transmission in burdach nucleus analysis of single units. Brain Research, 13(1), 129-139. doi:https://doi.org/10.1016/0006-8993(69)90147-4

Chalupa, L. M., \& Rhoades, R. W. (1977). Responses of visual, somatosensory, and auditory neurones in the golden hamster's superior colliculus. The Journal of Physiology, 270(3), 595-626. doi:https://doi.org/10.1113/jphysiol.1977.sp011971

Chan-Palay, V., Palay, S. L., Brown, J. T., \& Van Itallie, C. (1977). Sagittal organization of olivocerebellar and reticulocerebellar projections: Autoradiographic studies with 35S-methionine. Experimental Brain Research, 30(4), 561-576. doi:https://doi.org/10.1007/BF00237645

Chang, H.-T., \& Ruch, T. C. (1947). Organization of the dorsal columns of the spinal cord and their nuclei in the spider monkey. Journal of Anatomy, 81(Pt 2), 140.

Cheek, M. D., Rustioni, A., \& Trevino, D. L. (1975). Dorsal column nuclei projections to the cerebellar cortex in cats as revealed by the use of the retrograde transport of horseradish peroxidase. Journal of Comparative Neurology, 164(1), 31-46. doi:https://doi.org/10.1002/cne.901640104

Cheema, S., Rustioni, A., \& Whitsel, B. L. (1985). Sensorimotor cortical projections to the primate cuneate nucleus. Journal of Comparative Neurology, 240(2), 196-211. doi:https://doi.org/10.1002/cne.902400209

Cheema, S., Whitsel, B. L., \& Rustioni, A. (1983). The corticocuneate pathway in the cat: relations among terminal distribution patterns, cytoarchitecture, and single neuron functional properties. Somatosensory Research, 1(2), 169-205. doi:https://doi.org/10.3109/07367228309144547

Cheney, P. D., \& Preston, J. B. (1976). Classification and response characteristics of muscle spindle afferents in the primate. Journal of Neurophysiology, 39(1), 1-8. doi:https://doi.org/10.1152/jn.1976.39.1.1

Clemo, H. R., \& Stein, B. E. (1983). Organization of a fourth somatosensory area of cortex in cat. Journal of Neurophysiology, 50(4), 910-925. doi:https://doi.org/10.1152/jn.1983.50.4.910

Cliffer, K. D., \& Giesler, G. J. (1989). Postsynaptic dorsal column pathway of the rat. III. Distribution of ascending afferent fibers. Journal of Neuroscience, 9(9), 3146-3168. doi:https://doi.org/10.1523/JNEUROSCl.09-09-03146.1989

Cliffer, K. D., Hasegawa, T., \& Willis, W. D. (1992). Responses of neurons in the gracile nucleus of cats to innocuous and noxious stimuli: basic characterization and antidromic activation from the thalamus. Journal of Neurophysiology, 68(3), 818-832. doi:https://doi.org/10.1152/in.1992.68.3.818

Cooke, J. D., Larson, B., Oscaesson, O., \& Sjölund, B. (1971). Organization of afferent connections to cuneocerebellar tract. Experimental Brain Research, 13(4), 359-377. doi:https://doi.org/10.1007/BF00234337

Cooke, J. D., Larson, B., Oscarsson, O., \& Sjölund, B. (1971). Origin and termination of cuneocerebellar tract. Experimental Brain Research, 13(4), 339-358. doi:https://doi.org/10.1007/BF00234336

Cooper, L. L., \& Dostrovsky, J. O. (1985). Projection from dorsal column nuclei to dorsal mesencephalon. Journal of Neurophysiology, 53(1), 183-200. doi:https://doi.org/10.1152/jn.1985.53.1.183

Costa-García, M., \& Nuñez, A. (2004). Nociceptive stimuli induce changes in somatosensory responses of rat dorsal column nuclei neurons. Brain Research, 1025(1), 169-176. doi:https://doi.org/10.1016/j.brainres.2004.07.082

Crapse, T. B., Lau, H., \& Basso, M. A. (2018). A role for the superior colliculus in decision criteria. Neuron, 97(1), 181-194.e186. doi:https://doi.org/10.1016/i.neuron.2017.12.006

Crockett, D. P., Maslany, S., \& Egger, M. D. (1996). Synaptophysin immunoreactivity and distributions of calcium-binding proteins highlight the functional organization of the rat's dorsal column nuclei. Brain Research, 707(1), 31-46. doi:https://doi.org/10.1016/0006-8993(95)01213-3 
Crockett, D. P., Maslany, S., Harris, S. L., \& Egger, M. D. (1993). Enhanced cytochrome-oxidase staining of the cuneate nucleus in the rat reveals a modifiable somatotopic map. Brain Research, 612(1-2), 41-55. doi:https://doi.org/10.1016/0006-8993(93)91642-6

Culberson, J. L., \& Brushart, T. M. (1989). Somatotopy of digital nerve projections to the cuneate nucleus in the monkey. Somatosensory \& Motor Research, 6(3), 319-330. doi:https://doi.org/10.3109/08990228909144680

Danielsson, I., \& Norrsell, U. (1985). Somatosensory, short latency activation in the intercollicular region of the cat's mesencephalon. Acta Physiologica Scandinavica, 124(3), 479-482. doi:https://doi.org/10.1111/j.1748-1716.1985.tb07686.x

Danielsson, I., \& Norssell, U. (1986). Somatosensory units in the cat's intercollicular region. Acta Physiologica Scandinavica, 128(4), 579-586. doi:https://doi.org/10.1111/j.17481716.1986.tb08015.x

Darian-Smith, I. (2011). The sense of touch: Performance and peripheral neural processes. Comprehensive Physiology. doi:https://doi.org/10.1002/cphy.cp010317

Dart, A., \& Gordon, G. (1973). Some properties of spinal connections of the cat's dorsal column nuclei which do not involve the dorsal columns. Brain Research, 58(1), 61-68. doi:https://doi.org/10.1016/0006-8993(73)90823-8

De-Doncker, L., Picquet, F., Petit, J., \& Falempin, M. (2003). Characterization of spindle afferents in rat soleus muscle using ramp-and-hold and sinusoidal stretches. Journal of Neurophysiology, 89(1), 442-449. doi:https://doi.org/10.1152/jn.00153.2002

de Pommery, J., Roudier, F., \& Menétrey, D. (1984). Postsynaptic fibers reaching the dorsal column nuclei in the rat. Neuroscience Letters, 50(1-3), 319-323. doi:https://doi.org/10.1016/03043940(84)90506-8

Delhaye, B. P., Long, K. H., \& Bensmaia, S. J. (2018). Neural basis of touch and proprioception in primate cortex. Comprehensive Physiology, 8(4), 1575-1602. doi:https://doi.org/10.1002/cphy.c170033

Desclin, J. C. (1974). Histological evidence supporting the inferior olive as the major source of cerebellar climbing fibers in the rat. Brain Research, 77(3), 365-384. doi:https://doi.org/10.1016/0006-8993(74)90628-3

Diamond, M. E., Armstrong-James, M., \& Ebner, F. F. (1992). Somatic sensory responses in the rostral sector of the posterior group (POm) and in the ventral posterior medial nucleus (VPM) of the rat thalamus. Journal of Comparative Neurology, 318(4), 462-476. doi:https://doi.org/10.1002/cne.903180410

Dolleman-van Der Weel, M. J., \& Witter, M. P. (1996). Projections from the nucleus reuniens thalami to the entorhinal cortex, hippocampal field CA1, and the subiculum in the rat arise from different populations of neurons. Journal of Comparative Neurology, 364(4), 637-650. doi:https://doi.org/10.1002/(sici)1096-9861(19960122)364:4<637::Aid-cne3>3.0.Co;2-4

Dostrovsky, J. O. (1980). Raphe and periaqueductal gray induced suppression of non-nociceptive neuronal responses in the dorsal column nuclei and trigeminal sub-nucleus caudalis. Brain Research, 200(1), 184-189. doi:https://doi.org/10.1016/0006-8993(80)91106-3

Drager, U. C., \& Hubel, D. H. (1975). Responses to visual stimulation and relationship between visual, auditory, and somatosensory inputs in mouse superior colliculus. Journal of Neurophysiology, 38(3), 690-713. doi:https://doi.org/10.1152/jn.1975.38.3.690

Dykes, R. W., Rasmusson, D. D., Sretavan, D., \& Rehman, N. B. (1982). Submodality segregation and receptive-field sequences in cuneate, gracile, and external cuneate nuclei of the cat. Journal of Neurophysiology, 47(3), 389-416. doi:https://doi.org/10.1152/jn.1982.47.3.389

Dykes, R. W., Sur, M., Merzenich, M. M., Kaas, J. H., \& Nelson, R. J. (1981). Regional segregation of neurons responding to quickly adapting, slowly adapting, deep and Pacinian receptors within thalamic ventroposterior lateral and ventroposterior inferior nuclei in the squirrel monkey (Saimiri sciureus). Neuroscience, 6(8), 1687-1692. doi:https://doi.org/10.1016/03064522(81)90235-9 
Ebbesson, S. O. E. (1968). A connection between the dorsal column nuclei and the dorsal accessory olive. Brain Research, 8(2), 393-397. doi:https://doi.org/10.1016/0006-8993(68)90062-0

Edin, B. B., \& Vallbo, A. B. (1990a). Dynamic response of human muscle spindle afferents to stretch. Journal of Neurophysioly, 63(6), 1297-1306. doi:https://doi.org/10.1152/jn.1990.63.6.1297

Edin, B. B., \& Vallbo, A. B. (1990b). Muscle afferent responses to isometric contractions and relaxations in humans. Journal of Neurophysiology, 63(6), 1307-1313. doi:https://doi.org/10.1152/jn.1990.63.6.1307

Edwards, S. B. (1972). The ascending and descending projections of the red nucleus in the cat: an experimental study using an autoradiographic tracing method. Brain Research, 48, 45-63. doi:https://doi.org/10.1016/0006-8993(72)90170-9

Edwards, S. B., Ginsburgh, C. L., Henkel, C. K., \& Stein, B. E. (1979). Sources of subcortical projections to the superior colliculus in the cat. Journal of Comparative Neurology, 184(2), 309-329. doi:https://doi.org/10.1002/cne.901840207

Ekerot, C., \& Larson, B. (1972). Differential termination of the exteroceptive and proprioceptive components of the cuneocerebellar tract. Brain Research, 36(2), 420-424. doi:https://doi.org/10.1016/0006-8993(72)90748-2

Ellis, L. C., \& Rustioni, A. (1981). A correlative HRP, Golgi, and EM study of the intrinsic organization of the feline dorsal column nuclei. Journal of Comparative Neurology, 197(2), 341-367. doi:https://doi.org/10.1002/cne.901970210

Enevoldson, T. P., \& Gordon, G. (1984). Spinally projecting neurons in the dorsal column nuclei: Distribution, dendritic trees and axonal projections. Experimental Brain Research, 54(3), 538550. doi:https://doi.org/10.1007/bf00235479

Enevoldson, T. P., \& Gordon, G. (1989). Postsynaptic dorsal column neurons in the cat: a study with retrograde transport of horseradish peroxidase. Experimental Brain Research, 75(3), 611-620. doi:https://doi.org/10.1007/BF00249912

Feldman, S. G., \& Kruger, L. (1980). An axonal transport study of the ascending projection of medial lemniscal neurons in the rat. Journal of Comparative Neurology, 192(3), 427-454. doi:https://doi.org/10.1002/cne.901920305

Ferraro, A., \& Barrera, S. (1935). The nuclei of the posterior funiculi in Macacus rhesus: An anatomic and experimental investigation. Archives of Neurology \& Psychiatry, 33(2), 262-275. doi:https://doi.org/10.1001/archneurpsyc.1935.02250140018002

Ferrington, D. G., Downie, J. W., \& Willis, W. D. (1988). Primate nucleus gracilis neurons: responses to innocuous and noxious stimuli. Journal of Neurophysiology, 59(3), 886-907. doi:https://doi.org/10.1152/jn.1988.59.3.886

Flink, R., Wiberg, M., \& Blomqvist, A. (1983). The termination in the mesencephalon of fibres from the lateral cervical nucleus. An anatomical study in the cat. Brain Research, 259(1), 11-20. doi:https://doi.org/10.1016/0006-8993(83)91062-4

Florence, S. L., Wall, J. T., \& Kaas, J. H. (1988). The somatotopic pattern of afferent projections from the digits to the spinal cord and cuneate nucleus in macaque monkeys. Brain Research, 452(12), 388-392. doi:https://doi.org/10.1016/0006-8993(88)90045-5

Florence, S. L., Wall, J. T., \& Kaas, J. H. (1989). Somatotopic organization of inputs from the hand to the spinal gray and cuneate nucleus of monkeys with observations on the cuneate nucleus of humans. Journal of Comparative Neurology, 286(1), 48-70. doi:https://doi.org/10.1002/cne.902860104

Florence, S. L., Wall, J. T., \& Kaas, J. H. (1991). Central projections from the skin of the hand in squirrel monkeys. Journal of Comparative Neurology, 311(4), 563-578. doi:https://doi.org/10.1002/cne.903110410

Gandhi, N. J., \& Katnani, H. A. (2011). Motor functions of the superior colliculus. Annual Review of Neuroscience, 34(1), 205-231. doi:https://doi.org/10.1146/annurev-neuro-061010-113728

García Del Caño, G., Uria, I., Gerrikagoitia, I., \& Martínez-Millán, L. (2004). Connection from the dorsal column nuclei to the superior colliculus in the rat: Topographical organization and 
somatotopic specific plasticity in response to neonatal enucleation. Journal of Comparative Neurology, 468(3), 410-424. doi:https://doi.org/10.1002/cne.10982

Geborek, P., Jörntell, H., \& Bengtsson, F. (2013). Stimulation within the cuneate nucleus suppresses synaptic activation of climbing fibers. Frontiers in Neural Circuits, 6, 120. doi:https://doi.org/10.3389/fncir.2012.00120

Gerhart, K. D., Wilcox, T. K., Chung, J. M., \& Willis, W. D. (1981). Inhibition of nociceptive and nonnociceptive responses of primate spinothalamic cells by stimulation in medial brain stem. Journal of Neurophysiology, 45(1), 121-136. doi:https://doi.org/10.1152/jn.1981.45.1.121

Gerrits, N. M., Voogd, J., \& Nas, W. S. C. (1985). Cerebellar and olivary projections of the external and rostral internal cuneate nuclei in the cat. Experimental Brain Research, 57(2), 239-255. doi:https://doi.org/10.1007/BF00236529

Giesler, G. J., Nahin, R. L., \& Madsen, A. M. (1984). Postsynaptic dorsal column pathway of the rat. I. Anatomical studies. Journal of Neurophysiology, 51(2), 260-275. doi:https://doi.org/10.1152/jn.1984.51.2.260

Gordon, G., \& Grant, G. (1982). Dorsolateral spinal afferents to some medullary sensory nuclei. Experimental Brain Research, 46(1), 12-23. doi:https://doi.org/10.1007/bf00238093

Gordon, G., \& Horrobin, D. (1967). Antidromic and synaptic responses in the cat's gracile nucleus to cerebellar stimulation. Brain Research, 5(3), 419-421. doi:https://doi.org/10.1016/0006$\underline{\text { 8993(67)90048-0 }}$

Gordon, G., \& Jukes, M. G. M. (1964a). Descending influences on the exteroceptive organizations of the cat's gracile nucleus. The Journal of Physiology, 173(2), 291-319. doi:https://doi.org/10.1113/jphysiol.1964.sp007457

Gordon, G., \& Jukes, M. G. M. (1964b). Dual organization of the exteroceptive components of the cat's gracile nucleus. The Journal of Physiology, 173(2), 263-290. doi:https://doi.org/10.1113/iphysiol.1964.sp007456

Gordon, G., \& Paine, C. H. (1960). Functional organization in nucleus gracilis of the cat. The Journal of Physiology, 153(2), 331-349. doi:https://doi.org/10.1113/jphysiol.1960.sp006537

Gordon, G., \& Seed, W. A. (1961). An investigation of nucleus gracilis of the cat by antidromic stimulation. The Journal of Physiology, 155(3), 589-601. doi:https://doi.org/10.1113/iphysiol.1961.sp006649

Grant, G., Boivie, J., \& Silfvenius, H. (1973). Course and termination of fibres from the nucleus $Z$ of the medulla oblongata. An experimental light microscopical study in the cat. Brain Research, 55(1), 55-70. doi:https://doi.org/10.1016/0006-8993(73)90488-5

Grasso, C., Li Volsi, G., \& Barresi, M. (2016). Serotonin modifies the spontaneous spiking activity of gracile nucleus neurons in rats: role of 5-HT1A and 5-HT2 receptors. Archives Italiennes de Biologie, 154(2-3), 39-49. doi:https://doi.org/10.4449/aib.v154i2/3.3430

Griffin, A. L. (2015). Role of the thalamic nucleus reuniens in mediating interactions between the hippocampus and medial prefrontal cortex during spatial working memory. Frontiers in Systems Neuroscience, 9(29). doi:https://doi.org/10.3389/fnsys.2015.00029

Grigg, P. (1994). Peripheral neural mechanisms in proprioception. Journal of Sport Rehabilitation, 3(1), 2-17. doi:https://doi.org/10.1123/jsr.3.1.2

Groenewegen, H. J., Boesten, A. J. P., \& Voogd, J. (1975). The dorsal column nuclear projections to the nucleus ventralis posterior lateralis thalami and the inferior olive in the cat: an autoradiographic study. Journal of Comparative Neurology, 162(4), 505-517. doi:https://doi.org/10.1002/cne.901620407

Groh, J. M., \& Sparks, D. L. (1996). Saccades to somatosensory targets. Il. motor convergence in primate superior colliculus. Journal of Neurophysiology, 75(1), 428-438. doi:https://doi.org/10.1152/jn.1996.75.1.428

Halata, Z., Grim, M., \& Bauman, K. I. (2003). Friedrich Sigmund Merkel and his "Merkel cell", morphology, development, and physiology: review and new results. The Anatomical Record, 271(1), 225-239. doi:https://doi.org/10.1002/ar.a.10029 
Hamilton, T. C., \& Johnson, J. I. (1973). Somatotopic organization related to nuclear morphology in the cuneate-gracile complex of opossums Didelphis marsupialis virginiana. Brain Research, 51, 125-140. doi:https://doi.org/10.1016/0006-8993(73)90368-5

Hand, P. J. (1966). Lumbosacral dorsal root terminations in the nucleus gracilis of the cat. Some observations on terminal degeneration in other medullary sensory nuclei. Journal of Comparative Neurology, 126(2), 137-156. doi:https://doi.org/10.1002/cne.901260201

Hand, P. J., \& Van Winkle, T. (1977). The efferent connections of the feline nucleus cuneatus. Journal of Comparative Neurology, 171(1), 83-109. doi:https://doi.org/10.1002/cne.901710107

Handwerker, H. O., Kilo, S., \& Reeh, P. W. (1991). Unresponsive afferent nerve fibres in the sural nerve of the rat. The Journal of Physiology, 435, 229. doi:https://doi.org/10.1113/jphysiol.1991.sp018507

Haring, J. H., \& Rowinski, M. J. (1982). A horseradish peroxidase study of projections from the main and external cuneate nuclei to the cerebellum of the North American raccoon. Journal of Comparative Neurology, 211(4), 363-376. doi:https://doi.org/10.1002/cne.902110404

Haring, J. H., Rowinski, M. J., \& Pubols, B. H. (1984). Electrophysiology of raccoon cuneocerebellar neurons. Somatosensory Research, 247-264. doi:https://doi.org/10.3109/07367228409144549

Hazlett, J. C., Dom, R., \& Martin, G. F. (1972). Spino-bulbar, spino-thalamic and medial lemniscal connections in the american opossum, Didelphis marsupialis virginiana. Journal of Comparative Neurology, 146(1), 95-117. doi:https://doi.org/10.1002/cne.901460107

Heino, R., \& Westman, J. (1991). Quantitative analysis of the feline dorsal column nuclei and their GABAergic and non-GABAergic neurons. Anatomy and Embryology, 184(3), 181-193. doi:https://doi.org/10.1007/BF01673255

Hornung, J.-P. (2003). The human raphe nuclei and the serotonergic system. Journal of Chemical Neuroanatomy, 26(4), 331-343. doi:https://doi.org/10.1016/j.jchemneu.2003.10.002

Huang, Y., \& Mogenson, G. (1974). Differential effects of incertal and hypothalamic lesions on food and water intake. Experimental Neurology, 43(1), 276-280. doi:https://doi.org/10.1016/00144886(74)90146-0

Hummelsheim, H., \& Wiesendanger, M. (1985). Neuronal responses of medullary relay cells to controlled stretches of forearm muscles in the monkey. Neuroscience, 16(4), 989-996. doi:https://doi.org/10.1016/0306-4522(85)90111-3

Hummelsheim, H., Wiesendanger, R., Wiesendanger, M., \& Bianchetti, M. (1985). The projection of low-threshold muscle afferents of the forelimb to the main and external cuneate nuclei of the monkey. Neuroscience, 16(4), 979-987. doi:https://doi.org/10.1016/0306-4522(85)90110-1

Iggo, A., \& Muir, A. R. (1969). The structure and function of a slowly adapting touch corpuscle in hairy skin. The Journal of Physiology, 200(3), 763-796. doi:https://doi.org/10.1113/jphysiol.1969.sp008721

Isomura, G., \& Hámori, J. (1988). Three types of neurons in the medial cuneate nucleus of the cat. Neuroscience Research, 5(5), 395-408. doi:https://doi.org/10.1016/0168-0102(88)90025-9

Ito, M. (1984). The cerebellum and neural control. New York: Raven press.

Itoh, K., Kamiya, H., Mitani, A., Yasui, Y., Takada, M., \& Mizuno, N. (1987). Direct projections from the dorsal column nuclei and the spinal trigeminal nuclei to the cochlear nuclei in the cat. Brain Research, 400(1), 145-150. doi:https://doi.org/10.1016/0006-8993(87)90662-7

Itoh, K., Kaneko, T., Kudo, M., \& Mizuno, N. (1984). The intercollicular region in the cat: a possible relay in the parallel somatosensory pathways from the dorsal column nuclei to the posterior complex of the thalamus. Brain Research, 308(1), 166-171. doi:https://doi.org/10.1016/00068993(84)90931-4

Jain, R., \& Shore, S. (2006). External inferior colliculus integrates trigeminal and acoustic information: Unit responses to trigeminal nucleus and acoustic stimulation in the guinea pig. Neuroscience Letters, 395(1), 71-75. doi:https://doi.org/10.1016/i.neulet.2005.10.077 
Jami, L. (1992). Golgi tendon organs in mammalian skeletal muscle: functional properties and central $\begin{array}{llll}\text { actions. } \quad \text { Physiological 623-666. } & \end{array}$ doi:https://doi.org/10.1152/physrev.1992.72.3.623

Jane, J. A., \& Schroeder, D. M. (1971). A comparison of dorsal column nuclei and spinal afferents in the European hedgehog (Erinaceus europeaus). Experimental Neurology, 30(1), 1-17. doi:https://doi.org/10.1016/0014-4886(71)90216-0

Jankowska, E., Rastad, J., \& Zarzecki, P. (1979). Segmental and supraspinal input to cells of origin of non-primary fibres in the feline dorsal columns. The Journal of Physiology, 290(2), 185-200. doi:https://doi.org/10.1113/jphysiol.1979.sp012767

Jasmin, L., Courville, J., \& Bakker, D. A. (1985). Afferent projections from forelimb muscles to the external and main cuneate nuclei in the cat. Anatomy and Embryology, 171(3), 275-284. doi:https://doi.org/10.1007/BF00347016

Jenkins, B. A., \& Lumpkin, E. A. (2017). Developing a sense of touch. Development, 144(22), 4078-4090. doi:https://doi.org/10.1242/dev.120402

Ji, Z., \& Hawkes, R. (1994). Topography of purkinje cell compartments and mossy fiber terminal fields in lobules ii and iii of the rat cerebellar cortex: Spinocerebellar and cuneocerebellar projections. Neuroscience, 61(4), 935-954. doi:https://doi.org/10.1016/0306-4522(94)904146

Johansson, H., \& Silfvenius, H. (1977a). Axon-collateral activation by dorsal spinocerebellar tract fibres of group I relay cells of nucleus $\mathrm{Z}$ in the cat medulla oblongata. The Journal of Physiology, 265(2), 341-369. doi:https://doi.org/10.1113/jphysiol.1977.sp011720

Johansson, H., \& Silfvenius, H. (1977b). Connexions from large, ipsilateral hind limb muscle and skin afferents to the rostral main cuneate nucleus and to the nucleus $X$ region in the cat. The Journal of Physiology, 265(2), 395-428. doi:https://doi.org/10.1113/jphysiol.1977.sp011722

Johansson, H., \& Silfvenius, H. (1977c). Input from ipsilateral proprio-and exteroceptive hind limb afferents to nucleus $Z$ of the cat medulla oblongata. The Journal of Physiology, 265(2), 371393. doi:https://doi.org/10.1113/jphysiol.1977.sp011721

Johansson, R. S., \& Flanagan, J. R. (2009). Coding and use of tactile signals from the fingertips in object manipulation tasks. Nature Reviews Neuroscience, 10(5), 345-359. doi:https://doi.org/10.1038/nrn2621

Johansson, R. S., Landström, U., \& Lundström, R. (1982). Responses of mechanoreceptive afferent units in the glabrous skin of the human hand to sinusoidal skin displacements. Brain Research, 244(1), 17-25. doi:https://doi.org/10.1016/0006-8993(82)90899-X

Johnson, J. I., Welker, W. I., \& Pubols, B. H. (1968). Somatotopic organization of raccoon dorsal column nuclei. Journal of Comparative Neurology, 132(1), 1-43. doi:https://doi.org/10.1002/cne.901320102

Johnson, K. O. (2001). The roles and functions of cutaneous mechanoreceptors. Current Opinion in Neurobiology, 11(4), 455-461. doi:http://dx.doi.org/10.1016/S0959-4388(00)00234-8

Jones, E. G., \& Friedman, D. P. (1982). Projection pattern of functional components of thalamic ventrobasal complex on monkey somatosensory cortex. Journal of Neurophysiology, 48(2), 521-544. doi:http://dx.doi.org/10.1152/jn.1982.48.2.521

Jörntell, H., Bengtsson, F., Geborek, P., Spanne, A., Terekhov, A. V., \& Hayward, V. (2014). Segregation of tactile input features in neurons of the cuneate nucleus. Neuron, 83(6), 1444-1452.

Jundi, A. S., Saadé, N. E., Banna, N. R., \& Jabbur, S. J. (1982). Modification of transmission in the cuneate nucleus by raphe and periaqueductal gray stimulation. Brain Research, 250(2), 349352. doi:https://doi.org/10.1016/0006-8993(82)90429-2

Kaas, J. H. (2004). Somatosensory system. In G. Paxinos \& J. K. Mai (Eds.), The Human Nervous System (2nd ed., pp. 1059-1092). New York: Elsevier Academic.

Kaas, J. H., Nelson, R. J., Sur, M., Lin, C.-S., \& Merzenich, M. M. (1979). Multiple representations of the body within the primary somatosensory cortex of primates. Science, 204(4392), 521-523. doi:http://dx.doi.org/10.1126/science.107591 
Kaelber, W. W., \& Smith, T. B. (1979). Projections of the zona incerta in the cat, with stimulation controls. Experimental Neurology, 63(1), 177-200. doi:https://doi.org/10.1016/00144886(79)90192-4

Keller, J. H., \& Hand, P. J. (1970). Dorsal root projections to nucleus cuneatus of the cat. Brain Research, 20(1), 1-17. doi:https://doi.org/10.1016/0006-8993(70)90149-6

Kemplay, S., \& Webster, K. E. (1989). A quantitative study of the projections of the gracile, cuneate and trigeminal nuclei and of the medullary reticular formation to the thalamus in the rat. Neuroscience, 32(1), 153-167. doi:https://doi.org/10.1016/0306-4522(89)90115-2

Kitagawa, J., Tsuboi, Y., Ogawa, A., Ren, K., Hitomi, S., Saitoh, K., . . I Iwata, K. (2005). Involvement of dorsal column nucleus neurons in nociceptive transmission in aged rats. Journal of Neurophysiology, 94(6), 4178-4187. doi:https://doi.org/10.1152/jn.00243.2005

Kitamura, T., \& Yamada, J. (1989). Spinocerebellar tract neurons with axons passing through the inferior or superior cerebellar peduncles. Brain, Behavior and Evolution, 34(3), 133-142. doi:https://doi.org/10.1159/000116499

Knibestöl, M. (1973). Stimulus-response functions of rapidly adapting mechanoreceptors in the human glabrous skin area. The Journal of Physiology, 232(3), 427-452. doi:https://doi.org/10.1113/iphysiol.1973.sp010279

Knibestöl, M. (1975). Stimulus-response functions of slowly adapting mechanoreceptors in the human glabrous skin area. The Journal of Physiology, 245(1), 63-80. doi:https://doi.org/10.1113/jphysiol.1975.sp010835

Kosinski, R. J., Azizi, S. A., Border, B. G., \& Mihailoff, G. A. (1986). Origin and ultrastructural identification of dorsal column nuclear synaptic terminals in the basilar pontine gray of rats. Journal of Comparative Neurology, 253(1), 92-104. doi:https://doi.org/10.1002/cne.902530108

Kosinski, R. J., Azizi, S. A., \& Mihailoff, G. A. (1988). Convergence of cortico-and cuneopontine projections onto components of the pontocerebellar system in the rat: an anatomical and electrophysiological study. Experimental Brain Research, 71(3), 541-556. doi:https://doi.org/10.1007/BF00248746

Kosinski, R. J., Lee, H. S., \& Mihailoff, G. A. (1988). A double retrograde fluorescent tracing analysis of dorsal column nuclear projections to the basilar pontine nuclei, thalamus, and superior colliculus in the rat. Neuroscience Letters, 85(1), 40-46. doi:https://doi.org/10.1016/03043940(88) $90425-9$

Kosinski, R. J., Neafsey, E. J., \& Castro, A. J. (1986). A comparative topographical analysis of dorsal column nuclear and cerebral cortical projections to the basilar pontine gray in rats. Journal of Comparative Neurology, 244(2), 163-173. doi:https://doi.org/10.1002/cne.902440204

Krauzlis, R. J., Basso, M. A., \& Wurtz, R. H. (2000). Discharge properties of neurons in the rostral superior colliculus of the monkey during smooth-pursuit eye movements. Journal of Neurophysiology, 84(2), 876-891. doi:https://doi.org/10.1152/jn.2000.84.2.876

Krauzlis, R. J., Lovejoy, L. P., \& Zénon, A. (2013). Superior colliculus and visual spatial attention. Annual Review of Neuroscience, 36(1), 165-182. doi:https://doi.org/10.1146/annurev-neuro-062012170249

Kristensson, K., Olsson, Y., \& Sjöstrand, J. (1971). Axonal uptake and retrograde transport of exogenous proteins in the hypoglossal nerve. Brain Research, 32(2), 399-406. doi:https://doi.org/10.1016/0006-8993(71)90332-5

Kruger, L., Siminoff, R., \& Witkovsky, P. (1961). Single neuron analysis of dorsal column nuclei and spinal nucleus of trigeminal in cat. Journal of Neurophysiology, 24(4), 333-349. doi:https://doi.org/10.1152/in.1961.24.4.333

Kuypers, H. G. J. M. (1958). An anatomical analysis of cortico-bulbar connexions to the pons and lower brain stem in the cat. Journal of Anatomy, 92(2), 198-218. 
Kuypers, H. G. J. M., Hoffman, A. L., \& Beasley, R. M. (1961). Distribution of cortical "feedback" fibers in the nuclei cuneatus and gracilis. Proceedings of the Society for Experimental Biology and Medicine, 108(3), 634-637. doi:https://doi.org/10.3181/00379727-108-27019

Kuypers, H. G. J. M., \& Maisky, V. A. (1975). Retrograde axonal transport of horseradish peroxidase from spinal cord to brain stem cell groups in the cat. Neuroscience Letters, 1(1), 9-14. doi:https://doi.org/10.1016/0304-3940(75)90004-X

Kuypers, H. G. J. M., \& Tuerk, J. D. (1964). The distribution of cortical fibres within the nuclei cuneatus and gracilis in the cat. Journal of Anatomy, 98(Pt 2), 143.

Kwiat, G. C., \& Basbaum, A. I. (1992). The origin of brainstem noradrenergic and serotonergic projections to the spinal cord dorsal horn in the rat. Somatosensory \& Motor Research, 9(2), 157-173. doi:https://doi.org/10.3109/08990229209144768

Lamas, J. A., Martinez, L., \& Canedo, A. (1994). Pericruciate fibres to the red nucleus and to the medial bulbar reticular formation. Neuroscience, 62(1), 115-124. doi:https://doi.org/10.1016/03064522(94)90319-0

Landgren, S., \& Silfvenius, H. (1971). Nucleus Z, the medullary relay in the projection path to the cerebral cortex of group I muscle afferents from the cat's hind limb. The Journal of Physiology, 218(3), 551-571. doi:https://doi.org/10.1113/iphysiol.1971.sp009633

Lavail, J. H., \& Lavail, M. M. (1972). Retrograde Axonal Transport in the Central Nervous System. Science, 176(4042), 1416-1417. doi:https://doi.org/10.1126/science.176.4042.1416

Leem, J. W., Willis, W. D., \& Chung, J. M. (1993). Cutaneous sensory receptors in the rat foot. Journal of Neurophysiology, 69(5), 1684-1699. doi:https://doi.org/10.1152/jn.1993.69.5.1684

Leiras, R., Velo, P., Martín-Cora, F., \& Canedo, A. (2010). Processing afferent proprioceptive information at the main cuneate nucleus of anesthetized cats. The Journal of Neuroscience, 30(46), 15383-15399. doi:https://doi.org/10.1523/JNEUROSCI.2193-10.2010

Leong, S. K., Shieh, J. Y., \& Wong, W. C. (1984). Localizing spinal-cord-projecting neurons in adult albino rats. Journal of Comparative Neurology, 228(1), 1-17. doi:https://doi.org/10.1002/cne.902280103

Li, C. X., Yang, Q., \& Waters, R. S. (2012). Functional and structural organization of the forelimb representation in cuneate nucleus in rat. Brain Research, 1468, 11-28. doi:https://doi.org/10.1016/j.brainres.2012.03.048

Li, H., \& Mizuno, N. (1997). Single neurons in the spinal trigeminal and dorsal column nuclei project to both the cochlear nucleus and the inferior colliculus by way of axon collaterals: a fluorescent retrograde double-labeling study in the rat. Neuroscience Research, 29(2), 135-142. doi:https://doi.org/10.1016/S0168-0102(97)00082-5

Li, L., Rutlin, M., Abraira, V. E., Cassidy, C., Kus, L., Gong, S., . . Koerber, H. R. (2011). The functional organization of cutaneous low-threshold mechanosensory neurons. Cell, 147(7), 1615-1627. doi:https://doi.org/10.1016/i.cell.2011.11.027

Liu, C. N. (1956). Afferent nerves to Clarke's and the lateral cuneate nuclei in the cat. AMA Archives of $\begin{array}{llll}\text { Neurology } \quad \text { \& } & \text { 75(1), } & \text { 67-77. }\end{array}$ doi:https://doi.org/10.1001/archneurpsyc.1956.02330190083009

Liu, K., Kim, J., Kim, D. W., Zhang, Y. S., Bao, H., Denaxa, M., . . Wickersham, I. R. (2017). Lhx6-positive GABA-releasing neurons of the zona incerta promote sleep. Nature, 548(7669), 582-587. doi:https://doi.org/10.1038/nature23663

Liu, M., Blanco-Centurion, C., Konadhode, R., Begum, S., Pelluru, D., Gerashchenko, D., . . Shiromani, P. J. (2011). Orexin gene transfer into zona incerta neurons suppresses muscle paralysis in narcoleptic mice. Journal of Neuroscience, 31(16), 6028-6040. doi:https://doi.org/10.1523/JNEUROSCI.6069-10.2011

Löken, L. S., Wessberg, J., McGlone, F., \& Olausson, H. (2009). Coding of pleasant touch by unmyelinated afferents in humans. Nature Neuroscience, 12(5), 547. doi:https://doi.org/10.1038/nn.2312 
Loutit, A. J., Maddess, T., Redmond, S. J., Morley, J. W., Stuart, G. J., \& Potas, J. R. (2017). Characterisation and functional mapping of surface potentials in the rat dorsal column nuclei. The Journal of Physiology, 595(13), 4507-4524. doi:https://doi.org/10.1113/JP273759

Loutit, A. J., \& Potas, J. R. (2020). Restoring somatosensation: advantages and current limitations of targeting the brainstem dorsal column nuclei complex. Frontiers in Neuroscience, 14. doi:https://doi.org/10.3389/fnins.2020.00156

Loutit, A. J., Shivdasani, M. N., Maddess, T., Redmond, S. J., Morley, J. W., Stuart, G. J., . . Potas, J. R. (2019). Peripheral nerve activation evokes machine-learnable signals in the dorsal column nuclei. Frontiers in Systems Neuroscience, 13(11). doi:https://doi.org/10.3389/fnsys.2019.00011

Low, J. S. T., John, L. A. M.-S., \& Tracey, D. J. (1986). Nucleus Z in the rat: Spinal afferents from collaterals of dorsal spinocerebellar tract neurons. Journal of Comparative Neurology, 243(4), 510-526. doi:https://doi.org/10.1002/cne.902430406

Lund, R. D., \& Webster, K. E. (1967). Thalamic afferents from the dorsal column nuclei. An experimental anatomical study in the rat. Journal of Comparative Neurology, 130(4), 301-311. doi:https://doi.org/10.1002/cne.901300403

Luo, W., Enomoto, H., Rice, F. L., Milbrandt, J., \& Ginty, D. D. (2009). Molecular identification of rapidly adapting mechanoreceptors and their developmental dependence on ret signaling. Neuron, 64(6), 841-856. doi:https://doi.org/10.1016/j.neuron.2009.11.003

Macefield, V. G. (2005). Physiological characteristics of low-threshold mechanoreceptors in joints, muscle and skin in human subjects. Clinical and Experimental Pharmacology \& Physiology, 32(1-2), 135-144. doi:https://doi.org/10.1111/j.1440-1681.2005.04143.x

Magherini, P. C., Pompeiano, O., \& Seguin, J. J. (1975). Responses of nucleus z neurons to vibration of hindlimb extensor muscles in the decerebrate cat. Archives Italiennes de Biologie, 113(2), 150187. doi:https://doi.org/10.4449/aib.v113i2.2753

Magherini, P. C., Pompeiano, O., \& Sequin, J. J. (1974). The response of nucleus z neurons to sinusoidal stretch of hindlimb extensor muscles. Brain Research, 73(2), 343-349. doi:https://doi.org/10.1016/0006-8993(74)91055-5

Malmierca, E., \& Nuñez, A. (1998). Corticofugal action on somatosensory response properties of rat nucleus gracilis cells. Brain Research, 810(1), 172-180. doi:https://doi.org/10.1016/s00068993(98)00920-2

Malmierca, E., \& Nuñez, A. (2004). Primary somatosensory cortex modulation of tactile responses in nucleus gracilis cells of rats. European Journal of Neuroscience, 19(6), 1572-1580. doi:https://doi.org/10.1111/j.1460-9568.2004.03256.x

Mantle-St. John, L. A., \& Tracey, D. J. (1987). Somatosensory nuclei in the brainstem of the rat: independent projections to the thalamus and cerebellum. Journal of Comparative Neurology, 255(2), 259-271. doi:https://doi.org/10.1002/cne.902550209

Mariño, J., Aguilar, J., \& Canedo, A. (1999). Cortico-subcortical synchronization in the chloraloseanesthetized cat. Neuroscience, 93(2), 409-411. doi:https://doi.org/10.1016/503064522(99)00248-1

Mariño, J., Canedo, A., \& Aguilar, J. (1999). Sensorimotor cortical influences on cuneate nucleus rhythmic activity in the anesthetized cat. Neuroscience, 95(3), 657-673. doi:https://doi.org/10.1016/S0306-4522(99)00414-5

Martinez, L., Lamas, J. A., \& Canedo, A. (1995). Pyramidal tract and corticospinal neurons with branching axons to the dorsal column nuclei of the cat. Neuroscience, 68(1), 195-206. doi:https://doi.org/10.1016/0306-4522(95)00133-4

Maslany, S., Crockett, D. P., \& Egger, M. D. (1991). Somatotopic organization of the dorsal column nuclei in the rat: transganglionic labelling with B-HRP and WGA-HRP. Brain Research, 564(1), 56-65. doi:http://dx.doi.org/10.1016/0006-8993(91)91351-Z 
Maslany, S., Crockett, D. P., \& Egger, M. D. (1992). The cuneate nucleus in the rat does have an anatomically distinct middle region. Neuroscience Letters, 139(1), 130-134. doi:https://doi.org/10.1016/0304-3940(92)90874-7

Massopust, L. C., Hauge, D. H., Ferneding, J. C., Doubek, W. G., \& Taylor, J. J. (1985). Projection systems and terminal localization of dorsal column afferents: An autoradiographic and horseradish peroxidase study in the rat. Journal of Comparative Neurology, 237(4), 533-544. doi:https://doi.org/10.1016/0304-3940(92)90874-710.1002/cne.902370409

Matsushita, M. (1999). Projections from the upper lumbar cord to the cerebellar nuclei in the rat, studied by anterograde axonal tracing. Journal of Comparative Neurology, 412(4), 633-648. doi:https://doi.org/10.1002/(SICI)1096-9861(19991004)412:4<633::AID-CNE5>3.0.CO;2-Q

Matsushita, M., \& Yaginuma, H. (1989). Spinocerebellar projections from spinal border cells in the cat as studied by anterograde transport of wheat germ agglutinin-horseradish peroxidase. Journal of Comparative Neurology, 288(1), 19-38. doi:https://doi.org/10.1002/cne.902880103

Matyas, F., Sreenivasan, V., Marbach, F., Wacongne, C., Barsy, B., Mateo, C., . . Petersen, C. C. H. (2010). Motor control by sensory cortex. Science, 330(6008), 1240-1243. doi:https://doi.org/10.1126/science.1195797

May, P. J. (2006). The mammalian superior colliculus: laminar structure and connections. Progress in Brain Research, 151, 321-378. doi:https://doi.org/10.1016/S0079-6123(05)51011-2

May, P. J., \& Basso, M. A. (2018). Connections between the zona incerta and superior colliculus in the monkey and squirrel. Brain Structure and Function, 223(1), 371-390. doi:https://doi.org/10.1007/s00429-017-1503-2

May, P. J., Sun, W., Wright, N. F., \& Erichsen, J. T. (2020). Pupillary light reflex circuits in the macaque monkey: the preganglionic Edinger-Westphal nucleus. Brain Structure and Function, 225(1), 403-425. doi:https://doi.org/10.1007/s00429-019-02000-w

McComas, A. J. (1963). Responses of the rat dorsal column system to mechanical stimulation of the hind paw. The Journal of Physiology, 166(3), 435-448. doi:https://doi.org/10.1113/iphysiol.1963.sp007115

McCurdy, M. L., Gibson, A. R., \& Houk, J. C. (1992). Spatial overlap of rubrospinal and corticospinal terminals with input to the inferior olive. Neurolmage, 1(1), 23-41. doi:https://doi.org/10.1016/1053-8119(92)90005-8

McCurdy, M. L., Houk, J. C., \& Gibson, A. R. (1998). Organization of ascending pathways to the forelimb area of the dorsal accessory olive in the cat. Journal of Comparative Neurology, 392(1), 115133. doi:https://doi.org/10.1002/(SICI)1096-9861(19980302)392:1<115::AIDCNE8>3.0.CO;2-5

McHaffie, J. G., Kruger, L., Clemo, H. R., \& Stein, B. E. (1988). Corticothalamic and corticotectal somatosensory projections from the anterior ectosylvian sulcus (SIV cortex) in neonatal cats: An anatomical demonstration with HRP and 3H-leucine. Journal of Comparative Neurology, 274(1), 115-126. doi:https://doi.org/10.1002/cne.902740111

Mihailoff, G. A., Burne, R. A., Azizi, S. A., Norell, G., \& Woodward, D. J. (1981). The pontocerebellar system in the rat: An HRP study. II. Hemispheral components. Journal of Comparative Neurology, 197(4), 559-577. doi:https://doi.org/10.1002/cne.901970403

Mihailoff, G. A., Watt, C. B., \& Burne, R. A. (1981). Evidence suggesting that both the corticopontine and cerebellopontine systems are each composed of two separate neuronal populations: an electron microscopic and horseradish peroxidase study in the rat. Journal of Comparative Neurology, 195(2), 221-242. doi:https://doi.org/10.1002/cne.901950204

Miki, K., Fukuoka, T., Tokunaga, A., \& Noguchi, K. (1997). Calcitonin gene-related peptide increase in the rat spinal dorsal horn and dorsal column nucleus following peripheral nerve injury: Upregulation in a subpopulation of primary afferent sensory neurons. Neuroscience, 82(4), 12431252. doi:https://doi.org/10.1016/S0306-4522(97)00258-3 
Millar, J., \& Basbaum, A. I. (1975). Topography of the projection of the body surface of the cat to cuneate and gracile nuclei. Experimental Neurology, 49(1), 281-290. doi:http://dx.doi.org/10.1016/0014-4886(75)90211-3

Mitrofanis, J. (2005). Some certainty for the "zone of uncertainty"? Exploring the function of the zona incerta. Neuroscience, 130(1), 1-15. doi:https://doi.org/10.1016/j.neuroscience.2004.08.017

Mjaatvedt, A. E., \& Wong-Riley, M. T. T. (1988). Relationship between synaptogenesis and cytochrome oxidase activity in Purkinje cells of the developing rat cerebellum. Journal of Comparative Neurology, 277(2), 155-182. doi:https://doi.org/10.1002/cne.902770202

Molenaar, G. J. (1976). The rhombencephalon of Python reticulatus, a snake possessing infrared receptors. Netherlands Journal of Zoology, 27(2), 133-181. doi:https://doi.org/10.1163/002829677X00018

Molinari, H. H. (1984). Ascending somatosensory projections to the dorsal accessory olive: an anatomical study in cats. Journal of Comparative Neurology, 223(1), 110-123. doi:https://doi.org/10.1002/cne.902230109

Molinari, H. H., Schultze, K. E., \& Strominger, N. L. (1996). Gracile, cuneate, and spinal trigeminal projections to inferior olive in rat and monkey. Journal of Comparative Neurology, 375(3), 467480. doi:https://doi.org/10.1002/(sici)1096-9861(19961118)375:3<467::Aid-cne9>3.0.Co;2-0

Moon, H. C., \& Park, Y. S. (2017). Reduced GABAergic neuronal activity in zona incerta causes neuropathic pain in a rat sciatic nerve chronic constriction injury model. Journal of pain research, 10, 1125. doi:https://doi.org/10.2147/JPR.S131104

Mountcastle, V. B. (1984). Central nervous mechanisms in mechanoreceptive sensibility. Comprehensive Physiology, 3, 789-878. doi:https://doi.org/10.1002/cphy.cp010318

Munger, B. L., Pubols, L. M., \& Pubols, B. H. (1971). The Merkel rete papilla-a slowly adapting sensory receptor in mammalian glabrous skin. Brain Research, 29(1), 47-61. doi:https://doi.org/10.1016/0006-8993(71)90416-1

Murray, P. D., Masri, R., \& Keller, A. (2010). Abnormal anterior pretectal nucleus activity contributes to central pain syndrome. Journal of Neurophysiology, 103(6), 3044-3053. doi:https://doi.org/10.1152/jn.01070.2009

Nagata, T., \& Kruger, L. (1979). Tactile neurons of the superior colliculus of the cat: Input and physiological properties. Brain Research, 174(1), 19-37. doi:https://doi.org/10.1016/00068993(79)90801-1

Naito, J., \& Kawamura, K. (1982). Thalamocortical neurons projecting to the areas surrounding the anterior and middle suprasylvian sulci in the cat. Experimental Brain Research, 45(1), 59-70. doi:https://doi.org/10.1007/bf00235763

Nicolelis, M. A. L., Chapin, J. K., \& Lin, R. C. S. (1992). Somatotopic maps within the zona incerta relay parallel GABAergic somatosensory pathways to the neocortex, superior colliculus, and brainstem. Brain Research, 577(1), 134-141. doi:https://doi.org/10.1016/00068993(92)90546-L

Nijensohn, D. E., \& Kerr, F. W. L. (1975). The ascending projections of the dorsolateral funiculus of the spinal cord in the primate. Journal of Comparative Neurology, 161(3), 459-469. doi:https://doi.org/10.1002/cne.901610310

Niu, J., Ding, L., Li, J. J., Kim, H., Liu, J., Li, H., . . . Son, Y.-J. (2013). Modality-based organization of ascending somatosensory axons in the direct dorsal column pathway. The Journal of Neuroscience, 33(45), 17691-17709. doi:https://doi.org/10.1523/JNEUROSCI.3429-13.2013

Nord, S. G. (1967). Somatotopic organization in the spinal trigeminal nucleus, the dorsal column nuclei and related structures in the rat. The Journal of Comparative Neurology, 130(4), 343-356. doi:https://doi.org/10.1002/cne.901300406

Noriega, A. L., \& Wall, J. T. (1991). Parcellated organization in the trigeminal and dorsal column nuclei of primates. Brain Research, 565(2), 188-194. doi:https://doi.org/10.1016/00068993(91)91649-L 
Nyberg, G. (1988). Representation of the forepaw in the feline cuneate nucleus: a transganglionic transport study. Journal of Comparative Neurology, 271(1), 143-152. doi:https://doi.org/10.1002/cne.902710114

Nyberg, G., \& Blomqvist, A. (1982). The termination of forelimb nerves in the feline cuneate nucleus demonstrated by the transganglionic transport method. Brain Research, 248(2), 209-222. doi:https://doi.org/10.1016/0006-8993(82)90579-0

Nyberg, G., \& Blomqvist, A. (1984). The central projection of muscle afferent fibres to the lower medulla and upper spinal cord: an anatomical study in the cat with the transganglionic transport method. Journal of Comparative Neurology, 230(1), 99-109. doi:https://doi.org/10.1002/cne.902300109

Odutola, A. B. (1977). On the location of reticular neurons projecting to the cuneo-gracile nuclei in the rat. Experimental Neurology, 54(1), 54-59. doi:https://doi.org/10.1016/0014-4886(77)90234$\underline{5}$

Ostapoff, E. M., \& Johnson, J. I. (1988). Distribution of cells projecting to thalamus vs. those projecting to cerebellum in subdivisions of the dorsal column nuclei in raccoons. Journal of Comparative Neurology, 267(2), 211-230. doi: https://doi.org/10.1002/cne.902670206

Ostapoff, E. M., Johnson, J. I., \& Albright, B. C. (1983). Mechanosensory projections to cuneate, gracile, and external cuneate nuclei in a tree squirrel (fox squirrel, Sciurus niger). Neuroscience, 9(1), 107-127. doi:https://doi.org/10.1016/0306-4522(83)90050-7

Ostapoff, E. M., Johnson, J. I., \& Albright, B. C. (1988). Medullary sources of projections to the kinesthetic thalamus in raccoons: External and basal cuneate nuclei and cell groups $\mathrm{x}$ and $\mathrm{z}$. Journal of Comparative Neurology, 267(2), 231-252. doi:https://doi.org/10.1002/cne.902670207

Padberg, J., Cerkevich, C., Engle, J., Rajan, A. T., Recanzone, G., Kaas, J., \& Krubitzer, L. (2009). Thalamocortical connections of parietal somatosensory cortical fields in macaque monkeys are highly divergent and convergent. Cerebral Cortex, 19(9), 2038-2064. doi:https://doi.org/10.1093/cercor/bhn229

Palmeri, A., Bellomo, M., Giuffrida, R., \& Sapienza, S. (1999). Motor cortex modulation of exteroceptive information at bulbar and thalamic lemniscal relays in the cat. Neuroscience, 88(1), 135-150. doi:https://doi.org/10.1016/S0306-4522(98)00205-X

Paxinos, G., Huang, X.-F., Sengul, G., \& Watson, C. (2012). Organization of brainstem nuclei. In The Human Nervous System (3rd ed.). London, UK: Elsevier.

Pearson, J. C., \& Garfunkel, D. A. (1983). Evidence for thalamic projections from external cuneate nucleus, cell groups $Z$ and $X$, and the mesencephalic nucleus of the trigeminal nerve in squirrel monkey. Neuroscience Letters, 41(1-2), 41-47. doi:https://doi.org/10.1016/03043940(83)90220-3

Périer, C., Tremblay, L., Féger, J., \& Hirsch, E. C. (2002). Behavioral consequences of bicuculline injection in the subthalamic nucleus and the zona incerta in rat. Journal of Neuroscience, 22(19), 8711-8719. doi:https://doi.org/10.1523/JNEUROSCI.22-19-08711.2002

Perl, E. R. (1968). Myelinated afferent fibres innervating the primate skin and their response to noxious stimuli. The Journal of Physiology, 197(3), 593-615. doi:https://doi.org/10.1113/iphysiol.1968.sp008576

Pompeiano, O., \& Brodal, A. (1957). Spino-vestibular fibers in the cat. An experimental study. Journal of Comparative Neurology, 108(3), 353-381. doi:https://doi.org/10.1002/cne.901080302

Proske, U., \& Gandevia, S. C. (2012). The proprioceptive senses: their roles in signaling body shape, body position and movement, and muscle force. Physiological Reviews, 92(4), 1651-1697. doi:https://doi.org/10.1152/physrev.00048.2011

Puelles, E., Martínez-de-la-Torre, M., Watson, C., \& Puelles, L. (2012). Chapter 10 - Midbrain. In C. Watson, G. Paxinos, \& L. Puelles (Eds.), The Mouse Nervous System (pp. 337-359). San Diego: Academic Press. 
Puelles, L., Martinez-de-la-Torre, M., Ferran, J.-L., \& Watson, C. (2012). Chapter 9 - Diencephalon. In C. Watson, G. Paxinos, \& L. Puelles (Eds.), The Mouse Nervous System (pp. 313-336). San Diego: Academic Press.

Qi, H. X., Gharbawie, O. A., Wong, P., \& Kaas, J. H. (2011). Cell-poor septa separate representations of digits in the ventroposterior nucleus of the thalamus in monkeys and prosimian Galagos. Journal of Comparative Neurology, 519(4), 738-758. doi:https://doi.org/10.1002/cne.22545

Qi, H. X., \& Kaas, J. H. (2006). Organization of primary afferent projections to the gracile nucleus of the dorsal column system of primates. Journal of Comparative Neurology, 499(2), 183-217. doi:https://doi.org/10.1002/cne.21061

Quy, P. N., Fujita, H., Sakamoto, Y., Na, J., \& Sugihara, I. (2011). Projection patterns of single mossy fiber axons originating from the dorsal column nuclei mapped on the aldolase $\mathrm{C}$ compartments in the rat cerebellar cortex. Journal of Comparative Neurology, 519(5), 874899. doi:https://doi.org/10.1002/cne.22555

Ramanathan, K. R., Ressler, R. L., Jin, J., \& Maren, S. (2018). Nucleus reuniens is required for encoding and retrieving precise, hippocampal-dependent contextual fear memories in rats. Journal of Neuroscience, 38(46), 9925-9933. doi:https://doi.org/10.1523/JNEUROSCI.1429-18.2018

Rasmusson, D. D. (1988). Projections of digit afferents to the cuneate nucleus in the raccoon before and after partial deafferentation. Journal of Comparative Neurology, 277(4), 549-556. doi:https://doi.org/10.1002/cne.902770408

Rasmusson, D. D. (1989). The projection pattern of forepaw nerves to the cuneate nucleus of the raccoon. Neuroscience Letters, 98(2), 129-134. doi:https://doi.org/10.1016/03043940(89)90497-7

Rees, H., \& Roberts, M. H. T. (1993). The anterior pretectal nucleus: a proposed role in sensory processing. Pain, 53(2), 121-135. doi:https://doi.org/10.1016/0304-3959(93)90072-W

Ricardo, J. A. (1981). Efferent connections of the subthalamic region in the rat. II. The zona incerta. Brain Research, 214(1), 43-60. doi:https://doi.org/10.1016/0006-8993(81)90437-6

Rinvik, E., \& Walberg, F. (1975). Studies on the cerebellar projections from the main and external cuneate nuclei in the cat by means of retrograde axonal transport of horseradish peroxidase. Brain Research, 95(2-3), 371-381. doi:https://doi.org/10.1016/0006-8993(75)90114-6

Robards, M. J. (1979). Somatic neurons in the brainstem and neocortex projecting to the external nucleus of the inferior colliculus: an anatomical study in the opossum. Journal of Comparative Neurology, 184(3), 547-565. doi:https://doi.org/10.1002/cne.901840308

Robards, M. J., Watkins, D. W., \& Masterton, R. B. (1976). An anatomical study of some somesthetic afferents to the intercollicular terminal zone of the midbrain of the opossum. Journal of Comparative Neurology, 170(4), 499-524. doi:https://doi.org/10.1002/cne.901700408

Robinson, F. R., Houk, J. C., \& Gibson, A. R. (1987). Limb specific connections of the cat magnocellular red nucleus. Journal of Comparative Neurology, 257(4), 553-577. doi:https://doi.org/10.1002/cne.902570406

Roda, J. M., \& Reinoso-Suárez, F. (1983). Topographical organization of the thalamic projections to the cortex of the anterior ectosylvian sulcus in the cat. Experimental Brain Research, 49(1), 131139. doi:https://doi.org/10.1007/BF00235548

Roger, M., \& Cadusseau, J. (1985). Afferents to the zona incerta in the rat: A combined retrograde and anterograde study. Journal of Comparative Neurology, 241(4), 480-492. doi:https://doi.org/10.1002/cne.902410407

Romanowski, C. A., Mitchell, I. J., \& Crossman, A. R. (1985). The organisation of the efferent projections of the zona incerta. Journal of Anatomy, 143, 75-95.

Rosén, I. (1969). Localization in caudal brain stem and cervical spinal cord of neurones activated from forelimb group I afferents in the cat. Brain Research, 16(1), 55-71. doi:https://doi.org/10.1016/0006-8993(69)90085-7

Rüegg, D. G., Séguin, J. J., \& Wiesendanger, M. (1977). Effects of electrical stimulation of somatosensory and motor areas of the cerebral cortex on neurones of the pontine nuclei in 
squirrel monkeys. Neuroscience, 2(6), 923-927. doi:https://doi.org/10.1016/03064522(77)90115-4

Rüegg, D. G., \& Wiesendanger, M. (1975). Corticofugal effects from sensorimotor area I and somatosensory area II on neurones of the pontine nuclei in the cat. The Journal of Physiology, 247(3), 745-757. doi:https://doi.org/10.1113/jphysiol.1975.sp010955

Rustioni, A. (1973). Non-primary afferents to the nucleus gracilis from the lumbar cord of the cat. Brain Research, 51, 81-95. doi:https://doi.org/10.1016/0006-8993(73)90366-1

Rustioni, A., \& Hayes, N. L. (1981). Corticospinal tract collaterals to the dorsal column nuclei of cats. Experimental Brain Research, 43(3-4), 237-245. doi:https://doi.org/10.1007/BF00238364

Rustioni, A., Hayes, N. L., \& O'Neill, S. (1979). Dorsal column nuclei and ascending spinal afferents in macaques. Brain, 102(1), 95-125. doi:https://doi.org/10.1093/brain/102.1.95

Rustioni, A., \& Kaufman, A. B. (1977). Identification of cells of origin of non-primary afferents to the dorsal column nuclei of the cat. Experimental Brain Research, 27(1), 1-14. doi:https://doi.org/10.1007/BF00234821

Rustioni, A., Schmechel, D. E., Cheema, S., \& Fitzpatrick, D. (1984). Glutamic acid decarboxylasecontaining neurons in the dorsal column nuclei of the cat. Somatosensory Research, 1(4), 329357. doi:https://doi.org/10.3109/07367228409144554

Sadjadpour, K., \& Brodal, A. (1968). The vestibular nuclei in man. A morphological study in the light of experimental findings in the cat. Journal fur Hirnforschung, 10(4), 299.

Sanders, K. H., \& Zimmermann, M. (1986). Mechanoreceptors in rat glabrous skin: redevelopment of function after nerve crush. Journal of Neurophysiology, 55(4), 644-659. doi:https://doi.org/10.1152/jn.1986.55.4.644

Sarko, D. K., Johnson, J. I., Switzer, R. C., Welker, W. I., \& Reep, R. L. (2007). Somatosensory nuclei of the manatee brainstem and thalamus. The Anatomical Record, 290(9), 1138-1165. doi:https://doi.org/10.1002/ar.20573

Sawyer, E. K., Turner, E. C., \& Kaas, J. H. (2016). Somatosensory brainstem, thalamus, and cortex of the California sea lion (Zalophus californianus). Journal of Comparative Neurology, 524(9), 1957-1975. doi:https://doi.org/10.1002/cne.23984

Schroeder, D. M., \& Jane, J. A. (1971). Projection of dorsal column nuclei and spinal cord to brainstem and thalamus in the tree shrew, Tupaia glis. Journal of Comparative Neurology, 142(3), 309350. doi:https://doi.org/10.1002/cne.901420305

Schroeder, D. M., \& Jane, J. A. (1976). The intercollicular area of the inferior colliculus. Brain, Behavior and Evolution, 13(2-3), 125-141. doi:https://doi.org/10.1159/000123805

Schwark, H. D., \& Ilyinsky, O. B. (2001). Inflammatory pain reduces correlated activity in the dorsal column nuclei. Brain Research, 889(1), 295-302. doi:https://doi.org/10.1016/S0006$\underline{\text { 8993(00)03137-1 }}$

Scott, J. J. A. (1990). Classification of muscle spindle afferents in the peroneus brevis muscle of the cat. Brain Research, 509(1), 62-70. doi:https://doi.org/10.1016/0006-8993(90)90309-Y

Serapide, M. F., Pantó, M. R., Parenti, R., Zappalá, A., \& Cicirata, F. (2001). Multiple zonal projections of the basilar pontine nuclei to the cerebellar cortex of the rat. Journal of Comparative Neurology, 430(4), 471-484. doi:https://doi.org/10.1002/10969861(20010219)430:4<471::Aid-cne1044>3.0.Co;2-g

Shambes, G. M., Gibson, J. M., \& Welker, W. (1978). Fractured Somatotopy in Granule Cell Tactile Areas of Rat Cerebellar Hemispheres Revealed by Micromapping; pp. 116-140. Brain, Behavior and Evolution, 15(2), 116-140. doi:https://doi.org/10.1159/000123775

Shammah-Lagnado, S. J., Negrão, N., \& Ricardo, J. A. (1985). Afferent connections of the zona incerta: A horseradish peroxidase study in the rat. Neuroscience, 15(1), 109-134. doi:https://doi.org/10.1016/0306-4522(85)90127-7

Smith, M. C., \& Deacon, P. (1984). Topographical anatomy of the posterior columns of the spinal cord in man: The long ascending fibres. Brain, 107(3), 671-698. doi:https://doi.org/10.1093/brain/107.3.671 
Somana, R., \& Walberg, F. (1980). A re-examination of the cerebellar projections from the gracile, main and external cuneate nuclei in the cat. Brain Research, 186(1), 33-42. doi:https://doi.org/10.1016/0006-8993(80)90253-X

Sotgiu, M. L., \& Margnelli, M. (1976). Electrophysiological identification of pontomedullary reticular neurons directly projecting into dorsal column nuclei. Brain Research, 103(3), 443-453. doi:https://doi.org/10.1016/0006-8993(76)90443-1

Sotgiu, M. L., \& Marini, G. (1977). Reticulo-cuneate projections as revealed by horseradish peroxidase axonal transport. Brain Research, 128(2), 341-345. doi:https://doi.org/10.1016/00068993(77)90999-4

Stein, B. E., Spencer, R. F., \& Edwards, S. B. (1983). Corticotectal and corticothalamic efferent projections of SIV somatosensory cortex in cat. Journal of Neurophysiology, 50(4), 896-909. doi:https://doi.org/10.1152/jn.1983.50.4.896

Stein, B. E., Stanford, T. R., \& Rowland, B. A. (2014). Development of multisensory integration from the perspective of the individual neuron. Nature Reviews Neuroscience, 15, 520. doi:https://doi.org/10.1038/nrn3742

Steriade, M., \& Llinás, R. R. (1988). The functional states of the thalamus and the associated neuronal interplay. Physiological Reviews, 649-742. doi:https://doi.org/10.1152/physrev.1988.68.3.649

Strata, F., Coq, J.-O., \& Kaas, J. (2003). The chemo-and somatotopic architecture of the Galago cuneate and gracile nuclei. Neuroscience, 116(3), 831-850. doi:https://doi.org/10.1016/S03064522(02)00694-2

Sun, W., \& May, P. J. (2014). Central pupillary light reflex circuits in the cat: I. The olivary pretectal nucleus. Journal of Comparative Neurology, 522(18), 3960-3977. doi:https://doi.org/10.1002/cne.23602

Supko, D. E., Uretsky, N. J., \& Wallace, L. J. (1991). Activation of AMPA/kainic acid glutamate receptors in the zona incerta stimulates locomotor activity. Brain Research, 564(1), 159-163. doi:https://doi.org/10.1016/0006-8993(91)91367-A

Swenson, R. S., Kosinski, R. J., \& Castro, A. J. (1984). Topography of spinal, dorsal column nuclear, and spinal trigeminal projections to the pontine gray in rats. Journal of Comparative Neurology, 222(2), 301-311. doi:https://doi.org/10.1002/cne.902220209

Tait, D. S., Phillips, J. M., Blackwell, A. D., \& Brown, V. J. (2017). Effects of lesions of the subthalamic nucleus/zona incerta area and dorsomedial striatum on attentional set-shifting in the rat. Neuroscience, 345, 287-296. doi:https://doi.org/10.1016/j.neuroscience.2016.08.008

Takakusaki, K., Chiba, R., Nozu, T., \& Okumura, T. (2016). Brainstem control of locomotion and muscle tone with special reference to the role of the mesopontine tegmentum and medullary reticulospinal systems. Journal of Neural Transmission, 123(7), 695-729. doi:https://doi.org/10.1007/s00702-015-1475-4

Tammer, R., Ehrenreich, L., \& Jürgens, U. (2004). Telemetrically recorded neuronal activity in the inferior colliculus and bordering tegmentum during vocal communication in squirrel monkeys (Saimiri sciureus). Behavioural Brain Research, 151(1), 331-336. doi:https://doi.org/10.1016/j.bbr.2003.09.008

Tawil, R. N., Saadé, N. E., Bitar, M., \& Jabbur, S. J. (1983). Polysensory interactions on single neurons of cat inferior colliculus. Brain Research, 269(1), 149-152. doi:https://doi.org/10.1016/00068993(83)90972-1

Therman, P. O. (1941). Transmission of impulses through the burdach nucleus. Journal of Neurophysiology, 4(2), 153-166. doi:https://doi.org/10.1152/jn.1941.4.2.153

Uddenberg, N. (1968). Functional organization of long, second-order afferents in the dorsal funiculus. Experimental Brain Research, 4(4), 377-382. doi:https://doi.org/10.1007/BF00235702

Valverde, F. (1966). The pyramidal tract in rodents. A study of its relations with the posterior column nuclei, dorsolateral reticular formation of the medulla oblongata, and cervical spinal cord. 
Zeitschrift für Zellforschung und Mikroskopische Anatomie, 71(3), 297-363. doi:https://doi.org/10.1007/bf00332585

Villanueva, L., Bernard, J. F., \& Le Bars, D. (1995). Distribution of spinal cord projections from the medullary subnucleus reticularis dorsalis and the adjacent cuneate nucleus: A phaseolus vulgaris- leucoagglutinin study in the rat. Journal of Comparative Neurology, 352(1), 11-32. doi:https://doi.org/10.1002/cne.903520103

Villanueva, L., Desbois, C., le Bars, D., \& Bernard, J. F. (1998). Organization of diencephalic projections from the medullary subnucleus reticularis dorsalis and the adjacent cuneate nucleus: a retrograde and anterograde tracer study in the rat. Journal of Comparative Neurology, 390(1), 133-160. doi:https://doi.org/10.1002/(SICI)1096-9861(19980105)390:1<133::AIDCNE11>3.0.CO;2-Y

Villarreal, C. F., Del Bel, E. A., \& Prado, W. A. (2003). Involvement of the anterior pretectal nucleus in the control of persistent pain: a behavioral and c-Fos expression study in the rat. PAIN ${ }^{\circledR}$, 103(1), 163-174. doi:https://doi.org/10.1016/S0304-3959(02)00449-9

Villarreal, C. F., \& Prado, W. A. (2007). Modulation of persistent nociceptive inputs in the anterior pretectal nucleus of the rat. Pain, 132(1), 42-52. doi:https://doi.org/10.1016/j.pain.2007.01.021

Walberg, F., Nordby, T., Hoffmann, K. P., \& Holländer, H. (1981). Olivary afferents from the pretectal nuclei in the cat. Anatomy and Embryology, 161(3), 291-304. doi:https://doi.org/10.1007/bf00301827

Wang, C.-C., \& Westlund, K. N. (2001). Responses of rat dorsal column neurons to pancreatic nociceptive stimulation. NeuroReport, 12(11), 2527-2530.

Watson, C. (2012). Chapter 12 - Hindbrain. In C. Watson, G. Paxinos, \& L. Puelles (Eds.), The Mouse Nervous System (pp. 398-423). San Diego: Academic Press.

Weber, J. T., \& Harting, J. K. (1980). The efferent projections of the pretectal complex: an autoradiographic and horseradish peroxidase analysis. Brain Research, 194(1), 1-28. doi:https://doi.org/10.1016/0006-8993(80)91315-3

Wei, J. Y., Kripke, B. R., \& Burgess, P. (1986). Classification of muscle spindle receptors. Brain Research, 370(1), 119-126. doi:https://doi.org/10.1016/0006-8993(86)91111-X

Weinberg, R. J., \& Rustioni, A. (1987). A cuneocochlear pathway in the rat. Neuroscience, 20(1), 209219. doi:https://doi.org/10.1016/0306-4522(87)90013-3

Weinberg, R. J., \& Rustioni, A. (1989). Brainstem projections to the rat cuneate nucleus. Journal of Comparative Neurology, 282(1), 142-156. doi:https://doi.org/10.1002/cne.902820111

Weiss, C., Houk, J. C., \& Gibson, A. R. (1990). Inhibition of sensory responses of cat inferior olive neurons produced by stimulation of red nucleus. Journal of Neurophysiology, 64(4), 11701185. doi:https://doi.org/10.1152/jn.1990.64.4.1170

Whitsel, B. L., Petrucelli, L. M., \& Sapiro, G. (1969). Modality representation in the lumbar and cervical fasciculus gracilis of squirrel monkeys. Brain Research, 15(1), 67-78. doi:https://doi.org/10.1016/0006-8993(69)90310-2

Whitsel, B. L., Petrucelli, L. M., Sapiro, G., \& Ha, H. (1970). Fiber sorting in the fasciculus gracilis of squirrel monkeys. Experimental Neurology, 29(2), 227-242. doi:https://doi.org/10.1016/0014-4886(70)90054-3

Wiberg, M., \& Blomqvist, A. (1984a). The projection to the mesencephalon from the dorsal column nuclei. An anatomical study in the cat. Brain Research, 311(2), 225-244. doi:https://doi.org/10.1016/0006-8993(84)90086-6

Wiberg, M., \& Blomqvist, A. (1984b). The spinomesencephalic tract in the cat: Its cells of origin and termination pattern as demonstrated by the intraaxonal transport method. Brain Research, 291(1), 1-18. doi:https://doi.org/10.1016/0006-8993(84)90645-0

Wiberg, M., Westman, J., \& Blomqvist, A. (1986). The projection to the mesencephalon from the sensory trigeminal nuclei. An anatomical study in the cat. Brain Research, 399(1), 51-68. doi:https://doi.org/10.1016/0006-8993(86)90600-1 
Wiberg, M., Westman, J., \& Blomqvist, A. (1987). Somatosensory projection to the mesencephalon: An anatomical study in the monkey. Journal of Comparative Neurology, 264(1), 92-117. doi:https://doi.org/10.1002/cne.902640108

Willcockson, H. H., Carlton, S. M., \& Willis, W. D. (1987). Mapping study of serotoninergic input to diencephalic-projecting dorsal column neurons in the rat. Journal of Comparative Neurology, 261(4), 467-480. doi:https://doi.org/10.1002/cne.902610402

Winer, J. A., \& Schreiner, C. E. (2005). The central auditory system: A functional analysis. In J. A. Winer \& C. E. Schreiner (Eds.), The Inferior Colliculus (pp. 1-68). New York, NY: Springer New York.

Witham, C. L., \& Baker, S. N. (2011). Modulation and transmission of peripheral inputs in monkey cuneate and external cuneate nuclei. Journal of Neurophysiology, 106, 2764-2775.

Wong-Riley, M. T. (1989). Cytochrome oxidase: an endogenous metabolic marker for neuronal activity. Trends in Neurosciences, 12(3), 94-101. doi:https://doi.org/10.1016/0166-2236(89)90165-3

Woudenberg, R. A. (1970). Projections of mechanoreceptive fields to cuneate-gracile and spinal trigeminal nuclear regions in sheep. Brain Research, 17(3), 417-437. doi:https://doi.org/10.1016/0006-8993(70)90250-7

Wree, A., Itzev, D. E., Schmitt, O., \& Usunoff, K. G. (2005). Neurons in the dorsal column nuclei of the rat emit a moderate projection to the ipsilateral ventrobasal thalamus. Anatomy and Embryology, 210(3), 155-162. doi:https://doi.org/10.1007/s00429-005-0012-x

Wu, H.-S., Sugihara, I., \& Shinoda, Y. (1999). Projection patterns of single mossy fibers originating from the lateral reticular nucleus in the rat cerebellar cortex and nuclei. Journal of Comparative Neurology, 411(1), 97-118. doi:https://doi.org/10.1002/(sici)10969861(19990816)411:1<97::Aid-cne8>3.0.Co;2-o

Xu, J., \& Wall, J. (1996). Cutaneous representations of the hand and other body parts in the cuneate nucleus of a primate, and some relationships to previously described cortical representations. Somatosensory \& Motor Research, 13(3-4), 187-197. doi:https://doi.org/10.3109/08990229609052575

Xu, J., \& Wall, J. (1999). Functional organization of tactile inputs from the hand in the cuneate nucleus and its relationship to organization in the somatosensory cortex. Journal of Comparative Neurology, 411(3), 369-389. doi:https://doi.org/10.1002/(SICI)10969861(19990830)411:3<369::AID-CNE2>3.0.CO;2-F

Yamada, J., Shirao, K., Kitamura, T., \& Sato, H. (1991). Trajectory of spinocerebellar fibers passing through the inferior and superior cerebellar peduncles in the rat spinal cord: A study using horseradish peroxidase with pedunculotomy. Journal of Comparative Neurology, 304(1), 147160. doi:https://doi.org/10.1002/cne.903040111

Yáñez, J., Suárez, T., Quelle, A., Folgueira, M., \& Anadón, R. (2018). Neural connections of the pretectum in zebrafish (Danio rerio). Journal of Comparative Neurology, 526(6), 1017-1040. doi:https://doi.org/10.1002/cne.24388

Zhang, X., \& van den Pol, A. N. (2017). Rapid binge-like eating and body weight gain driven by zona incerta GABA neuron activation. Science, 356(6340), 853-859. doi:https://doi.org/10.1126/science.aam7100

Zhao, F., Welsh, D., Williams, M., Coimbra, A., Urban, M. O., Hargreaves, R., . . Williams, D. S. (2012). fMRI of pain processing in the brain: A within-animal comparative study of BOLD vs. CBV and noxious electrical vs. noxious mechanical stimulation in rat. Neurolmage, 59(2), 1168-1179. doi:https://doi.org/10.1016/i.neuroimage.2011.08.002

Zhao, Z. D., Chen, Z., Xiang, X., Hu, M., Xie, H., Jia, X., ... Shen, W. L. (2019). Zona incerta GABAergic neurons integrate prey-related sensory signals and induce an appetitive drive to promote hunting. Nature Neuroscience, 22(6), 921-932. doi:https://doi.org/10.1038/s41593-019-0404$\underline{5}$

Zhou, J., \& Shore, S. (2006). Convergence of spinal trigeminal and cochlear nucleus projections in the inferior colliculus of the guinea pig. Journal of Comparative Neurology, 495(1), 100-112. doi:https://doi.org/10.1002/cne.20863 
Zimmerman, A., Bai, L., \& Ginty, D. D. (2014). The gentle touch receptors of mammalian skin. Science, 346(6212), 950-954. doi:https://doi.org/10.1126/science.1254229 


\section{Figures and legends}

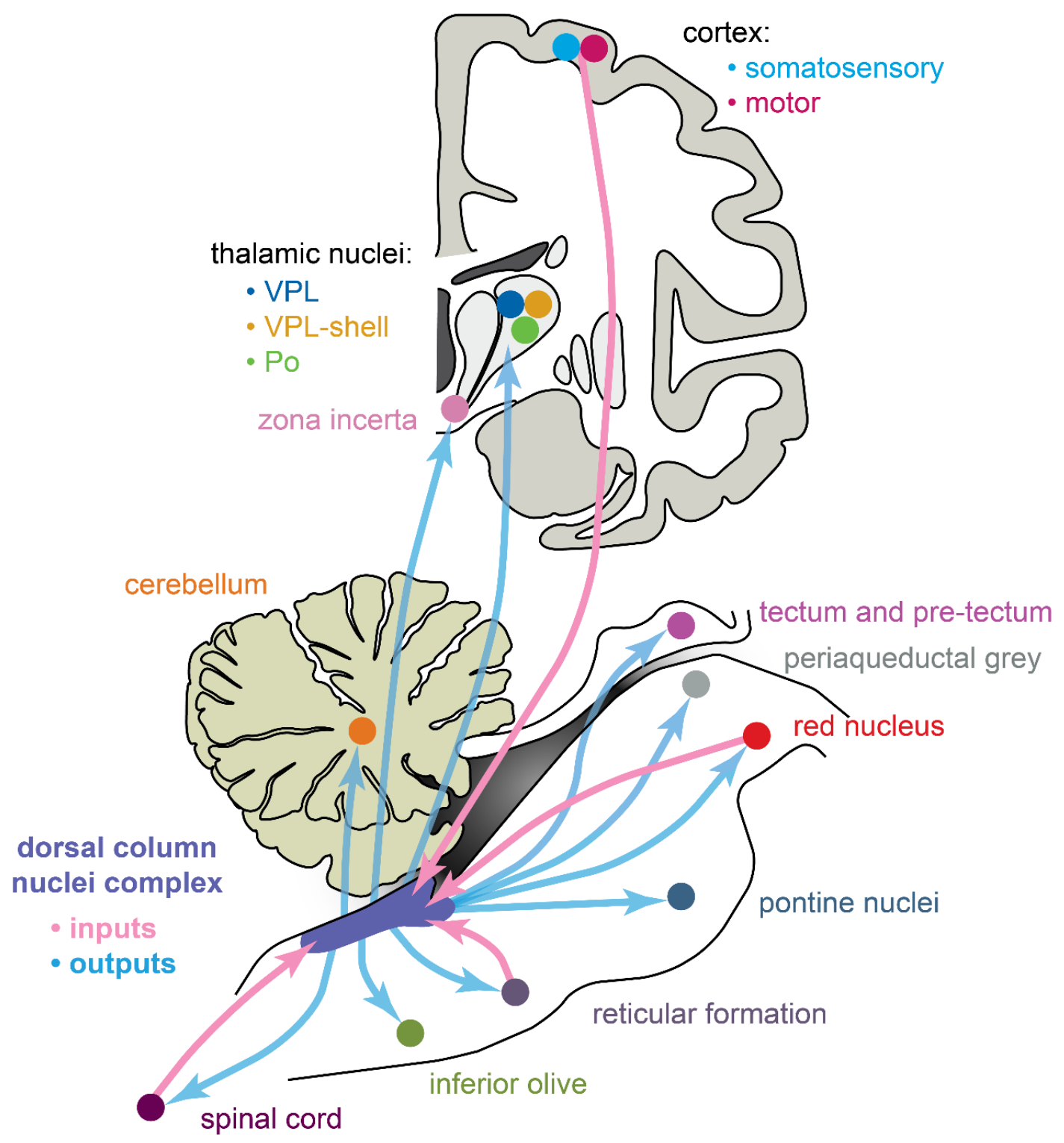

Graphical Abstract: The dorsal column nuclei complex (DCN-complex) includes the dorsal column nuclei (DCN, referring to the gracile and cuneate nuclei collectively), external cuneate, $\mathrm{X}$, and $\mathrm{Z}$ nuclei, and the median accessory nucleus. The DCN are organised by both somatotopy and modality, and have a diverse range of afferent inputs and projection targets. The functional organisation and connectivity of the DCN implicate them in a variety of sensorimotor functions, beyond their commonly accepted role in processing and transmitting somatosensory information to the thalamus, yet this is largely underappreciated in the literature. To improve our understanding of their sensorimotor functions, this review examines the morphology, organisation, and connectivity of the DCN and their associated nuclei. First, we briefly discuss the receptors, afferent fibres, and pathways involved in conveying tactile and proprioceptive information to the DCN. Next, we review the modality and somatotopic arrangements of the remaining constituents of the DCN-complex. Finally, we examine and discuss the functional implications of the myriad of DCNcomplex projection targets throughout the diencephalon, midbrain, and hindbrain, in addition to their modulatory inputs from the cortex. The organisation and connectivity of the DCN-complex suggest that these nuclei should be considered a complex integration and distribution hub for sensorimotor information. 
A

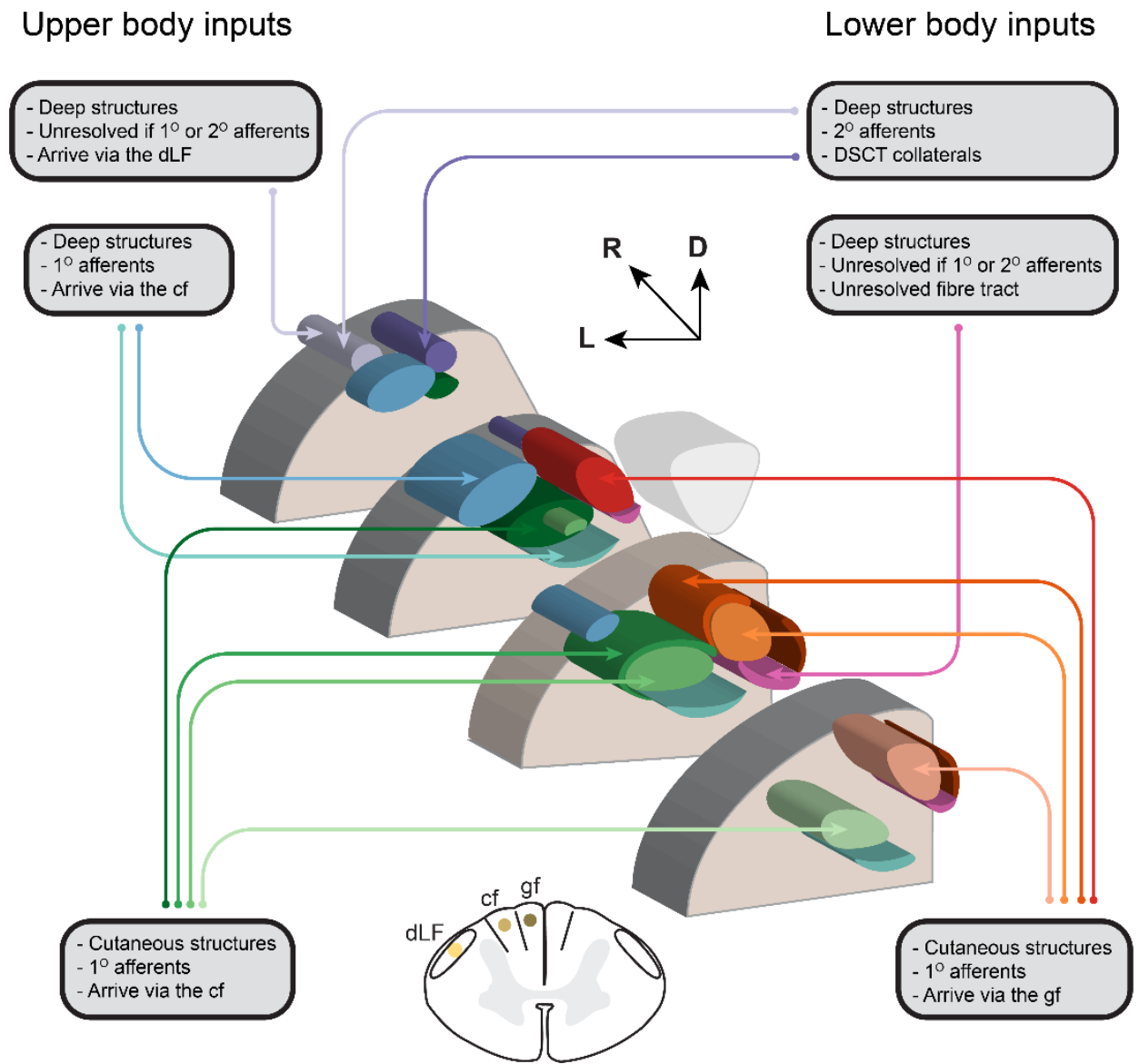

B
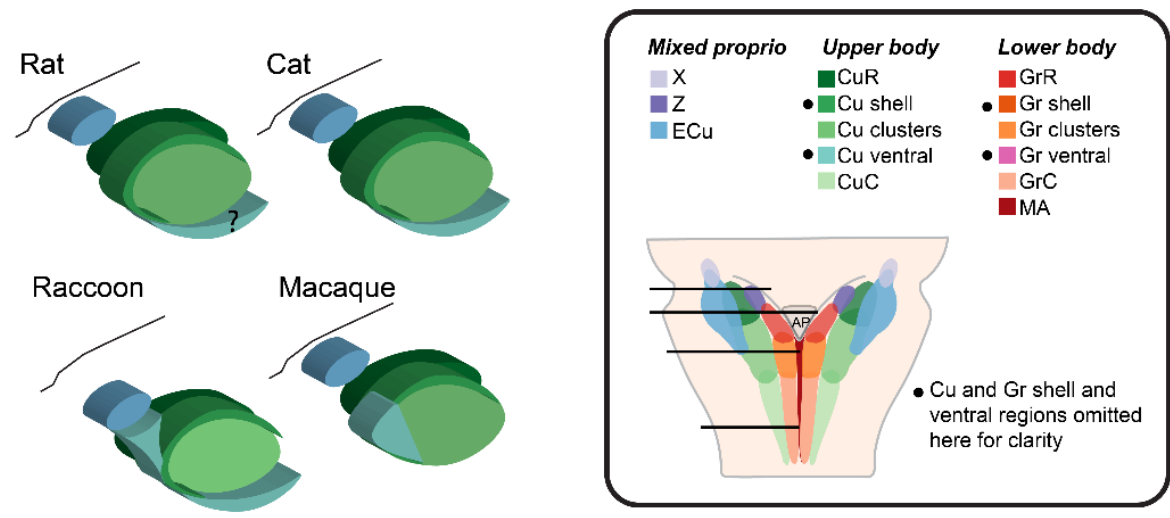

Figure 1. The organisation of the dorsal column nuclei-complex and their ascending afferent inputs. (A) A schematic representation of the dorsal medulla (left side only) shows the DCN-complex across four rostro-caudal levels. Arrows indicate ascending inputs from spinal cord or dorsal root ganglia neurons to each sub-region of the complex (colour coded according to the figure key). Grey boxes describe body regions and fibre tracts of the ascending afferents. All ascending afferents have receptive fields ipsilateral to their DCN-complex targets. Schematic of a spinal cord cross section illustrates the location of afferent fibre tracts. Orientations indicated: D, dorsal; L, lateral; R, rostral. (B) Species differences of the $\mathrm{Cu}$ ventral region is shown. $\mathrm{Cu}$ ventral appears to extend throughout the rostrocaudal zones in all four species, but changes shape for some species in the middle DCN. This region is defined by a more reticulated appearance which is unclear in rats, however like other species, receives predominantly proprioceptive inputs. In cats, $\mathrm{Cu}$ ventral is found at the base of the $\mathrm{Cu}$. Raccoons have a 'bridge' region of proprioceptiverecipient cells extending from the ECN to the ventral portion of CuM and CuR. Macaques and other 
primates have a triangular-shaped zone at the lateral edge of the $\mathrm{CuM}$ and $\mathrm{CuR}$, named pars triangularis. Pars triangularis is depicted within the CuM, but in more rostral segments (not shown) where the ECu is larger, this region would fill the space between the lateral portion of the $\mathrm{Cu}$ and the ventral medial portion of the $\mathrm{ECu}$. Insert: Schematic representation of the DCN-complex in the medulla viewed from the dorsal aspect (rostral orientated upward). Translucent shading demonstrates the overlap and dorso-ventral arrangements of nuclei. Obex is located at the caudal end of the fourth ventricle, where the GrR sit more laterally to either side of AP. Horizontal black lines indicate brainstem sections shown in A. Abbreviations: AP, area postrema; $\mathrm{CuC}$, caudal cuneate nuclei; $\mathrm{Cu}$ clusters, cluster regions of the middle cuneate nuclei; cf, cuneate fasciculus; $\mathrm{Cu}$ shell, shell region of the middle cuneate nuclei; $\mathrm{Cu}$ ventral, ventral region of the cuneate nuclei; CuR, rostral cuneate nuclei; DCN, dorsal column nuclei; dLF, dorsal aspect of the lateral funiculus; DSCT, dorsal spinocerebellar tract; ECu, external cuneate nuclei; GrC, caudal gracile nuclei; Gr clusters, cluster regions of the middle gracile nuclei; gf, gracile fasciculus; Gr shell, shell region of the middle gracile nuclei; Gr ventral, ventral region of the gracile nuclei; GrR, rostral gracile nuclei; X, nucleus X; Z, nucleus Z. 
Table 1. Morphology and neural characteristics of the dorsal column nuclei rostrocaudal zones. DCN neurons receive convergent inputs from multiple FA and or SA afferents. Therefore, 'FA' and 'SA' in this table does not necessarily correspond to the stereotyped response properties of peripheral afferents, as there could be differences in how each study interpreted FA and SA responses. Abbreviations: FA, fastadapting; SA, slowly-adapting; see Figure 1 for remaining abbreviations.

\begin{tabular}{|c|c|c|c|c|c|}
\hline & & General description & Cell types/sizes & Response properties & Receptive fields \\
\hline \multirow{2}{*}{ Rostral } & Gr & \multirow{2}{*}{$\begin{array}{l}\text { Appears reticulated } \\
\text { and less dense than } \\
\text { middle DCN }\end{array}$} & \multirow{2}{*}{$\begin{array}{l}\text { Mixed cell sizes } \\
\text { Many large cells }\end{array}$} & $\begin{array}{l}\text { Mostly FA, driven by } \\
\text { a mixture of deep and } \\
\text { cutaneous inputs }\end{array}$ & \multirow{2}{*}{$\begin{array}{l}\text { Mostly large } \\
\text { Dominated by } \\
\text { representation of } \\
\text { proximal and } \\
\text { axial body parts }\end{array}$} \\
\hline & $\mathrm{Cu}$ & & & $\begin{array}{l}\text { Mostly SA, driven by } \\
\text { deep inputs }\end{array}$ & \\
\hline \multirow{2}{*}{ Clusters } & $\mathrm{Gr}$ & $\begin{array}{l}\text { Dense cell clusters, } \\
\text { surrounded by cell- } \\
\text { poor septa } \\
\text { Less defined than in } \\
\text { the } \mathrm{Cu}\end{array}$ & \multirow{2}{*}{$\begin{array}{l}\text { Small or medium } \\
\text { round cells with } \\
\text { dense bushy } \\
\text { dendritic arbours }\end{array}$} & $\begin{array}{c}\text { Mostly FA cutaneous } \\
\text { with some SA } \\
\text { cutaneous responses }\end{array}$ & \multirow{2}{*}{$\begin{array}{l}\text { Mostly very } \\
\text { small } \\
\text { Dominated by } \\
\text { representation of } \\
\text { distal limbs }\end{array}$} \\
\hline & $\mathrm{Cu}$ & $\begin{array}{l}\text { Dense cell clusters, } \\
\text { surrounded by cell- } \\
\text { poor septa } \\
\text { More defined than in } \\
\text { the Gr }\end{array}$ & & $\begin{array}{l}\text { Mostly SA cutaneous } \\
\text { with some FA } \\
\text { cutaneous responses }\end{array}$ & \\
\hline \multirow{2}{*}{ Shell } & Gr & \multirow{2}{*}{$\begin{array}{l}\text { Thin reticulated shell } \\
\text { surrounding the } \\
\text { clusters region on } \\
\text { the medial, dorsal, } \\
\text { and lateral sides }\end{array}$} & \multirow{2}{*}{$\begin{array}{l}\text { Small or medium } \\
\text { round cells, some } \\
\text { spindle cells }\end{array}$} & $\begin{array}{c}\text { Mostly FA cutaneous } \\
\text { with some SA } \\
\text { cutaneous responses }\end{array}$ & \multirow{2}{*}{$\begin{array}{l}\text { Larger than } \\
\text { cluster region } \\
\text { cells } \\
\text { Dominated by } \\
\text { representation of } \\
\text { proximal and } \\
\text { axial body parts }\end{array}$} \\
\hline & $\mathrm{Cu}$ & & & $\begin{array}{l}\text { Mostly SA cutaneous } \\
\text { with some FA } \\
\text { cutaneous responses }\end{array}$ & \\
\hline \multirow[t]{2}{*}{ Ventral } & Gr & $\begin{array}{c}\text { Reticulated } \\
\text { appearance, no } \\
\text { obvious clustering }\end{array}$ & \multirow{2}{*}{$\begin{array}{l}\text { Small or medium } \\
\text { round cells, some } \\
\text { spindle cells, and } \\
\text { cells with large } \\
\text { radiating dendritic } \\
\text { arbours }\end{array}$} & $\begin{array}{l}\text { Mostly FA with some } \\
\text { SA responses, mostly } \\
\text { driven by } \\
\text { proprioceptive inputs, } \\
\text { although there are } \\
\text { fewer proprioceptive } \\
\text { inputs than in Cu } \\
\text { ventral }\end{array}$ & \multirow{2}{*}{$\begin{array}{l}\text { Larger than } \\
\text { cluster region } \\
\text { cells } \\
\text { Mostly from } \\
\text { more proximal } \\
\text { body regions. }\end{array}$} \\
\hline & $\mathrm{Cu}$ & $\begin{array}{c}\text { Ventral and lateral to } \\
\text { the cluster region, no } \\
\text { obvious clustering }\end{array}$ & & $\begin{array}{l}\text { Mostly SA with some } \\
\text { FA responses, mostly } \\
\text { driven by } \\
\text { proprioceptive inputs }\end{array}$ & \\
\hline \multirow{2}{*}{ Caudal } & Gr & \multirow{2}{*}{$\begin{array}{l}\text { Appears less dense } \\
\text { than middle DCN } \\
\text { with relatively } \\
\text { uniform cell } \\
\text { dispersion }\end{array}$} & \multirow{2}{*}{$\begin{array}{l}\text { Medium and large, } \\
\text { round cells, } \\
\text { scattered multipolar } \\
\text { and spindle cell } \\
\text { bodies }\end{array}$} & $\begin{array}{l}\text { Mostly cutaneous FA } \\
\text { responses } \\
\text { Higher proportion of } \\
\text { Pacinian-like (FA2) } \\
\text { responses }\end{array}$ & \multirow{2}{*}{$\begin{array}{l}\text { Mostly very large } \\
\text { Relatively even } \\
\text { representation of } \\
\text { the body }\end{array}$} \\
\hline & $\mathrm{Cu}$ & & & $\begin{array}{l}\text { Mostly cutaneous SA } \\
\text { responses } \\
\text { Higher proportion of } \\
\text { Pacinian-like (FA2) } \\
\text { responses }\end{array}$ & \\
\hline
\end{tabular}




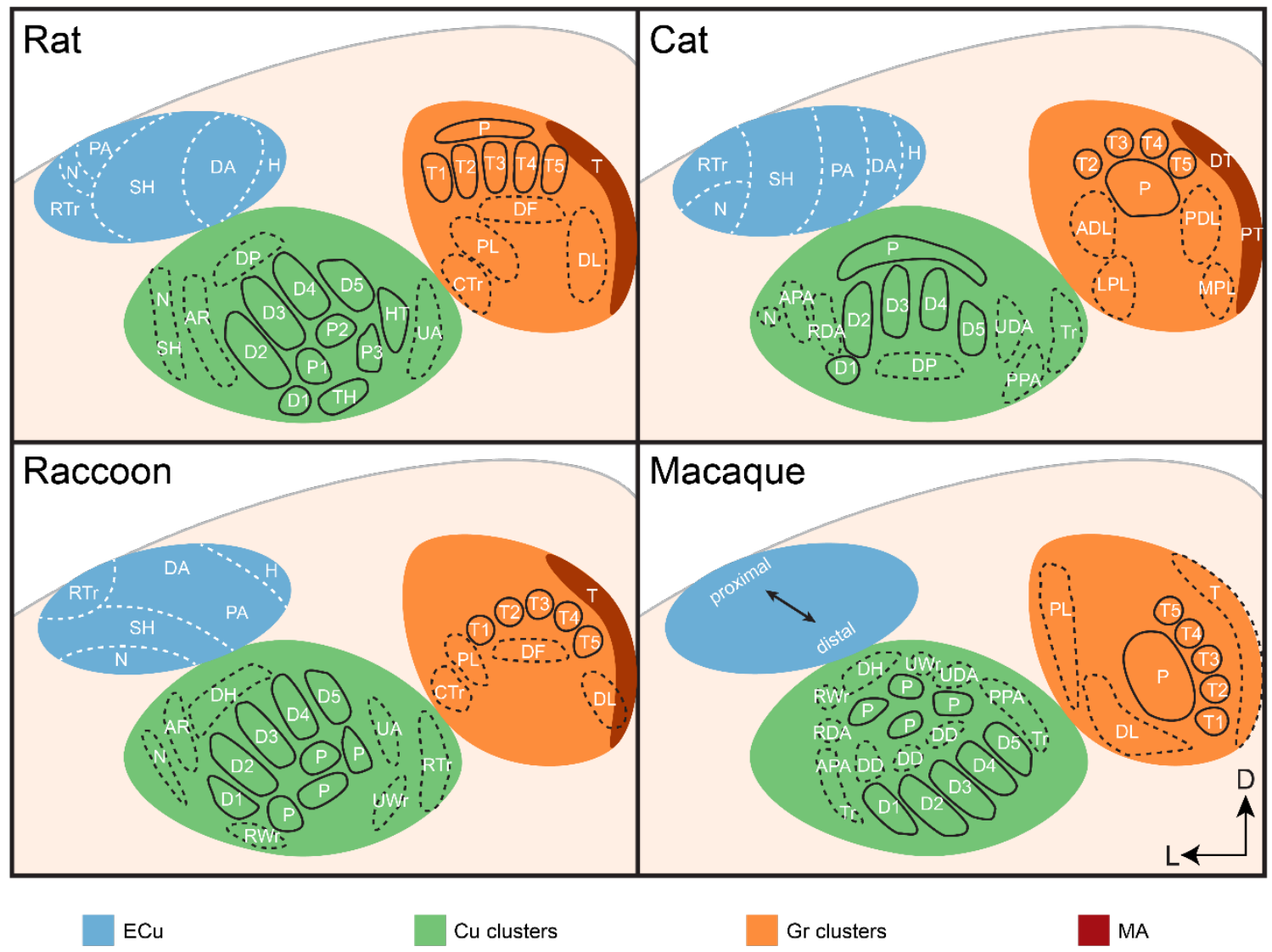

\begin{tabular}{|c|c|c|c|c|c|}
\hline ADL & anterior distal leg & $\mathrm{H}$ & hand & RDA & radial distal arm \\
\hline APA & anterior proximal arm & HT & hypothenar pad & $\mathrm{RTr}$ & rostral trunk \\
\hline AR & radial arm & LPL & lateral proximal leg & RWr & radial wrist \\
\hline $\mathrm{CTr}$ & caudal trunk & MPL & medial proximal leg & $\mathrm{SH}$ & shoulder \\
\hline D1-D5 & digits $1-5$ & $\mathrm{~N}$ & neck & $\mathrm{T}$ & tail \\
\hline DA & distal arm & $\mathrm{P}$ & palm & $\mathrm{T} 1-\mathrm{T} 5$ & toes $1-5$ \\
\hline DD & dorsal digits & P1-P3 & palmar pad 1-3 & $\mathrm{TH}$ & thenar pad \\
\hline DF & dorsal foot & PDL & posterior distal leg & $\operatorname{Tr}$ & trunk \\
\hline $\mathrm{DH}$ & dorsal hand & PA & proximal arm & UA & ulnar arm \\
\hline DL & distal leg & $\mathrm{PL}$ & proximal leg & UDA & ulnar distal arm \\
\hline DP & dorsal paw & PPA & posterior proximal arm & UWr & ulnar wrist \\
\hline DT & distal tail & PT & proximal tail & & \\
\hline
\end{tabular}

Figure 2. Somatotopy of DCN middle regions and the ECu of four commonly studied mammalian species. Comparison of rat, cat, raccoon, and macaque somatotopy of the DCN middle region, and the $\mathrm{ECu}$ reveals similarities and differences among species. Solid lines indicate representations of known or suggested clustering patterns, best revealed through $\mathrm{CO}$ reactivity, whereas dashed lines indicate cluster regions with poorly defined boundaries. Groups of afferents from different body regions, particularly the glabrous skin of the digits/toes and palmar/plantar pads, terminate on individual CO-dense clusters of the DCN, like those indicated by solid lines. Afferents from other body regions, particularly the lower body and trunk, may terminate in several CO-dense clusters, or in more nebulous CO-dense regions, like those 
indicated by dashed lines. A single CO-dense cluster may receive afferents from several different body regions, but this is unlikely in digit-associated clusters. Rats, raccoons, and macaques (and other primates) all show a characteristic crescent-shaped digit arrangement, with the palmar pads on the concave side of the crescent. Contrastingly, cats show a straighter digit arrangement, with the pad represented on the more convex side. The macaque hand representation is flipped upside-down compared to rats and raccoons, which appears to be different, even to other nonhuman primates, but may be similar in humans. For convenience, the ECu is shown at its largest cross-sectional area to display the somatotopy. However, the largest cross-sectional area would normally be found in more rostral locations compared to the middle DCN (see Figure 1). The ECu does not show clustering, and location mapping is poorly defined compared to the $\mathrm{Cu}$ and $\mathrm{Gr}$ (indicated by white dashed lines). ECu somatotopy in different species generally shows a medial to lateral progression of distal to proximal body regions. The macaque ECu map has not been well characterised but has been described to have distal body parts ventrally and medially, and proximal body parts dorsally and laterally. The table below the DCN maps contains abbreviations from the maps. Orientations indicated: L, lateral; D, dorsal. Abbreviations: CO, cytochrome oxidase. See Figure 1 legend for all other abbreviations. 

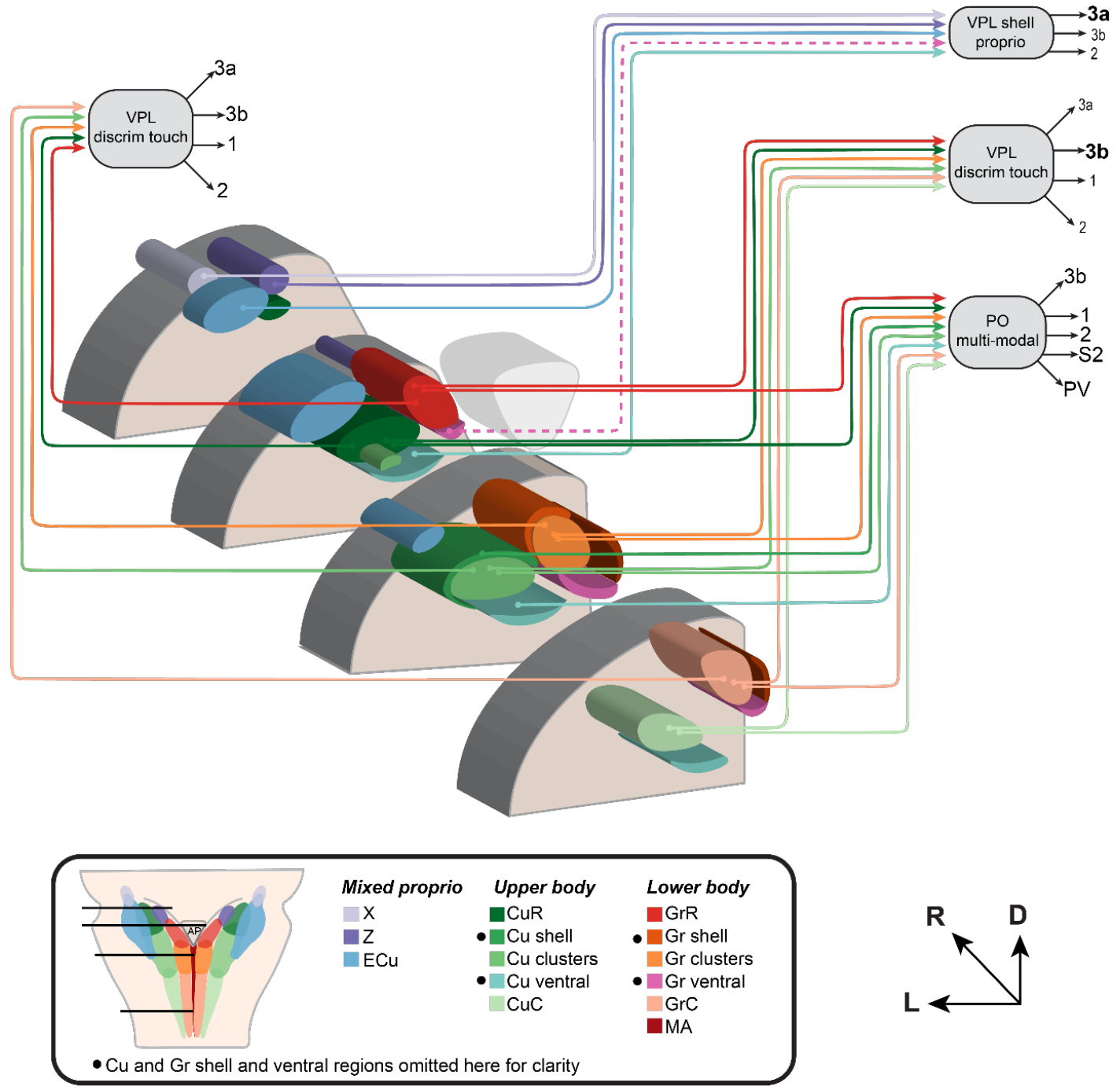

Figure 3. Thalamic targets of dorsal column nuclei-complex projections. The DCN-complex neurons projecting to the thalamus make up the cortical system, which is considered the dominant DCN output system. The arrows indicate projections from the DCN-complex to thalamic targets. Dashed line indicates a suggested, but unconfirmed connection. For clarity, arrows are shown for only one rostro-caudal level but represent the entire rostro-caudal extent of each respective region. The first cortical subsystem involves the VPL, which receives the most DCN projections and conveys discriminative touch information to cortical areas 3a, 3b, 1, and 2. The VPL receives almost all its inputs from the DCN clusters regions, with some input from rostral and caudal zones. The second cortical subsystem involves the VPL shell region that is the main target of the $\mathrm{DCN}$-complex that convey proprioceptive information to cortical areas $3 \mathrm{a}, 3 \mathrm{~b}$, and 2. Most of the VPL shell inputs originate from neurons in the ECu, ventral DCN, and X and $Z$. The third cortical subsystem involves thalamic Po, which receives multimodal inputs from most of the DCN, except the ventral zone, and projects to areas 3b, 1, 2, S2, and PV. Almost all thalamic projections from the DCN-complex are contralateral, except for a minor projection to the ipsilateral VPL, which originates from neurons in $\mathrm{CuR}$ and $\mathrm{Cu}$ clusters, and all $\mathrm{Gr}$ zones. The dominant cortical target of each subsystem is in bold. Orientations indicated: L, lateral; D, dorsal; R, rostral. Abbreviations: Po, posterior group of the thalamus; PV, the parietal ventral area; S2, secondary somatosensory cortex; VPL, ventroposterior lateral nucleus of the thalamus; VPL shell, the anterior shell surrounding the ventroposterior lateral nucleus of the thalamus. See Figure 1 legend for all other abbreviations, orientations and description of the insert. 

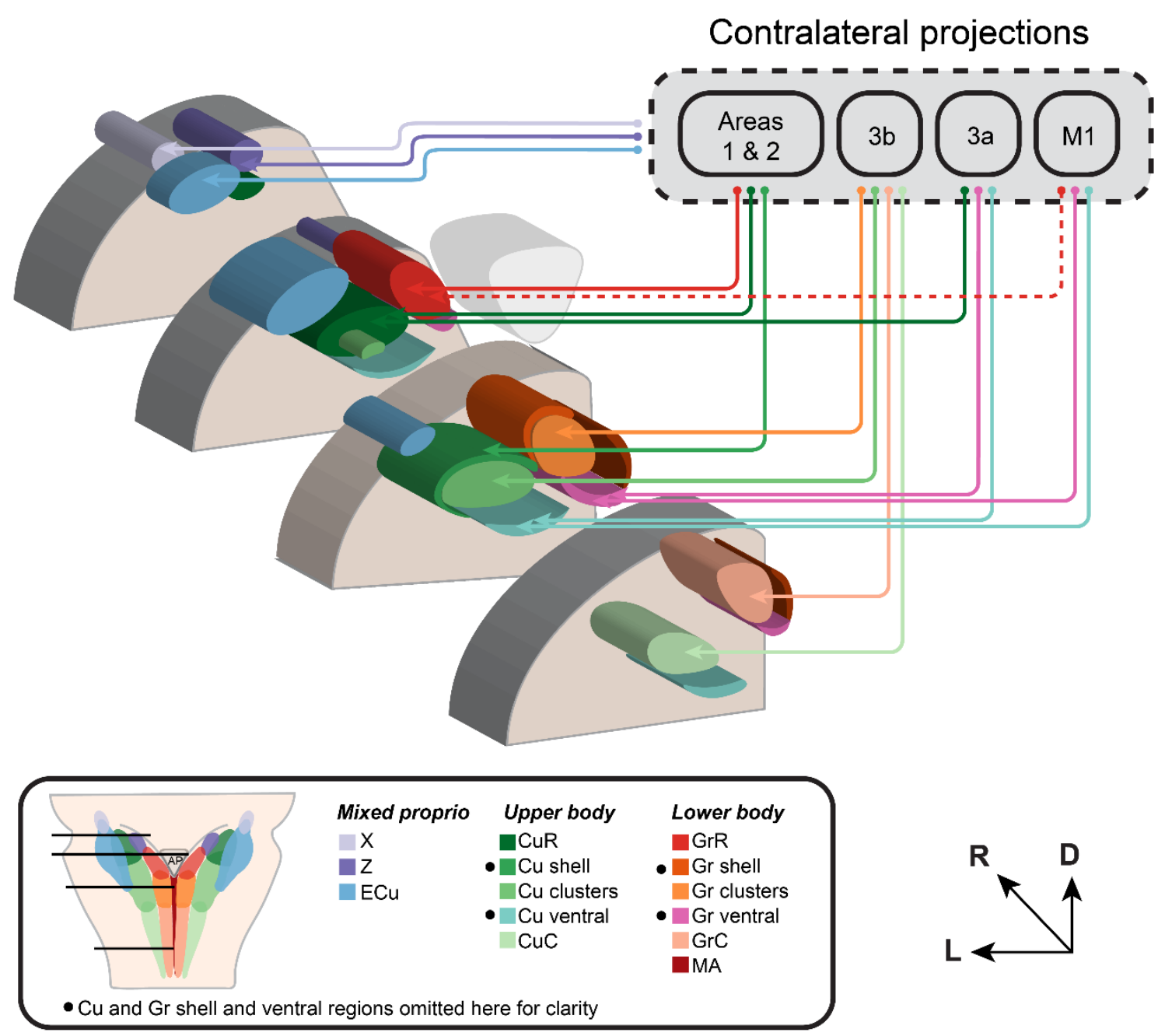

Figure 4. Sensorimotor cortical inputs to the dorsal column nuclei-complex. In addition to receiving peripheral and spinal ascending afferents, the DCN-complex also receives inputs from the sensorimotor cortex. Arrows indicate cortical inputs to DCN regions, for clarity, arrows are shown for only one rostrocaudal level but represent the entire rostro-caudal extent of each respective region. Red-dashed line indicates a suggested but unconfirmed connection. DCN regions that predominantly receive ascending cutaneous inputs, including the DCN clusters and caudal regions, receive corticofugal projections from area $3 \mathrm{~b}$. Regions that predominantly receive proprioceptive-related ascending inputs, including ventral and rostral DCN, receive corticofugal projections from areas $3 \mathrm{a}$ and 4 (M1). ECu, X, and Z all receive some inputs from the sensorimotor cortex but the specific cortical regions have not been defined (indicated by the grey box with a dashed line border). See Figure 1 legend for all other abbreviations, orientations and description of the insert. 


\section{Ipsilateral projections}

\section{Contralateral projections}
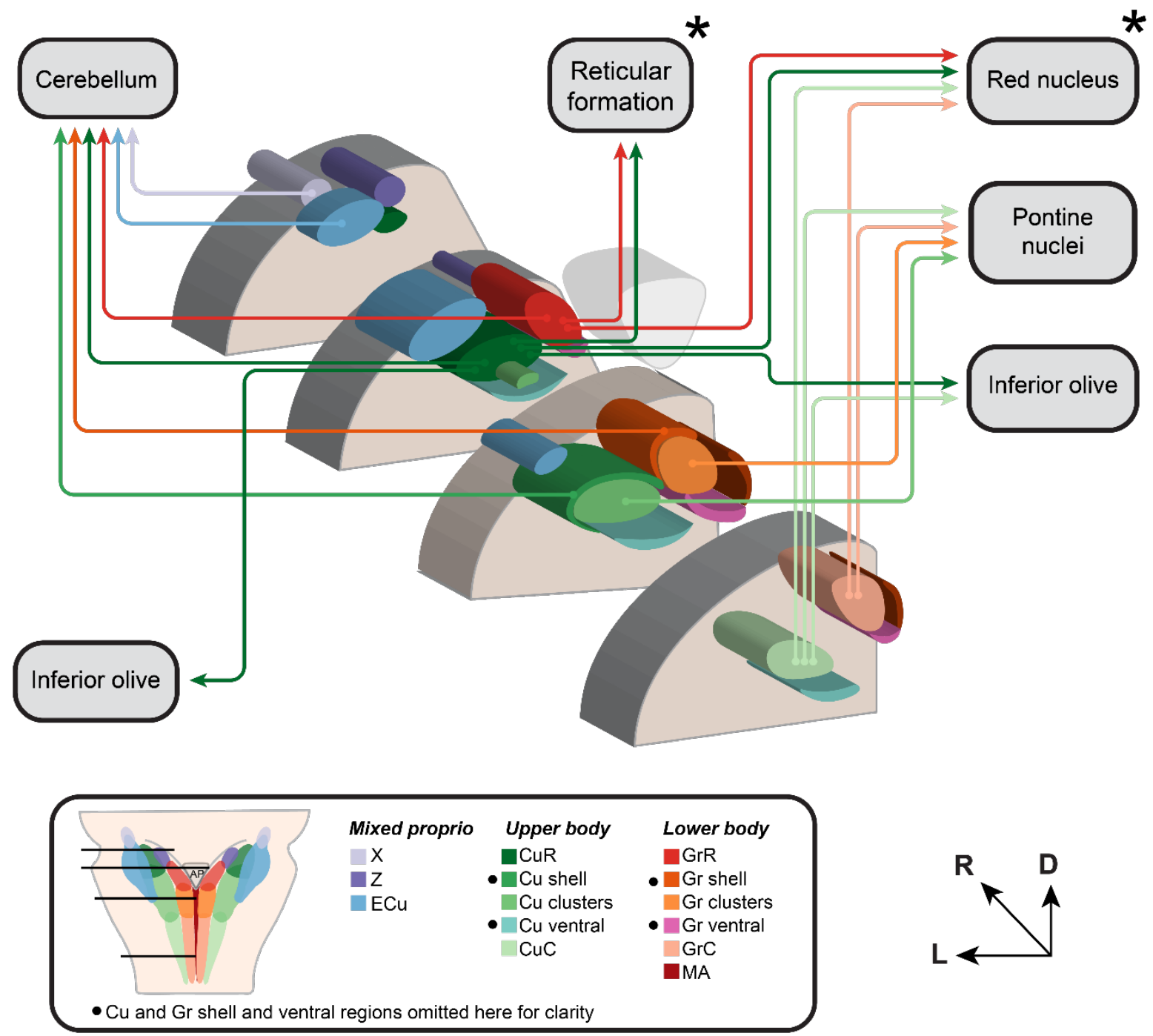

Figure 5. The cerebellar system projection targets of the dorsal column nuclei-complex. The dominant population of projections in the cerebellar system are to the ipsilateral cerebellum, from the ECu, rostral DCN, and some inputs from DCN shell regions and X. For clarity, the tectum, pretectum and zona incerta, that are also part of this system, are shown in Figure 7. Arrows indicate DCN-complex projections to cerebellar system targets, which, in addition to the cerebellum itself, include the RN, Pn, IO, and RF. For clarity, arrows are shown for only one rostro-caudal level but represent the entire rostro-caudal extent of each respective DCN-complex region. The IO and RN receive inputs from neural populations in the rostral and caudal DCN. The Pn receive inputs from the DCN clusters and caudal regions. Cerebellar, IO, and $\mathrm{RN}$ inputs predominantly convey proprioceptive-related information, but interestingly the pontine nuclei appear to receive cutaneous discriminative touch information. The Rt receives inputs from the rostral DCN and sends reciprocal projections to the same regions, while the $\mathrm{RN}$ send reciprocal inputs back to $\mathrm{Cu}$ clusters and $\mathrm{CuC}$ regions (asterisks indicate projection targets of reciprocal connectivity, see Figure 6). Abbreviations: DCN, dorsal column nuclei, ECu, external cuneate nuclei, IO, inferior olive; RN, red nucleus; Rt, reticular formation; Pn, pontine nuclei. See Figure 1 legend for all other abbreviations, orientations and description of the insert. 


\section{Bilateral projections}

\section{Contralateral projections}
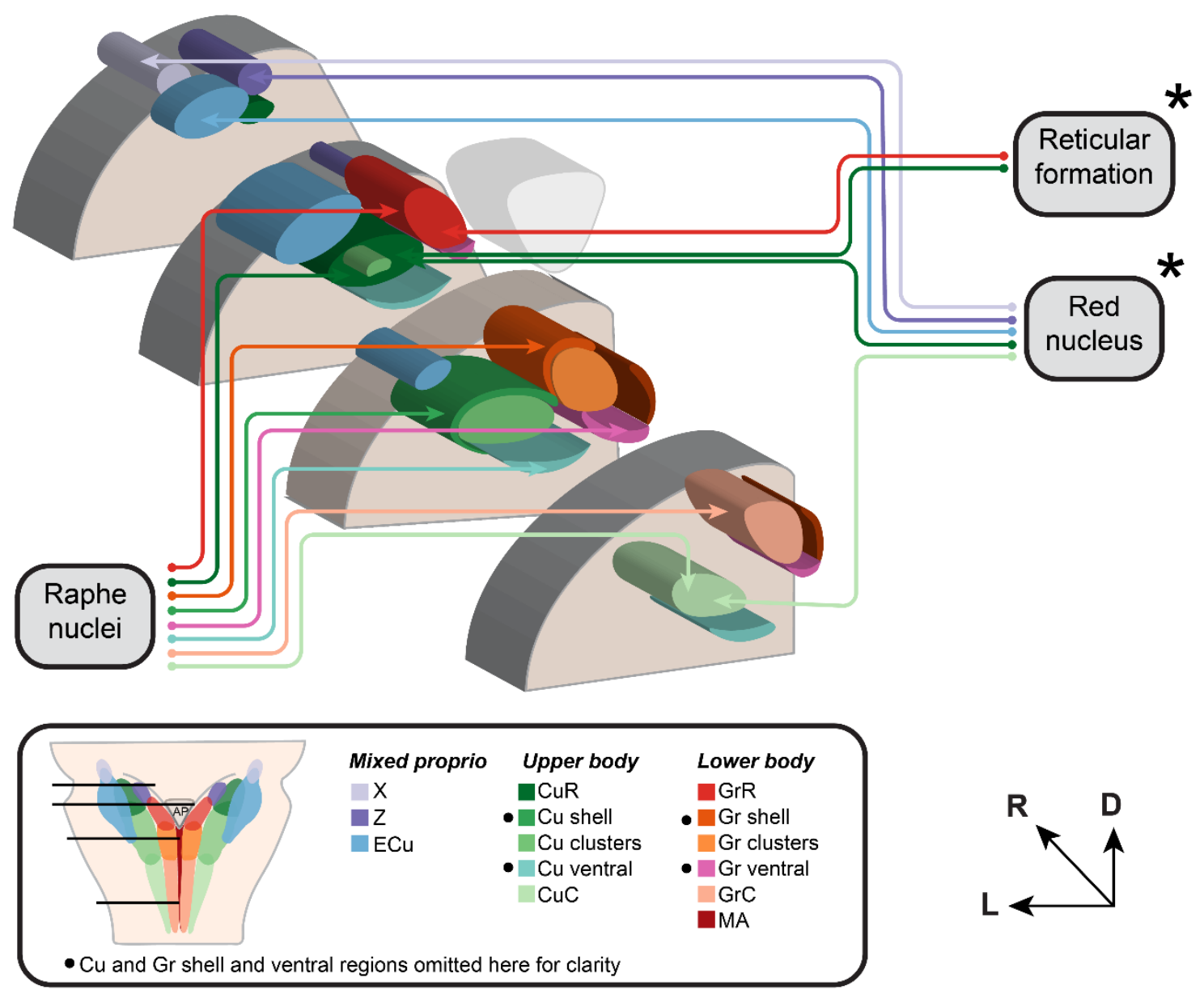

Figure 6. Subcortical dorsal column nuclei-complex inputs. In addition to receiving peripheral and spinal ascending afferents, and cortical descending inputs, the DCN-complex also receives inputs from the RN, Rt, and raphe nuclei. Arrows indicate DCN-complex inputs from subcortical targets. For clarity, arrows are shown for only one rostro-caudal level but represent the entire rostro-caudal extent of each respective region. The $\mathrm{RN}$ sends projections to the contralateral rostral and caudal $\mathrm{Cu}$, which are both regions that send reciprocal projections to the $\mathrm{RN}$. The $\mathrm{RN}$ also projects to $\mathrm{ECu}, \mathrm{X}$, and $\mathrm{Z}$, but these connections are not reciprocal. The Rt sends projections to the contralateral $\mathrm{CuR}$, and GrR, which both send reciprocal projections to the Rt. Asterisks indicate brain regions with reciprocal connectivity (see Figure 5). The raphe nuclei send bilateral connections to the all the DCN regions, except the cluster regions. Abbreviations: RN, red nucleus; Rt, reticular formation. See Figure 1 legend for all other abbreviations, orientations and description of the insert. 
Ipsilateral projections

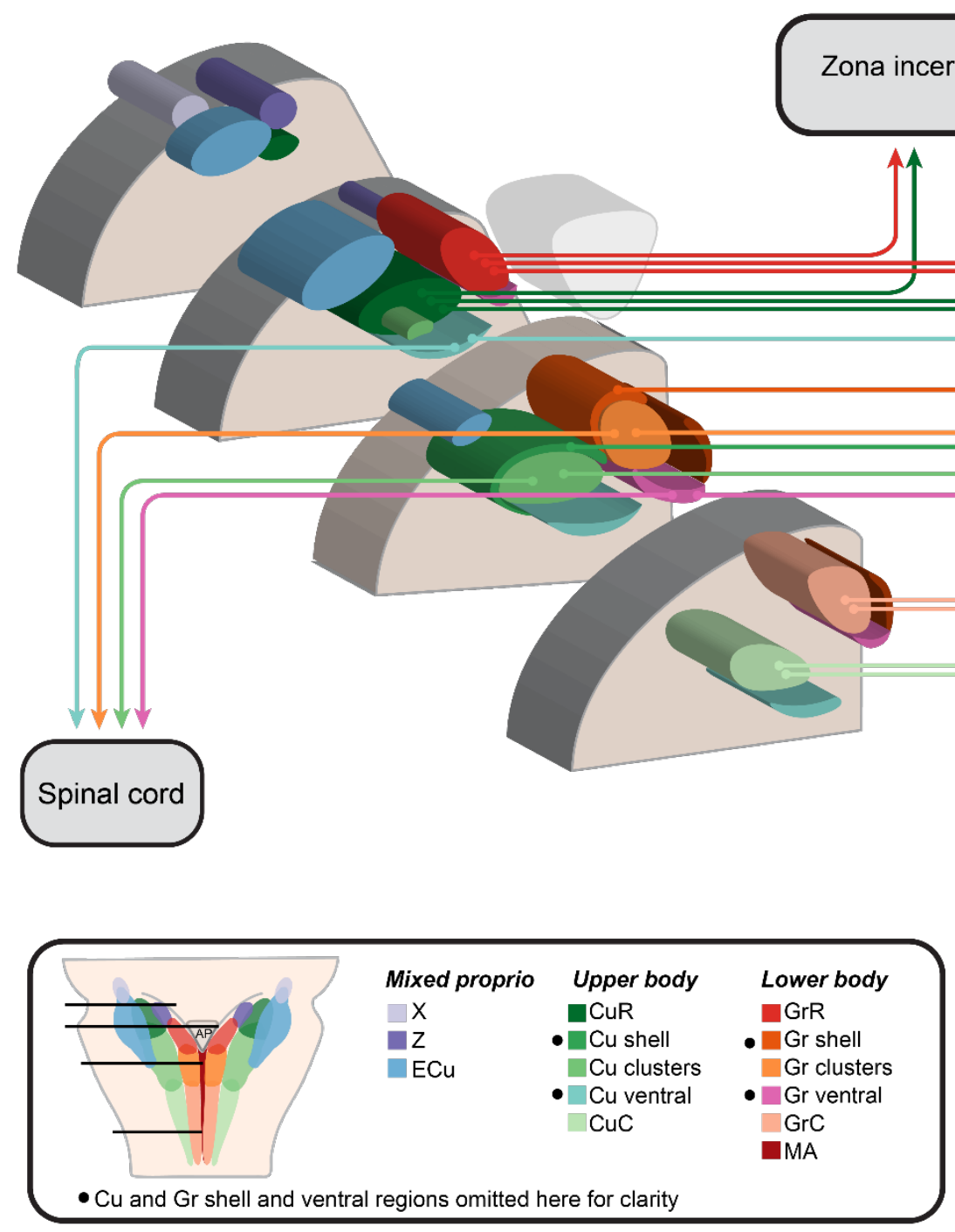

Contralateral projections
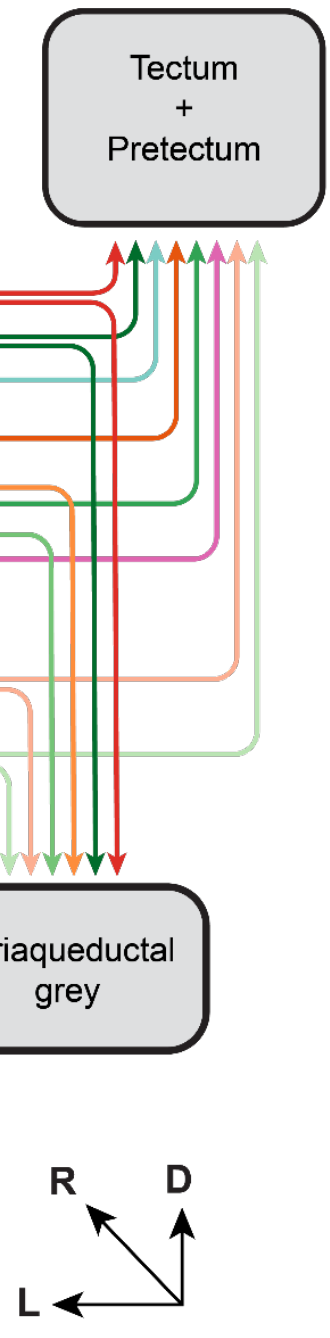

Figure 7. Spinal cord, brainstem, and diencephalic projection targets of the dorsal column nucleicomplex. The DCN-complex projections to the tectum, pretectum and zona incerta are considered part of the cerebellar system. For clarity, arrows indicate DCN-complex projections from only one rostro-caudal level but represent the entire rostro-caudal extent of each respective region. Tectum and pretectum projections originate from DCN regions outside the clusters, conveying multimodal somatosensory information. Zona incerta receives a small amount of multimodal input from the rostral DCN. The periaqueductal grey appears to receive inputs from all regions of the DCN, but these have not been properly defined. Ventral DCN regions receive primarily proprioceptive-related inputs from the spinal cord and dense corticofugal inputs from areas $3 \mathrm{a}$ and 4 . Ventral DCN also sends projections to the ipsilateral spinal cord. The main target in the spinal cord is lamina 4 of the dorsal horn, which is the location of cell bodies with axons that comprise the PSDC. Abbreviations: PSDC, postsynaptic dorsal column. See Figure 1 legend for all other abbreviations, orientations and description of the insert. 


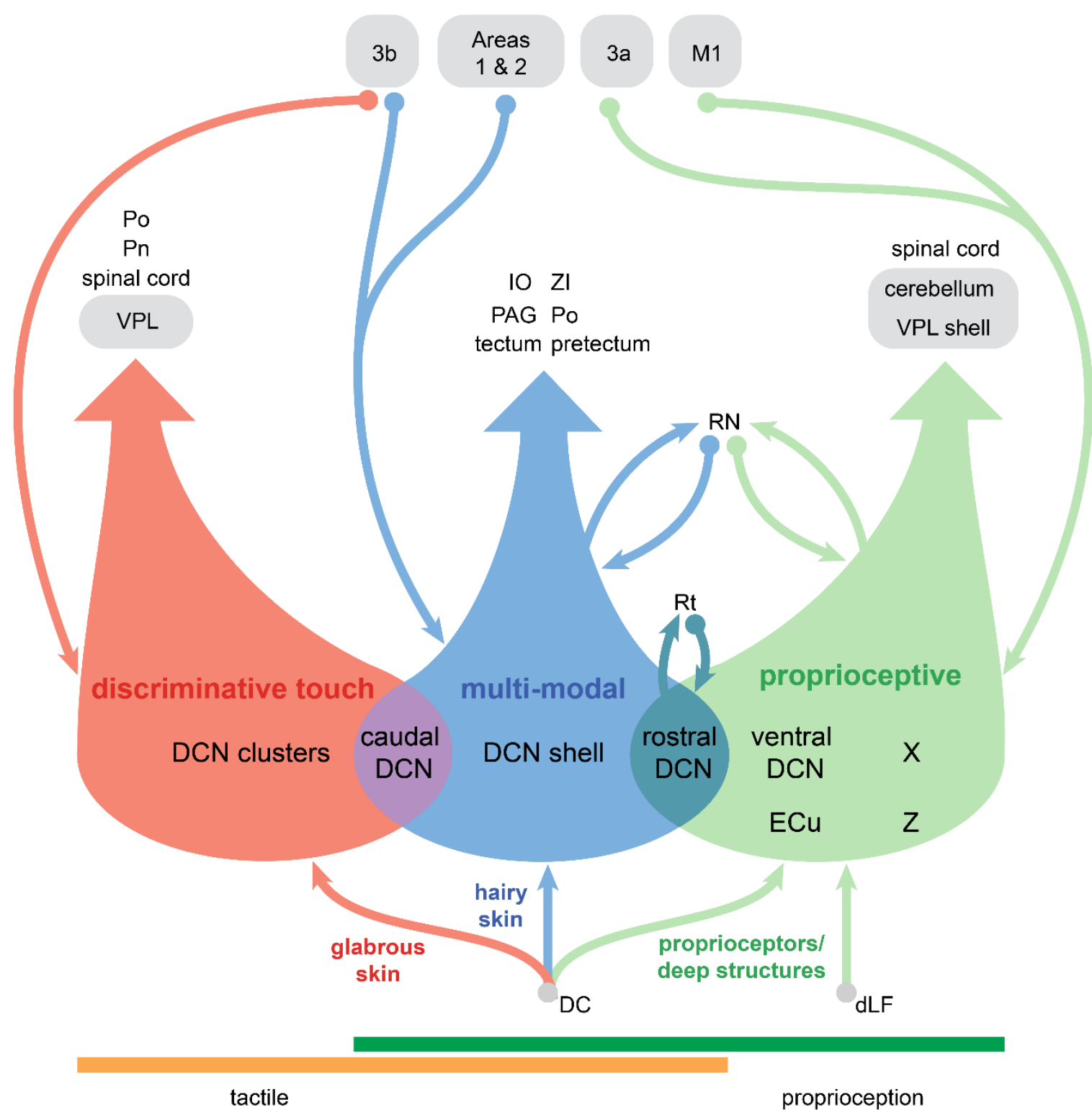

Figure 8. Organisation of three DCN-complex somatosensory functional systems. The schematic proposes the organisation of the DCN-complex into three functional systems; discriminative touch (red), proprioceptive (green) and multi-model (blue, involved in a mixture of tactile and proprioceptive functions). Bars at the bottom indicate the mix of inputs to these functional systems as tactile (yellow), proprioceptive (green), or a mixture of both (overlap). The dorsal columns (DC) carry a mixture of afferent inputs from cutaneous (glabrous and hairy skin) and deep structures to all three functional systems, whereas the dorsal aspect of the lateral funiculus (dLF) predominantly houses afferents from deep structures to the proprioceptive system (DC and dLF connectivity colour coded according the predominant peripheral afferents/structures). Venn diagram overlap for caudal and rostral DCN, indicate functional overlap between two systems. The outputs from each system (large arrows) shows the dominant (grey boxes) as well as other main brain targets. Inputs from cortical areas, as well as sub-cortical areas with reciprocal connections are shown (arrows colour coded according to the recipient system). The reticular formation (Rt) is reciprocally connected with the rostral DCN, and therefore may contribute to both multi-modal and/or proprioceptive functional systems. Abbreviations: DC, dorsal column; DCN, dorsal column nuclei; $\mathrm{dLF}$, dorsal aspect of the lateral funiculus; ECu, external cuneate nuclei; IO, inferior olive; M1, primary motor cortex (area 4); PAG, periaqueductal grey; Pn, pontine nuclei; Po, posterior nuclei of the thalamus; $\mathrm{RN}$, red nucleus; Rt, reticular formation; VPL, ventral posterior lateral nucleus of the thalamus; X, nucleus $\mathrm{X}$; Z, nucleus Z; ZI, zona incerta. 